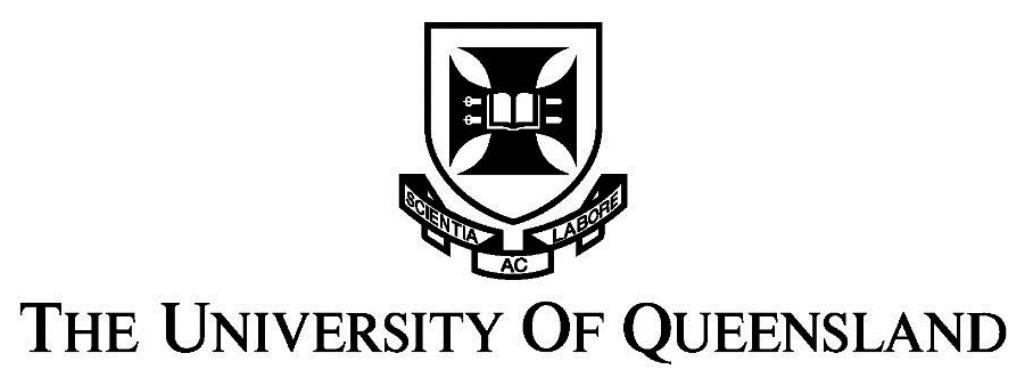

A U S T R A L I A

\title{
Practical options for cleaning biogas prior to on-farm use at piggeries
}

Alan Geoffrey Skerman

B Eng (Agric)

A thesis submitted for the degree of Master of Philosophy at

The University of Queensland in 2016

School of Chemical Engineering 



\section{Abstract}

Interest in the use of biogas from anaerobic digestion has been increasing within the Australian pork industry in recent years, driven by a significant potential for biogas use to buffer rising energy costs and to reduce carbon emissions from individual piggeries and across the whole pork industry. A recent life cycle assessment study suggested that a $64 \%$ reduction in piggery GHG emissions could be achieved by installing biogas capture and use systems. Further Government incentives have also contributed to the growing interest in on-farm biogas.

One of the major obstacles to adoption of on-farm biogas technology in the Australian pork sector is the presence of relatively high concentrations of hydrogen sulphide $\left(\mathrm{H}_{2} \mathrm{~S}\right)$ in raw piggery biogas, commonly in the range of 500 to $3000 \mathrm{ppm}$. Smelling like rotten eggs, $\mathrm{H}_{2} \mathrm{~S}$ is highly toxic and corrosive. Exposure to $\mathrm{H}_{2} \mathrm{~S}$, even at relatively low concentrations, can result in severe human health impacts, while corrosion and increased maintenance of biogas use equipment necessitates some form of biogas treatment to remove $\mathrm{H}_{2} \mathrm{~S}$ to suitable levels.

Many of the existing biogas treatment technologies used in other industries are not ideally suited for on-farm application in the Australian pork industry, because on-farm systems must be relatively simple, low-cost, safe, robust and scalable, producing minimal hazardous waste products. However, a literature review, which examined various existing biogas purification technologies, identified biological oxidation of $\mathrm{H}_{2} \mathrm{~S}$ and chemisorption with iron-based solid media as potential options for piggeries, provided that some key research and development gaps could be addressed. A particular issue with regard to chemisorption was the high cost of replacing commercial chemisorption medium (accounting for up to $5 \%$ of the savings derived from biogas use). Of further interest was the observation that the active components in commercial chemisorption media were also relatively common in natural materials such as soils, and even in some agricultural and industrial waste and by-products. However, such alternative chemisorption media required targeted laboratory and on-farm testing. With regard to biological oxidation, there was a need to determine whether the treated effluent outflow from a covered anaerobic lagoon could be used as a viable nutrient source in an external packed column system. This concept required testing on-farm. 
To assess chemisorption options, a detailed and carefully designed laboratory study tested and compared the $\mathrm{H}_{2} \mathrm{~S}$ removal capacity of a commercial iron-based medium (cg5) with that of a range of low-cost alternative media. The results of these trials indicated a far superior performance of a commercial cg5 medium, probably due to its engineered high porosity and high iron content (the active ingredient). However, a locally sourced red soil was a potentially feasible alternative medium, with reasonable chemisorption capacity and likely low cost and ready availability, depending on the piggery locality. While the pressure drop through the red soil bed was ten times that of the commercial $\mathrm{cg}_{5}$ pellets, this was effectively reduced by mixing the red soil with a bulking agent (sugar cane mulch, SCM), albeit with a dilution of the active ingredient. An unexpected but highly favourable increase in $\mathrm{H}_{2} \mathrm{~S}$ chemisorption capacity was observed following repeated regeneration of used red soil media by exposure to air, perhaps due to mechanical disruption or chemical reaction.

The laboratory data was extended to on-farm trials which confirmed the performance of the red soil and cg5 media. Interestingly, the on-farm chemisorption performance of both media was superior to the laboratory results, possibly due to the ingress of traces of oxygen with the biogas, causing continuous regeneration. The on-farm performance of a low-cost, biological $\mathrm{H}_{2} \mathrm{~S}$ treatment system was also tested, using treated CAL outflow as the liquid nutrient source sprayed over the column packing. The results were very promising, showing removal of over $90 \%$ of the $\mathrm{H}_{2} \mathrm{~S}$ from the raw biogas, reducing $\mathrm{H}_{2} \mathrm{~S}$ concentrations from $4,000 \mathrm{ppm}$ to less than $400 \mathrm{ppm}$. The recycled CAL effluent proved to be an effective liquid nutrient source, without needing excessive air addition to meet $\mathrm{O}_{2}$ scavenging requirements of residual carbon in the liquid, and with no notable changes to the prevailing $\mathrm{pH}$ of the liquid in the biological vessel. These results suggested that a simple biological oxidation system has considerable potential as a low-cost option for removing bulk $\mathrm{H}_{2} \mathrm{~S}$ from raw piggery biogas.

Overall, the relatively low chemisorption capacity of the red soil+SCM medium suggested that it would not be suitable as a primary treatment medium, but with the highly effective biological treatment step first removing the bulk of the $\mathrm{H}_{2} \mathrm{~S}$, perhaps red soil mixtures could be feasible for polishing of biogas to a consistent quality. The potential economic viability of this scenario was assessed in a feasibility analysis given in the thesis. Further testing of red soil in tandem with biological oxidation is recommended, as are regeneration studies to establish the actual chemisorption capacity of red soil mixtures and viable means to regenerate these media. 


\section{Declaration by author}

This thesis is composed of my original work, and contains no material previously published or written by another person except where due reference has been made in the text. I have clearly stated the contribution by others to jointly-authored works that I have included in my thesis.

I have clearly stated the contribution of others to my thesis as a whole, including statistical assistance, survey design, data analysis, significant technical procedures, professional editorial advice, and any other original research work used or reported in my thesis. The content of my thesis is the result of work I have carried out since the commencement of my research higher degree candidature and does not include a substantial part of work that has been submitted to qualify for the award of any other degree or diploma in any university or other tertiary institution. I have clearly stated which parts of my thesis, if any, have been submitted to qualify for another award.

I acknowledge that an electronic copy of my thesis must be lodged with the University Library and, subject to the policy and procedures of The University of Queensland, the thesis be made available for research and study in accordance with the Copyright Act 1968 unless a period of embargo has been approved by the Dean of the Graduate School.

I acknowledge that copyright of all material contained in my thesis resides with the copyright holder(s) of that material. Where appropriate I have obtained copyright permission from the copyright holder to reproduce material in this thesis. 


\section{Publications during candidature}

\section{Peer reviewed papers:}

Skerman, A.G., Heubeck, S., Batstone, D.J. and Tait, S. (2017) Low-cost filter media for removal of hydrogen sulphide from piggery biogas, Process Safety and Environmental Protection, 105, 117-126, http://dx.doi.org/10.1016/j.psep.2016.11.001.

Skerman, A.G., Heubeck, S., Batstone, D.J. and Tait, S. (2015) Alternative low-cost solid media for scrubbing of hydrogen sulphide from piggery biogas, Animal Production Science, 2015, 55, 1461, CSIRO publishing, http://dx.doi.org/10.1071/ANv55n12Ab051.

\section{Conference Papers}

Skerman, A.G., Heubeck, S., Tait, S. (2014b) Developing low cost options for on-farm biogas cleaning at piggeries, Bioenergy Australia 2014 Conference - Developing the economy through sustainable biomass, Glenelg, Adelaide, SA, 1-3 Dec 2014.

Skerman, A.G., Heubeck, S., Tait, S. (2014a) Poster presentation: Alternative biogas purification media for farm installations, International Conference: Progress in Biogas III Biogas production from agricultural biomass and organic residues, Stuttgart, Germany, 1011 September 2014.

\section{Publications included in this thesis}

Skerman, A.G., Heubeck, S., Batstone, D.J. and Tait, S. (2017) Low-cost filter media for removal of hydrogen sulphide from piggery biogas, Process Safety and Environmental Protection, 105, 117-126, http://dx.doi.org/10.1016/j.psep.2016.11.001. 


\section{Contributions by others to the thesis}

The following people contributed to this thesis:

\begin{tabular}{|c|c|}
\hline Contributor & Statement of contribution \\
\hline $\begin{array}{l}\text { Dr Stephan Tait } \\
\text { (UQ) }\end{array}$ & $\begin{array}{l}\text { Assisted with laboratory trial test rig fabrication. } \\
\text { Programmed the LabVIEW software used to control the } \\
\text { laboratory chemisorption trials. } \\
\text { Assisted with setting up, running and recording data for the on- } \\
\text { farm biological oxidation trials at piggery (B). } \\
\text { Reviewed drafts of the Journal Papers and Thesis. }\end{array}$ \\
\hline $\begin{array}{l}\text { Prof Damien Batstone } \\
\text { (UQ) }\end{array}$ & $\begin{array}{l}\text { Carried out Matlab curve fitting for the laboratory data. } \\
\text { Reviewed drafts of the Journal Papers. }\end{array}$ \\
\hline $\begin{array}{l}\text { Mr Stephan Heubeck } \\
\text { (NIWA NZ) }\end{array}$ & $\begin{array}{l}\text { Project initiation. } \\
\text { Co-author of joint draft publications. }\end{array}$ \\
\hline $\begin{array}{l}\text { Mr Lei Ge } \\
\text { (UQ) }\end{array}$ & $\begin{array}{l}\text { Conducted the particle density analyses using Helium } \\
\text { Pycnometry. }\end{array}$ \\
\hline $\begin{array}{l}\text { Dr David Mayer } \\
\text { (DAF) }\end{array}$ & $\begin{array}{l}\text { Assisted with simultaneous } \mathrm{F} \text { tests for slope }=1 \text { and } \\
\text { intercept }=0 \text { conducted on laboratory pressure drop data. }\end{array}$ \\
\hline $\begin{array}{l}\text { Ms Tracy Longhurst } \\
\text { (DAF) }\end{array}$ & $\begin{array}{l}\text { Assisted with laboratory analyses of materials and on-farm } \\
\text { biogas composition measurements at piggery }(A) \text {. }\end{array}$ \\
\hline $\begin{array}{l}\text { Mr John McAlpine } \\
\text { (DAF) }\end{array}$ & $\begin{array}{l}\text { Assisted with on-farm chemisorption media changeover, system } \\
\text { purging, leak testing and system start-up at piggery }(A) \text {. }\end{array}$ \\
\hline
\end{tabular}

\section{Statement of parts of the thesis submitted to qualify for the award of another degree}

No parts of this thesis have been submitted to qualify for the award of another degree. 


\section{Acknowledgements}

Firstly, I would like to sincerely thank my Principal Advisor, Dr Stephan Tait, for his enthusiasm, and generous contributions of time and knowledge in guiding me through the technical and academic aspects of this project. The contributions of my Associate Advisor, Professor Damien Batstone, and the other members of the Thesis Review Committee, Professor Bill Clarke (Chair) and Professor John Zhu, are also sincerely and gratefully acknowledged. I also thank Journal Paper co-author, Mr Stephan Heubeck (NIWA, NZ) for his valued input.

The contributions of the following people are also gratefully acknowledged: $\mathrm{Mr} \mathrm{Lei} \mathrm{Ge,}$ School of Chemical Engineering, University of Queensland, for conducting the Helium Pycnometry analyses, Dr David Mayer (DAF) for assistance with statistical analyses, Ms Tracy Longhurst (DAF) for assistance with laboratory analyses of materials and on-farm biogas composition monitoring, and Mr John McAlpine (DAF) for on-farm technical assistance.

This work would not have been possible without the generous cooperation and support of the owners and employees of piggeries $A$ and $B$ where the on-farm trials were carried out. I greatly appreciate the opportunity to make small contributions to the safety, profitability and sustainability of their individual enterprises and the industry as a whole.

I would like to acknowledge the funding support for this project provided by the Cooperative Research Centre for High Integrity Australian Pork (Pork CRC), the State of Queensland, acting through the Department of Agriculture and Fisheries (DAF) and the University of Queensland. The support of former Pork CRC Program Leader, Dr Rob Wilson, is also gratefully acknowledged.

On a personal note, I would like to thank my wife, Carolyn, for the unwavering love and support she has given me throughout my work career and particularly during this recent part-time foray into the world of academia. Lastly, I dedicate this work to my parents, Keith and Nancy Skerman, who toiled long and hard and made many sacrifices to ensure that their children had better educational opportunities than they had. 


\section{Keywords}

Biogas, hydrogen sulphide, iron oxide, pig, swine, manure, biological oxidation.

\section{Australian and New Zealand Standard Research Classifications (ANZSRC)}

ANZSRC code: 090703 Environmental Technologies, 40\%

ANZSRC code: 090409 Wastewater Treatment Processes, 40\%

ANZSRC code: 070299 Animal Production not elsewhere classified, 20\%

\section{Fields of Research (FoR) Classification}

FoR code: 0904 Chemical Engineering, 40\%

FoR code: 0907 Environmental Engineering, 40\%

FoR code: 0702 Animal Production, 20\% 


\section{Table of Contents}

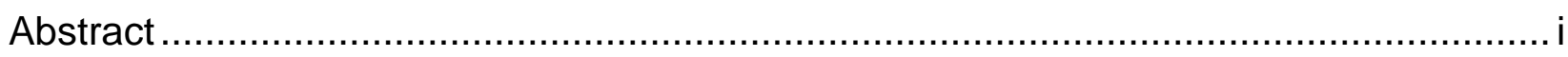

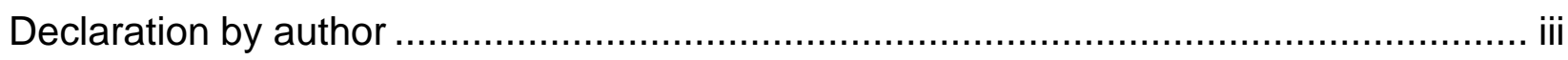

Publications during candidature ........................................................................... iv

Publications included in this thesis ........................................................................ iv

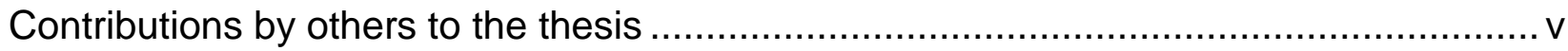

Statement of parts of the thesis submitted to qualify for the award of another degree .....v

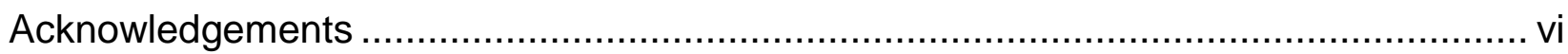

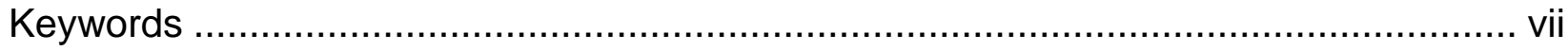

Australian and New Zealand Standard Research Classifications (ANZSRC)................ vii

Fields of Research (FoR) Classification .................................................................. vii

Table of Contents ...................................................................................................

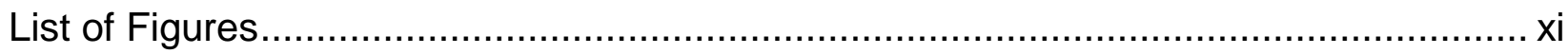

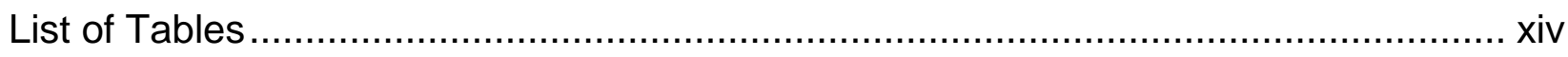

List of Abbreviations used in the thesis ..................................................................

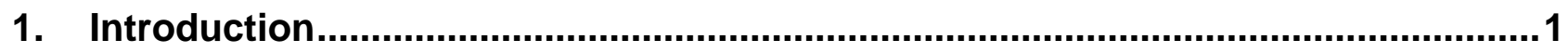

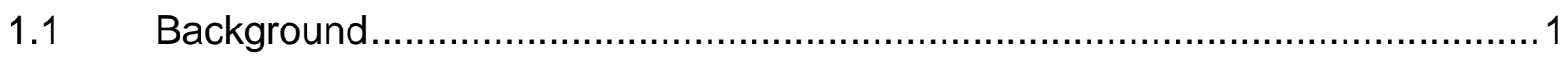

1.2 Research Opportunities and Gaps ........................................................... 4

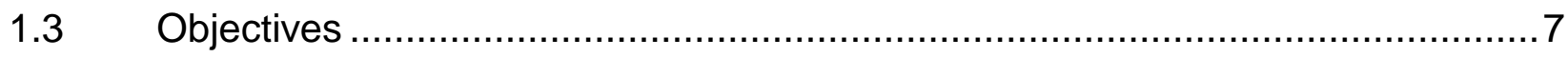

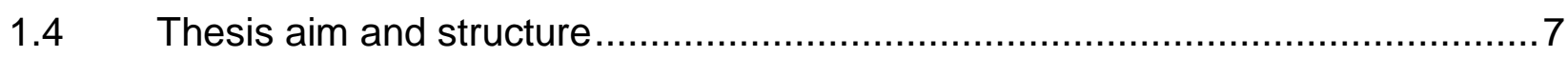

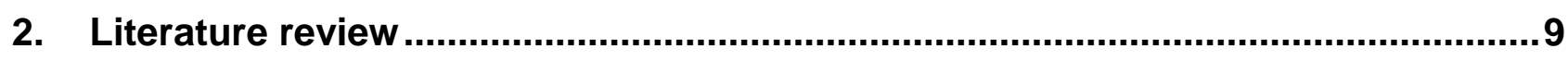

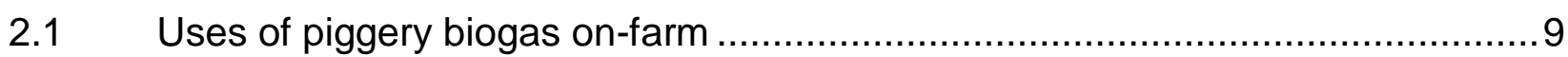

2.2 Hydrogen sulphide $\left(\mathrm{H}_{2} \mathrm{~S}\right)$, its formation, properties and impacts on biogas use 14

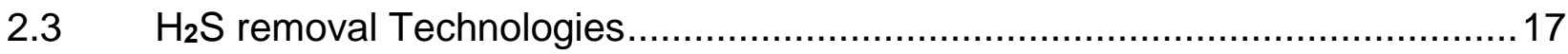

2.3.1 $\mathrm{H}_{2} \mathrm{~S}$ removal inside a digester or CAL ................................................... 18

2.3.1.1 Biological oxidation inside the digester or covered lagoon ................ 18

2.3.1.2 Chemical dosing of iron chloride into a digester.............................20 


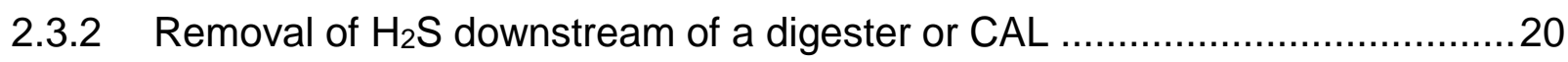

2.3.2.1 Chemisorption using iron oxide, iron hydroxide or zinc oxide ..........20

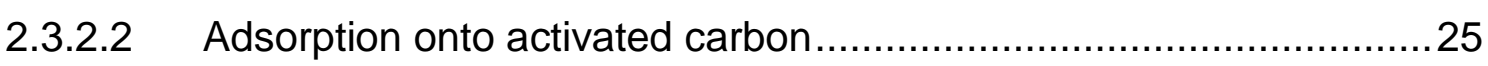

2.3.2.3 Absorption with liquids ........................................................26

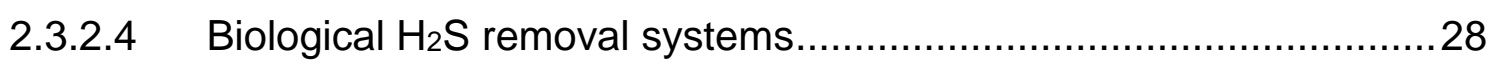

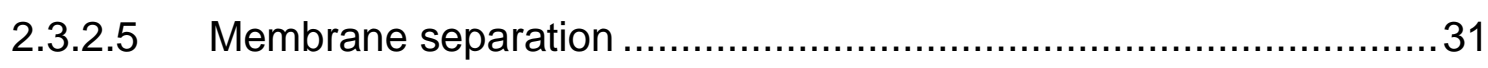

$2.4 \quad$ Overall comparison of biogas treatment options .......................................... 32

2.5 Practical options for $\mathrm{H}_{2} \mathrm{~S}$ removal from piggery biogas .................................33

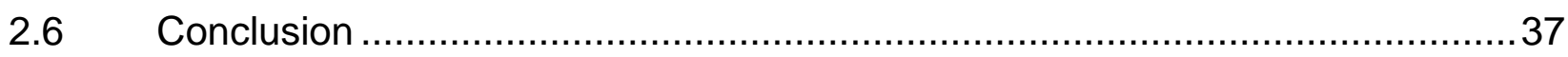

3. Low-cost filter media for removal of hydrogen sulphide from piggery biogas...38

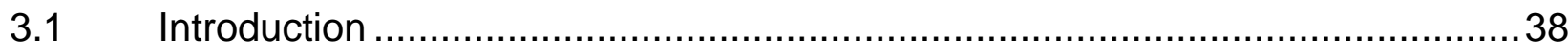

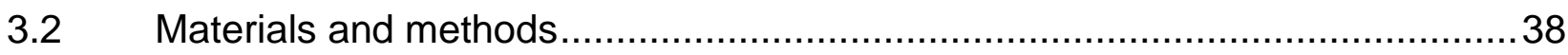

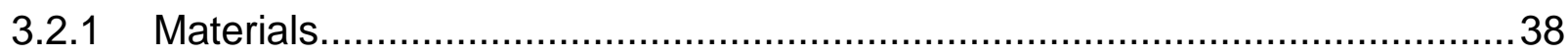

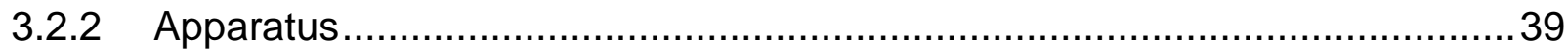

3.2.3 Batch $\mathrm{H}_{2} \mathrm{~S}$ removal studies.............................................................. 41

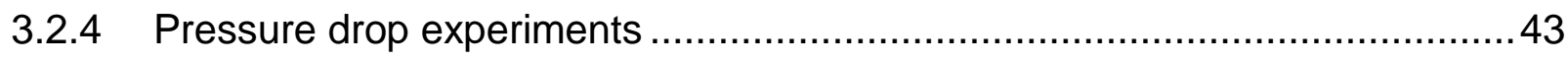

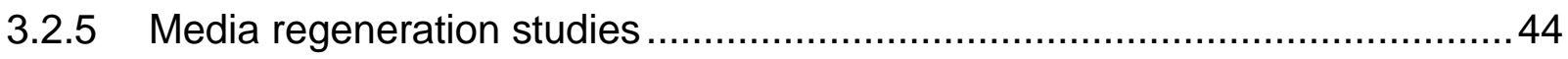

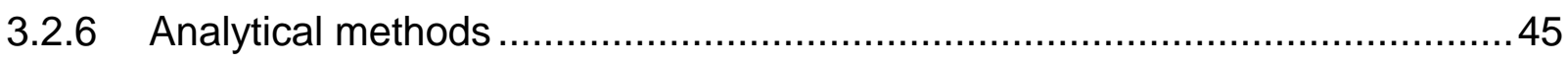

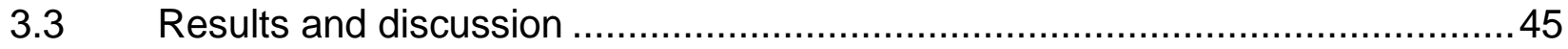

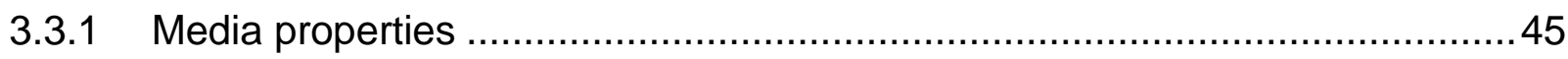

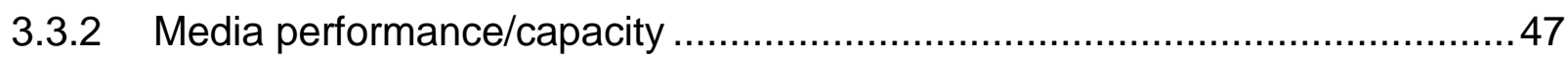

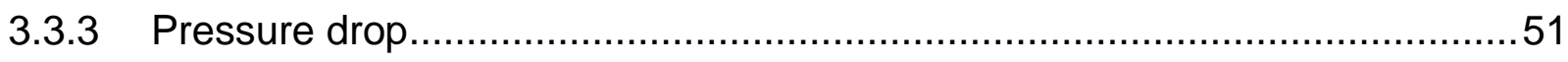

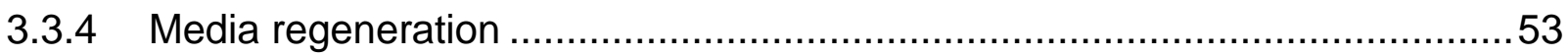

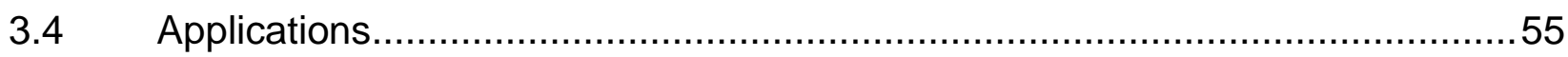

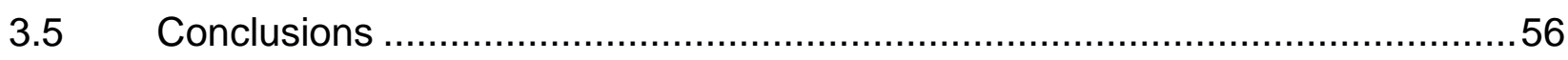

4. On-farm trials of low-cost options for hydrogen sulphide removal from piggery

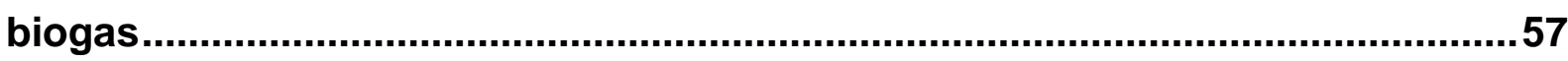

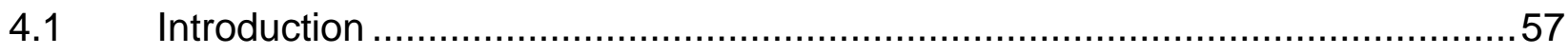

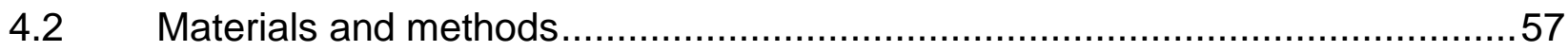

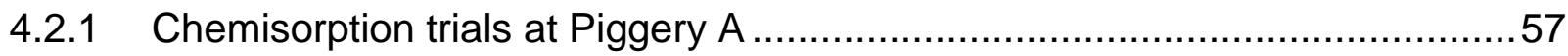




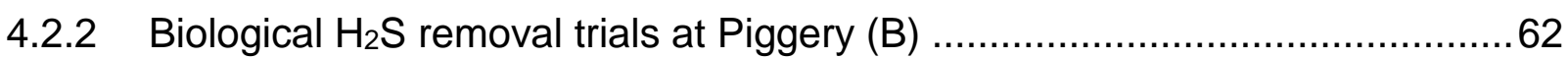

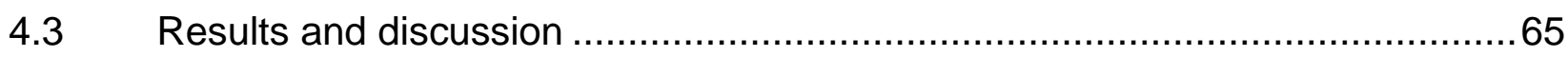

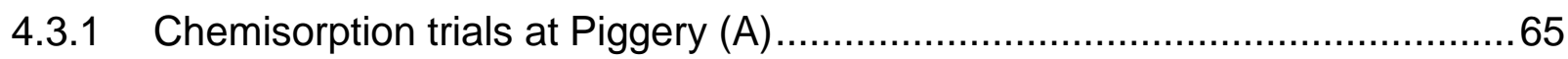

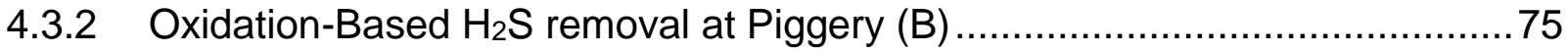

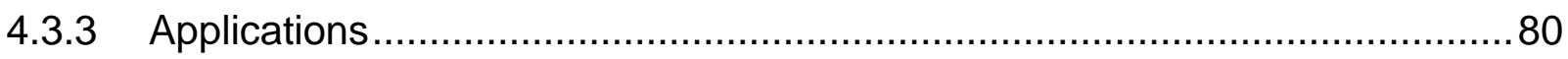

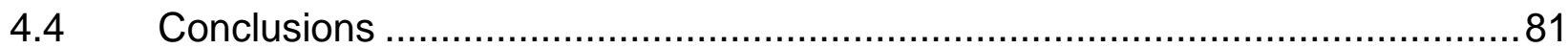

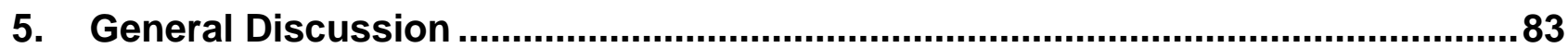

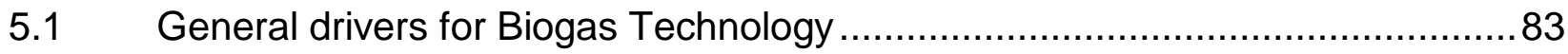

5.2 Biological oxidation - A low-cost primary treatment step for biogas ............... 83

5.3 Chemisorption - Low-cost alternative media for polishing of biogas............... 84

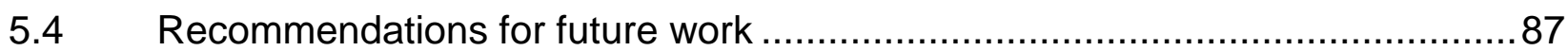

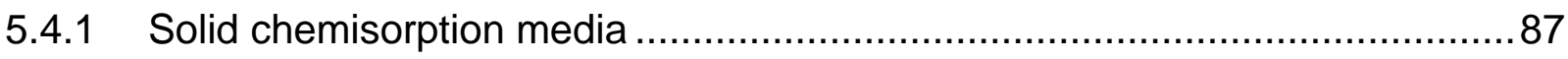

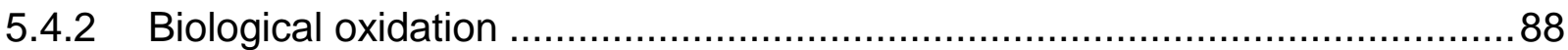

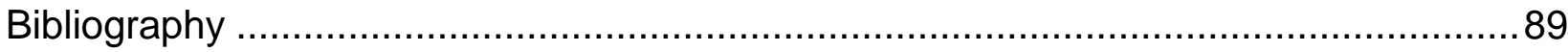




\section{List of Figures}

Figure 2.1 Range of biogas use options with particular reference to large scale dairy operations in the US (Mears, 2001).....

Figure 2.2 Trigeneration system schematic drawing showing heating, cooling and electrical energy potential from biogas (Simons Green Energy, 2014). 13

Figure 2.3. The distribution of sulphide species in water at a range of $\mathrm{pH}$ values. (McVay, $\mathrm{ND})$ 15

Figure 2.4. Solubility of $\mathrm{H}_{2} \mathrm{~S}$ in water over the relevant range of temperatures, for a partial gas pressure of $101.325 \mathrm{kPa}$ (1 atm). Based on Gevantman in Haynes (2016).

Figure 2.5. Schematic drawing showing standard SULFATREAT chemisorption column components (M-I SWACO, 2010).

Figure 2.6 Schematic drawing of SULFATREAT vessels used in lead/lag configuration (M-I SWACO, 2010).

Figure 2.7 Schematic drawing of a counter-current flow, packed-bed water scrubber (Skerman, et al., 2012).

Figure 2.8 Selexol flow scheme for sulphur removal (UOP, 2009) 27

Figure 2.9 Schematic drawing of a 'Biogas Sweetener' aerobic bio-trickling filter (BIOREM®, 2010).

Figure 2.10 Schematic drawing showing the THIOPAQ® biogas scrubbing process (based on Paques, 2015),

Figure 3.1 Schematic drawing of the apparatus used during the hydrogen sulphide sorption experiments.

Figure 3.2 A typical breakthrough curve for GAC plotted from the experimental data, showing the key times of interest ( $\mathrm{T}_{10}$ at breakthrough, $\mathrm{H}_{2} \mathrm{~S} \approx 10 \mathrm{ppm} ; \mathrm{T}_{200}$, $\mathrm{H}_{2} \mathrm{~S}=200 \mathrm{ppm} ; \mathrm{T}_{1000}, \mathrm{H}_{2} \mathrm{~S}=1000 \mathrm{ppm} ; \mathrm{T}_{1950}$ at saturation, $\left.\mathrm{H}_{2} \mathrm{~S}=1950 \mathrm{ppm}\right)$. The dashed curve is a fit of Equation 3.1.

Figure 3.3 Results from a reproducibility analysis performed on three separate samples of GAC showing mean sulphur removal capacities, with error bars estimated at the $95 \%$ confidence level. 
Figure 3.4 Breakthrough curves (column outlet $\mathrm{H}_{2} \mathrm{~S}$ concentrations vs. time) for the tested media. Data is presented for cg5 $(\bullet)$, composted feedlot manure $(\diamond)$, GSFS $(\Delta)$, biochar $(\bigcirc)$, compost $(\boldsymbol{\square})$, GAC $(\diamond)$ and Tor Street red soil $(\mathbf{\Lambda})$. Note the break in scale/change of scale on the time axes. Lines represent data extrapolated beyond the measured datasets, using the fitted logistic curves (Equations 3.1 and 3.2).

Figure 3.5 Pressure drop per unit depth of the red soil ( $\mathbf{(})$, red soil bulked with $20 \%$ SCM $\mathrm{v} / \mathrm{v}(\bullet)$, red soil bulked with $40 \% \mathrm{SCM} \mathrm{v} / \mathrm{v}(\boldsymbol{\Delta})$ and $\mathrm{cg}_{5}(\bullet)$ media, measured in the test column. Lines are regression fits with the Ergun equation (Equation 3.2) over a range of $\mathrm{N}_{2}$ flow velocities. 53

Figure 3.6 Breakthrough curves for a red soil (Tor St) sample tested in consecutive media regeneration trials. Lines represent data extrapolated beyond the measured datasets, using the fitted logistic curves (Equations 3.1 and 3.2). . 54

Figure 4.1 Schematic drawing of the test column and hot water boiler installed at piggery (A), as used in the on-farm trials. 59

Figure 4.2 Schematic drawing of the biological $\mathrm{H}_{2} \mathrm{~S}$ removal system trialled at piggery (B).

Figure 4.3 Volumetric concentrations of $\mathrm{CH}_{4}(\bullet), \mathrm{CO}_{2}(\bullet)$, balance gas $(\bullet)$ and $\mathrm{H}_{2} \mathrm{~S}(\bullet)$ measured upstream and downstream from the test column, plotted against the cumulative biogas volume treated in the column for the on-farm red soil+SCM 1 trial. Filled markers and full lines represent upstream concentrations while unfilled markers and dashed lines represent downstream concentrations. ....66

Figure 4.4 Volumetric concentrations of $\mathrm{CH}_{4}(\bullet), \mathrm{CO}_{2}(\bullet)$, balance gas $(\bullet)$ and $\mathrm{H}_{2} \mathrm{~S}(\bullet)$ measured upstream and downstream from the test column, plotted against the cumulative biogas volume treated in the column for the on-farm red soil+SCM 2 trial. Filled markers and full lines represent upstream concentrations while unfilled markers and dashed lines represent downstream concentrations. ....67

Figure 4.5 Volumetric concentrations of $\mathrm{CH}_{4}(\bullet), \mathrm{CO}_{2}(\bullet)$, balance gas $(\bullet)$ and $\mathrm{H}_{2} \mathrm{~S}(\bullet)$ measured upstream and downstream from the test column, plotted against the cumulative biogas volume treated in the column for the on-farm cg5 medium trial. Filled markers and full lines represent upstream concentrations while unfilled markers and dashed lines represent downstream concentrations. ....68 
Figure 4.6 Mass of $S$ removed by chemisorption, per unit mass of red soil, plotted against downstream $\mathrm{H}_{2} \mathrm{~S}$ concentrations, for the on-farm Red soil+SCM 1 (ם), onfarm Red soil+SCM $2(\diamond)$, laboratory Red soil+SCM $(\boldsymbol{\Delta})$ and laboratory red soil only $(\bigcirc)$ trials. Dashed lines are the two-phase exponential curves fitted to the laboratory data (Section 3.2.3).

Figure 4.7 Mass of $S$ removed by chemisorption, per unit mass of cg5 medium, plotted against downstream $\mathrm{H}_{2} \mathrm{~S}$ concentrations, for the on-farm ( $\square$ ) and laboratory $(\Delta)$ trials carried out using the cg5 medium. Dashed lines are the two-phase exponential curves fitted to the laboratory and on-farm data (Sections 3.2.3 and 4.2.1, respectively). 70

Figure 4.8 Measured (marker) and calculated (Ergun equation - dashed line) values of pressure drop across the chemisorption column, per unit depth of medium [Red soil+SCM $1(\square)$, Red soil+SCM $2(\diamond)$ and $\operatorname{cg} 5(\Delta)$ ], for the range of biogas flow velocities measured during the on-farm trials. The Ergun equation curves fitted to the laboratory trial results (Section 3.3.3) for the red soil+SCM ( - . - ) and $\operatorname{cg} 5\left(\ldots-{ }_{-}\right)$are also plotted for comparison with the on-farm results. ....73

Figure 4.9 Measured values of pressure drop across the on-farm chemisorption column, per unit depth of medium for the (a) red soil+SCM 1 ( $\square)$, red soil+SCM $2(\bullet)$ and (b) cg5 (O) media, over the range of $S$ chemisorption values measured during the on-farm trials.

Figure 4.10 Combined time series data showing concentrations of (a) $\mathrm{CH}_{4}(\diamond), \mathrm{CO}_{2}(\square)$, Balance ( $\triangle$ ) and (b) $\mathrm{H}_{2} \mathrm{~S}(\bullet)$ gases recorded upstream (filled markers and full lines) and downstream (unfilled markers and dashed lines) from the biological oxidation vessel over the five tests. Biogas flowrates are shown as dashed lines in (a) and (b). 75

Figure 4.11 Bar graph showing the mean concentrations and 95\% error bars for (a) $\mathrm{O}_{2}$ and (b) $\mathrm{H}_{2} \mathrm{~S}$, measured in the raw biogas coming from the CAL $(\mathbf{\nabla})$, in the raw biogas following air injection as estimated by calculation $(\square)$, and as measured in the treated biogas exiting the test column $(\boxplus)$, for the five tests and combined data. The biogas flowrates for tests 1 to 4 and the post test were $160,62,145,100$ and $160 \mathrm{~m}^{3} / \mathrm{h}$, respectively. 


\section{List of Tables}

Table 1.1 Recommended maximum $\mathrm{H}_{2} \mathrm{~S}$ concentrations in biogas used in a range of applications (adapted from Zicari, 2003).

Table 2.1. Selected physical and chemical properties of $\mathrm{H}_{2} \mathrm{~S}$ (adapted from Air Liquide, 2016 and 2012). 16

Table 2.2. Human physical reactions following exposure to $\mathrm{H}_{2} \mathrm{~S}$, at a range of concentrations (adapted from Aquafix, 2015).

Table 2.3 Summary of promising technologies for removing $\mathrm{H}_{2} \mathrm{~S}$ from biogas at Australian piggeries (adapted from Allan (2012), Ryckebosch et al. (2011) and Australian Pork Limited (2016)).

Table 2.4. Calculations used to estimate typical hydrogen sulphide removal costs for a 1000 sow farrow-to-finish (10,000 standard pig unit) piggery.

Table 3.1 Selected test media properties (mean values \pm error as $95 \%$ confidence interval in the mean values).

Table 3.2 Data for masses of sulphur removed (means $\pm 95 \%$ confidence intervals), corresponding to times of interest, $\mathrm{T}_{10}$ (breakthrough $\mathrm{H}_{2} \mathrm{~S}>10 \mathrm{ppm}$ ), $\mathrm{T}_{200}$ (when $\mathrm{H}_{2} \mathrm{~S}=200$ ppm), $\mathrm{T}_{1000}\left(\right.$ when $\mathrm{H}_{2} \mathrm{~S}=1000$ ppm) and $\mathrm{T}_{1950}(\approx$ saturation).

Table 3.3. Results of regression analyses of measured vs predicted (Ergun equation) pressure drop data for the combined and four individual sorption media.

Table 3.4 Masses of sulphur removed (capacity) for four consecutive media regeneration tests on the Tor Street red soil (Section 3.2.5).

Table 4.1 Basic physical characteristics and test conditions for the on-farm trials carried out on the two red soil+sugar cane mulch (SCM) mixtures and cg5 media....60

Table 4.2 Mean concentrations and 95\% confidence intervals for $\mathrm{CH}_{4}, \mathrm{CO}_{2}$, balance gases and $\mathrm{H}_{2} \mathrm{~S}$, measured upstream (US) and downstream (DS) of the chemisorption column, for the two red soil+SCM trials and the single cg5 trial. 
Table 4.3 Mass of $S$ removed by chemisorption, per unit mass of red soil, by the red soil+SCM, cg5 and red soil media, for both the on-farm and laboratory trials at a range of downstream $\mathrm{H}_{2} \mathrm{~S}$ concentrations. The laboratory and on-farm cg5 values were interpolated from curves fitted to the experimental data (Sections 3.2.3 and 4.2.1, respectively). All other values were linearly interpolated from the experimental data. 69

Table 4.4 Measured and calculated (Ergun equation) pressure drop values over the range of biogas flowrates measured during the on-farm trials of the red soil+SCM and cg5 media. 73

Table 4.5 Mean concentrations and $95 \%$ confidence intervals for the $\mathrm{CH}_{4}, \mathrm{CO}_{2}, \mathrm{O}_{2}$, balance and $\mathrm{H}_{2} \mathrm{~S}$ gases in the raw biogas and raw biogas + air mixture measured upstream from the biological oxidation vessel, and the treated biogas measured downstream from the biological oxidation vessel, for the five individual on-farm tests and the combined data. .76

Table 5.1. 500 sow farrow-to-finish case study summary, based on primary biogas treatment by biological oxidation and secondary treatment in a solid medium chemisorption column using red soil and cg5 media. 86 


\section{List of Abbreviations used in the thesis}

\begin{tabular}{ll} 
ANOVA & Analysis of Variance \\
CAL & Covered anaerobic lagoon \\
CAP & Covered anaerobic pond \\
CFI & Carbon farming initiative \\
CHP & Combined heat and power \\
CNG & Compressed natural gas \\
DAF & Department of Agriculture and Fisheries (Queensland Government) \\
DCB & Dithionite-citrate-bicarbonate \\
DN & Nominal diameter \\
DS & Downstream \\
ERF & Emissions reduction fund \\
FC & Fuel cell \\
GAC & Granular activated carbon \\
GHG & Greenhouse gas \\
GSFS & Granular steel furnace slag \\
ICE & Internal combustion engine \\
ICP-OES & Inductively coupled plasma optical emission spectroscopy \\
MCFC & Molten carbonate fuel cell \\
MFC & Mass flow controller \\
NB & Nominal bore \\
NIWA, NZ & National Institute of Water and Atmospheric Research, New Zealand \\
NPI & National pollutant inventory \\
OD & Outside diameter \\
PAFC & Phosphoric acid fuel cell \\
PEMFC & Proton exchange membrane fuel cell \\
PFA & Perfluoroalkoxy \\
PN & Nominal pressure \\
Pork CRC & Cooperative Research Centre for High Integrity Australian Pork \\
PSA & Pressure-swing adsorption \\
SCM & Sugar cane mulch \\
SEPS & Sedimentation and evaporation pond system \\
SOFC & Solid oxide fuel cell \\
SPU & Standard pig unit \\
\hline
\end{tabular}




$\begin{array}{ll}\text { SWJ } & \text { Solvent weld joint } \\ \text { TS } & \text { Total solids } \\ \text { UPVC } & \text { Unplasticised polyvinyl chloride } \\ \text { UQ } & \text { University of Queensland } \\ \text { US } & \text { Upstream } \\ \text { VOC } & \text { Volatile organic compound } \\ \text { VS } & \text { Volatile solids }\end{array}$




\section{Introduction}

\section{$1.1 \quad$ Background}

Interest in the collection, treatment and use of biogas from anaerobic digestion has been increasing within the Australian pork industry in recent years. For example, in February 2016 , as much as $13 \%$ of total pork production was sourced from farms employing biogas technology (Tait, 2016, pers comm). The main drivers for this interest have been the significant potential for biogas technology to reduce: (1) rising on-farm energy costs, including electricity costs, which represent $2 \%$ to the total cost of production for Australian piggeries (Willis, 2015); and (2) carbon emissions from individual enterprises and across the whole pork industry. The wide adoption of this technology could substantially advance the Australian pork industry towards meeting its adopted on-farm greenhouse gas (GHG) emissions target cap of $1 \mathrm{~kg} \mathrm{CO}$-e per $\mathrm{kg}$ of pork produced (Pork CRC, 2015). A recent life cycle assessment study (Wiedemann et al., 2016) suggested that the greatest reductions in piggery GHG emissions could be achieved by installing biogas capture and combined heat and power systems (CAP-CHP), resulting in total emissions reductions up to $64 \%$. Further financial incentives, such as the Australian Government's Carbon Farming Initiative (CFI) and more recently, the Emissions Reduction Fund (ERF), have also contributed to the current growing interest in on-farm biogas (Federal Register of Legislation F2015C00574, 2013).

One of the major obstacles impeding the widespread adoption of biogas technology onfarm in Australia, is the presence of relatively high concentrations of hydrogen sulphide $\left(\mathrm{H}_{2} \mathrm{~S}\right)$ in raw biogas collected from pig manure treatment. These concentrations are

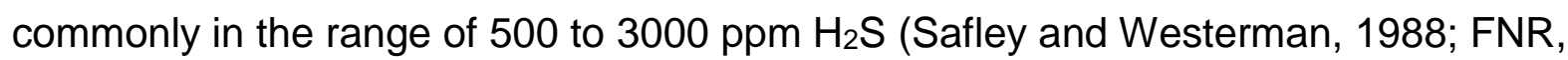
2005; Heubeck and Craggs, 2010 and Skerman, 2013).

Hydrogen sulphide is formed by microbiological reduction of sulphur containing compounds (sulphates, peptides, amino acids) present in the feedstock, during anaerobic digestion (Petersson and Wellinger, 2009). $\mathrm{H}_{2} \mathrm{~S}$ concentration in biogas can vary widely depending on the sulphur content and form of sulphur in the feedstock, over the range 10 to 10,000 ppmv (Abatzoglou and Bolvin, 2009). In the case of piggeries, the biogas $\mathrm{H}_{2} \mathrm{~S}$ concentration is likely to depend on the concentrations of sulphurous compounds in the pig feed, but also in drinking water and shed flushing water, both of which may be sourced 
from groundwater which commonly contains varying levels of sulphur. Traditionally and increasingly, dairy and other by-products, having relatively high sulphur concentrations, are being used in pig diet formulations. This can increase the sulphur loading in the manure and waste feed entering the anaerobic digestion system, further increasing biogas $\mathrm{H}_{2} \mathrm{~S}$ concentrations.

Smelling like rotten eggs, $\mathrm{H}_{2} \mathrm{~S}$ is a colourless, flammable, poisonous gas that is reasonably soluble in water and organic solvents and corrodes metals (Department of Sustainability, Environment, Water, Population and Communities, 2013). Being heavier than air (specific gravity 1.189), $\mathrm{H}_{2} \mathrm{~S}$ can accumulate in enclosed, poorly ventilated and even low-lying spaces (Innovative Waste Consulting Services, 2014).

Exposure to $\mathrm{H}_{2} \mathrm{~S}$ can result in the following impacts on human health (Department of Sustainability, Environment, Water, Population and Communities, 2013):

- at concentrations of 1000 to 2000 ppm, collapse, coma and death from respiratory failure within a few seconds after one or two inhalations;

- at concentrations of 100 to $200 \mathrm{ppm}$, insomnia, blurred vision, haemorrhage and death following exposure for one to eight hours;

- at lower concentrations (5 to $50 \mathrm{ppm}$ ), irritation of the eyes, nose and throat following exposure;

- following repeated exposures, headaches, anorexia, insomnia, paralysis, meningitis, slowed heart rate, bronchitis and a grey-green line on the gums.

- following a single exposure, headaches, dizziness, and nausea;

An 8-hour time-weighted average exposure limit of $10 \mathrm{ppm}$, and a short term exposure limit of 15 ppm are specified by Safe Work Australia (2013). The human nose can detect the presence of $\mathrm{H}_{2} \mathrm{~S}$ at very low concentrations. The odour threshold at which $50 \%$ of a human panel can detect the presence of $\mathrm{H}_{2} \mathrm{~S}$ is $0.47 \mathrm{ppb}$, while the recognition threshold for its characteristic "rotten egg" smell is higher but still low at around $4.70 \mathrm{ppb}$ (lowa State University Extension, 2004). Unfortunately, odour is not a reliable means of warning persons about the dangerous presence of $\mathrm{H}_{2} \mathrm{~S}$. That is, at concentrations $>140 \mathrm{mg} / \mathrm{m}^{3}$ (>99 ppm), the human olfactory nerve is said to become paralysed after a few inhalations, and the sense of smell disappears, followed by a lack of any awareness of the danger (Chou, 2003; Hirsch and Zavala, 1999). Given the likely concentrations of $\mathrm{H}_{2} \mathrm{~S}$ in raw piggery biogas of 500 to $3000 \mathrm{ppm}$, extreme care and careful management are essential in 
minimising the human health risks associated with on-farm collection, treatment and use of biogas (Australian Pork Limited, 2015).

The corrosive nature of $\mathrm{H}_{2} \mathrm{~S}$ can limit the life of biogas burning appliances such as engine generators for electricity production, and boilers used to produce hot water for heating of pig sheds. Even at low concentrations, $\mathrm{H}_{2} \mathrm{~S}$ in biogas can cause serious corrosion in metallic gas pipelines, gas holders and biogas conversion and utilisation equipment (Krich et al., 2005; Kuria and Maringa, 2008), as well as damage to the metal siding and roofing used in buildings (Mears, 2001). $\mathrm{H}_{2} \mathrm{~S}$ typically has to be removed from biogas in order to avoid corrosion in compressors, gas storage tanks and engines, as it is extremely reactive with most metals, and the reactivity of $\mathrm{H}_{2} \mathrm{~S}$ is enhanced by concentration and pressure, the presence of water and elevated temperatures (Wellinger and Linberg, 2005).

When biogas is burned, sulphur dioxide $\left(\mathrm{SO}_{2}\right)$ and sulphur trioxide $\left(\mathrm{SO}_{3}\right)$ are emitted and these gases are even more poisonous than $\mathrm{H}_{2} \mathrm{~S}$. For $\mathrm{SO}_{2}$, the 8-hour time-weighted average exposure limit is 2 ppm and the short term exposure limit is 5 ppm (Safe Work Australia, 2013), which is even lower than for $\mathrm{H}_{2} \mathrm{~S}$ (10 and 15 ppm, respectively). Together with moisture, $\mathrm{SO}_{2}$ and $\mathrm{SO}_{3}$ form the highly corrosive sulphuric and sulphurous acids $\left(\mathrm{H}_{2} \mathrm{SO}_{4}\right.$ and $\mathrm{H}_{2} \mathrm{SO}_{3}$, respectively). The lubricating oil of reciprocating generator engines fired on biogas can also become contaminated with sulphur, lose lubrication ability, and require more frequent changing (Allan, 2012). Lastly, sulphur dioxide emissions are also a precursor to acid rain (Kuria and Maringa, 2008).

It is anticipated that Australian piggeries will predominantly use biogas produced on-site to run internal combustion engine (ICE) generators for combined heat and power (CHP) applications, or to produce hot water in a boiler for direct heating of pig sheds. There has also been some interest in micro-turbines for electrical power generation, albeit at a significantly higher cost than an equivalent ICE generator. Unlike Europe, there is limited scope in Australia for supplying centralised natural gas grids from piggeries, because piggeries are generally located in relatively remote agricultural areas, well away from major population centres and energy-intensive industries. According to Table 1.1, the maximum $\mathrm{H}_{2} \mathrm{~S}$ content recommended for biogas use depends on the appliance that burns

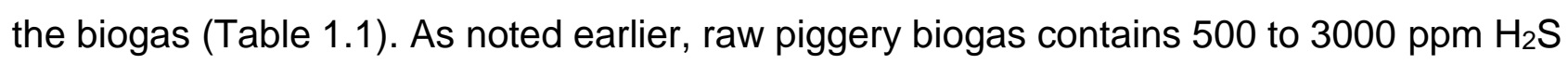
(Safley and Westerman, 1988; FNR, 2005; Heubeck and Craggs, 2010 and Skerman, 
2013), so from Table 1.1, it is clear that CHP units and boilers would likely require some removal of $\mathrm{H}_{2} \mathrm{~S}$ to make piggery biogas suitable for on-farm use.

Table 1.1 Recommended maximum $\mathrm{H}_{2} \mathrm{~S}$ concentrations in biogas used in a range of applications (adapted from Zicari, 2003).

\begin{tabular}{lll}
\hline Application & $\begin{array}{l}\text { Recommended maximum } \\
\text { biogas } \mathbf{H}_{2} \text { S concentrations } \\
\text { (ppm) }\end{array}$ & Reference \\
\hline Heating (Boilers) & 1000 & Wellinger and Linberg (2005) \\
Kitchen Stoves & 10 & Zicari (2003) \\
Internal Combustion Engines & 100 & Wellinger and Linberg (2005) \\
& $\begin{array}{l}\text { (Otto cycle engines } \\
\text { more susceptible than } \\
\text { diesel engines) }\end{array}$ & \\
Micro-turbines & 70,000 & Capstone Turbine Corp. (2003) \\
$\begin{array}{l}\text { Fuel Cells (FC): } \\
\text { PEMFC (Proton exchange membrane): }\end{array}$ & 20 & XENERGY (2002) \\
$\begin{array}{l}\text { PAFC Phosphoric acid): } \\
\text { MCFC (Molten carbonate): }\end{array}$ & 10 & \\
$\begin{array}{l}\text { SOFC (Solid oxide): } \\
\text { Stirling Engines }\end{array}$ & 1000 & STM Power (2002) \\
Natural Gas Upgrade & 4 & Wellinger and Linberg (2005) \\
& & Kohl and Neilsen (1997) \\
\hline
\end{tabular}

\section{$1.2 \quad$ Research Opportunities and Gaps}

Many of the existing biogas treatment technologies being used in other industries would not be ideally suited for $\mathrm{H}_{2} \mathrm{~S}$ removal on-farm in the Australian pork industry. On-farm systems need to provide a combination of (1) simple designs for low-skill maintenance purposes and a low cost, (2) safe, robust, low-cost, and low-skill operations (even when largely unsupervised), (4) a tolerance of significant variations in biogas flow and $\mathrm{H}_{2} \mathrm{~S}$ concentrations, (5) scalability, and (6) minimal and non-hazardous residues or waste. Identification and description of suitable technologies and purification media will help pig producers to better utilise biogas resources, protect biogas use equipment, and improve the safety and profitability of biogas use. The resulting improved ease and profitability of biogas use would accelerate uptake of biogas technology throughout the Australian pork industry, enhancing environmental sustainability whilst also reducing production costs.

The literature review given in Chapter 2 provides an overview of existing biogas purification technologies which have been successfully used in other industries. 
Technologies used to remove $\mathrm{H}_{2} \mathrm{~S}$ during digestion (biological oxidation and chemical precipitation by iron chloride dosing) and from the extracted biogas (chemisorption using iron oxide, iron hydroxide and zinc oxide, adsorption onto activated carbon, absorption with liquids, biological filters and membrane separation) were considered in that review. The most promising technologies identified for application within the Australian pork industry were biological oxidation of $\mathrm{H}_{2} \mathrm{~S}$ and chemisorption with iron-based solid media (Section 2.5). Biological oxidation can be either in the digester or in an external packed column. This technology is attractive because of its relative simplicity and low capital and operating costs, and its ability to substantially reduce $\mathrm{H}_{2} \mathrm{~S}$ concentrations even from high concentrations without the addition of expensive and hazardous chemicals. Drawbacks include (1) safety risks with the potential for forming an explosive biogas mixture if the addition of air $\left(\mathrm{O}_{2}\right)$ to the biogas is excessive, (2) possible inconsistent treatment performance, and (3) minor dilution of the biogas with $\mathrm{N}_{2}$ and $\mathrm{O}_{2}$ in added air. Of the 19 digesters that are currently operating at Australian piggeries, 13 are unmixed unheated covered ponds (Tait, 2016, pers comm). Biological treatment within such covered ponds may also inadvertently result in the recycling of elemental sulphur back to the liquid phase and subsequent accumulation of $\mathrm{H}_{2} \mathrm{~S}$.

The other promising technology, specifically chemisorption of $\mathrm{H}_{2} \mathrm{~S}$ onto a packed bed of iron oxide-rich solid media, is also a well-recognised biogas treatment method, in general. Chemisorption is also the most commonly applied biogas treatment method currently used at Australian piggeries. Several iron-oxide based commercial media are readily available for this application. Whilst some media can be partially regenerated by exposure to $\mathrm{O}_{2}$ (in air) in batch or continuous mode, iron-oxide media ultimately require replacement at regular intervals. Some drawbacks of chemisorption technology are the costs associated with supplying and replacing the solid media and managing the heat and hazardous offgases $\left(\mathrm{SO}_{2}\right)$ generated by the exothermic regeneration reaction.

Importantly, the literature review in Chapter 2 identified that the active compounds responsible for removing $\mathrm{H}_{2} \mathrm{~S}$ in chemisorption, namely the oxides of iron and/or zinc, are relatively common in natural materials such as soils, and even in some agricultural and industrial waste and by-products. Consequently, a range of other low-cost materials - such as soils and biodegradable wastes - may be useful low-cost alternatives for $\mathrm{H}_{2} \mathrm{~S}$ removal. Various prior studies (Section 2.5) suggested that $\mathrm{H}_{2} \mathrm{~S}$ removal could, at least in principle, be supported by many natural and waste materials. Accordingly, there is an opportunity 
and need to clarify the potential for using such low-cost alternative chemisorption media for on-farm removal of $\mathrm{H}_{2} \mathrm{~S}$. Further, the unconfirmed ability to regenerate spent media by exposure to oxygen (air) needs further investigation, because this could substantially increase the whole-of-life capacity of chemisorption media and therefore greatly reduce associated costs.

The laboratory study described in Chapter 3 identified a naturally-occurring red soil as a potentially feasible option for binding $\mathrm{H}_{2} \mathrm{~S}$ from biogas. The measured binding capacity of the red soil was significantly inferior to that of a commercial medium; however, red soils were seen as particularly attractive due to low cost and easy availability in some Australian regions. Of further concern was the potential for the on-farm performance of the red soil, as a $\mathrm{H}_{2} \mathrm{~S}$ removal medium, to differ greatly from that in the laboratory. Therefore, it was considered important to carry out on-farm trials to test the performance of the identified alternative filter medium, namely the red soil.

As noted above, biological oxidation showed significant potential for on-farm $\mathrm{H}_{2} \mathrm{~S}$ removal, but was expected to provide less consistent performance than chemisorption, unless the addition of air and the growth of microorganisms could be optimised for biological oxidation. However, such optimised operation would be highly unlikely in an on-farm scenario in Australia. As an alternative, biological $\mathrm{H}_{2} \mathrm{~S}$ removal could be preferred as a low-cost primary treatment step, before subsequent polishing using chemisorption. The reduced sulphur load on the subsequent chemisorption step could then reduce supply and labour costs associated with commercial media use, and/or improve the feasibility of using alternative filter media with lower $\mathrm{H}_{2} \mathrm{~S}$ binding capacities.

Biological oxidation of biogas $\mathrm{H}_{2} \mathrm{~S}$ in an external packed column would allow a greater degree of control of air injection, mixing, and nutrient provision, compared to biological oxidation inside the covered pond. However, a suitable nutrient and inoculum source would be needed, and it was of interest to test whether recycled covered anaerobic pond effluent could be used as such, because it is readily available, practical and low-cost at piggery sites. Furthermore, its use in this application has not been previously documented. 


\subsection{Objectives}

The following objectives were devised to address the research opportunities and gaps identified in Section 1.2.

Research objective 1: To identify cost-feasible options for removing $\mathrm{H}_{2} \mathrm{~S}$ from piggery biogas by testing and comparing the $\mathrm{H}_{2} \mathrm{~S}$ removal capacity of a commercial iron-based medium (cg5) with those of a range of low-cost alternative media, and to assess whether one of the alternative media could be regenerated, by exposure to air, for reuse as a filter medium. This objective was addressed as presented in Chapter 3 , via a carefully designed laboratory experimental study.

Research objective 2(i): To test and compare the on-farm performance of a selected alternative solid medium (red soil) and a commercial chemisorption medium in a full-scale trial at a commercial piggery.

Research objective 2(ii): To test the on-farm performance of a full-scale, low-cost, biological $\mathrm{H}_{2} \mathrm{~S}$ removal system, operating at a commercial piggery, and to assess the feasibility of using treated covered pond effluent as the microorganism nutrient and inoculum source.

Objectives 2(i) and 2(ii) were addressed, as outlined in Chapter 4, via a series of on-farm tests at two commercial piggeries.

\subsection{Thesis aim and structure}

Towards addressing the specific needs of the Australian pork industry and the specific research objectives identified above, this thesis research aimed to identify and characterise low-cost options for removing $\mathrm{H}_{2} \mathrm{~S}$ from piggery biogas. The technologies selected for further study were chosen from a large list of available options (refer to Chapter 2 for an overview), particularly because they were suitable for decentralised, onfarm use, in accordance with the criteria set out in Section 1.2. A detailed and carefully designed laboratory study was then executed (Research Objective 1, Chapter 3 ), to test and compare the $\mathrm{H}_{2} \mathrm{~S}$ removal capacity of a commercial iron-based medium (cg5) with those of a range of low-cost alternative media. The laboratory data was then extended into 
on-farm trials of the most promising identified options in order to test and compare on-farm performance with that in the lab. The on-farm performance of a low-cost, biological $\mathrm{H}_{2} \mathrm{~S}$ removal system, operating at a second commercial piggery, was also tested (Research Objective 2, Chapter 4). Chapter 5 of this thesis provides a general discussion of the overall outcomes and implications of the thesis results for a case study piggery scenario, and provides recommendations for future work. 


\section{Literature review}

This chapter provides a review of literature pertaining to this thesis, commencing with an overview of typical on-farm uses of biogas generated at piggeries, before discussing the formation, properties and impacts of hydrogen sulphide $\left(\mathrm{H}_{2} \mathrm{~S}\right)$, a key ingredient of concern in piggery biogas. The potential adverse impacts of $\mathrm{H}_{2} \mathrm{~S}$ on human and livestock health and piggery infrastructure are outlined, reinforcing the need for removal of $\mathrm{H}_{2} \mathrm{~S}$ prior to most on-farm uses of biogas. The chapter then summarises currently available technologies for removal of $\mathrm{H}_{2} \mathrm{~S}$ from biogas, highlighting specific technologies with potential for on-farm, decentralised implementation at pig farms, with reference to the selection criteria set out in Section 1.2. Lastly, Chapter 2 concludes by highlighting key research gaps and opportunities to be addressed in this thesis.

\subsection{Uses of piggery biogas on-farm}

The feasibility of adopting various biogas use technologies varies from farm to farm depending on the following factors (McGahan et al., 2013):

- size of piggery (generally defined by the number of standard pig units (SPU) housed in the piggery. One SPU produces $90 \mathrm{~kg}$ of volatile solids (VS) per year, as manure and waste feed, which is the amount of VS typically produced by an average sized grower pig (40 kg live weight) (Tucker et al., 2010). Hence the number of SPUs defines the manure loading and likely biogas production from anaerobic digestion of the piggery waste stream.

- type of piggery (breeder or grower with more potential biogas generated at grower units in comparison to breeder and weaner units);

- effluent management system (pull plug or flushing - some organic matter is degraded in a pull plug system prior to exiting the sheds, leading to a loss of biogas potential compared to an identical piggery with direct flush system);

- feed ration;

- site layout (whether or not the piggery is a multi-site operation);

- energy demands and whether there is a feed mill on site;

- energy cost;

- type of electricity supply (3-phase power gives the potential to sell excess electricity generated from biogas capture back to the grid); 
- location (different states have different legislative requirements);

- any available Government incentives to encourage uptake of biogas.

While increasing amounts of biogas are being used as transport fuel or for injection to the grid in various countries, these uses demand a higher quality of gas (Wellinger et al., 2013) which would be difficult, expensive and most likely impractical to achieve on-farm at piggeries in Australia. Figure 2.1 is a diagrammatic representation of the range of biogas use options with particular reference to large scale dairy operations in the US (Mears, 2001). Because these uses are applicable to an agricultural industry operating in a sparsely populated rural area, possibly with similar climatic conditions, the majority of these potential biogas uses are considered to be technically feasible for adoption by the Australian pork industry, as discussed in the following sections.

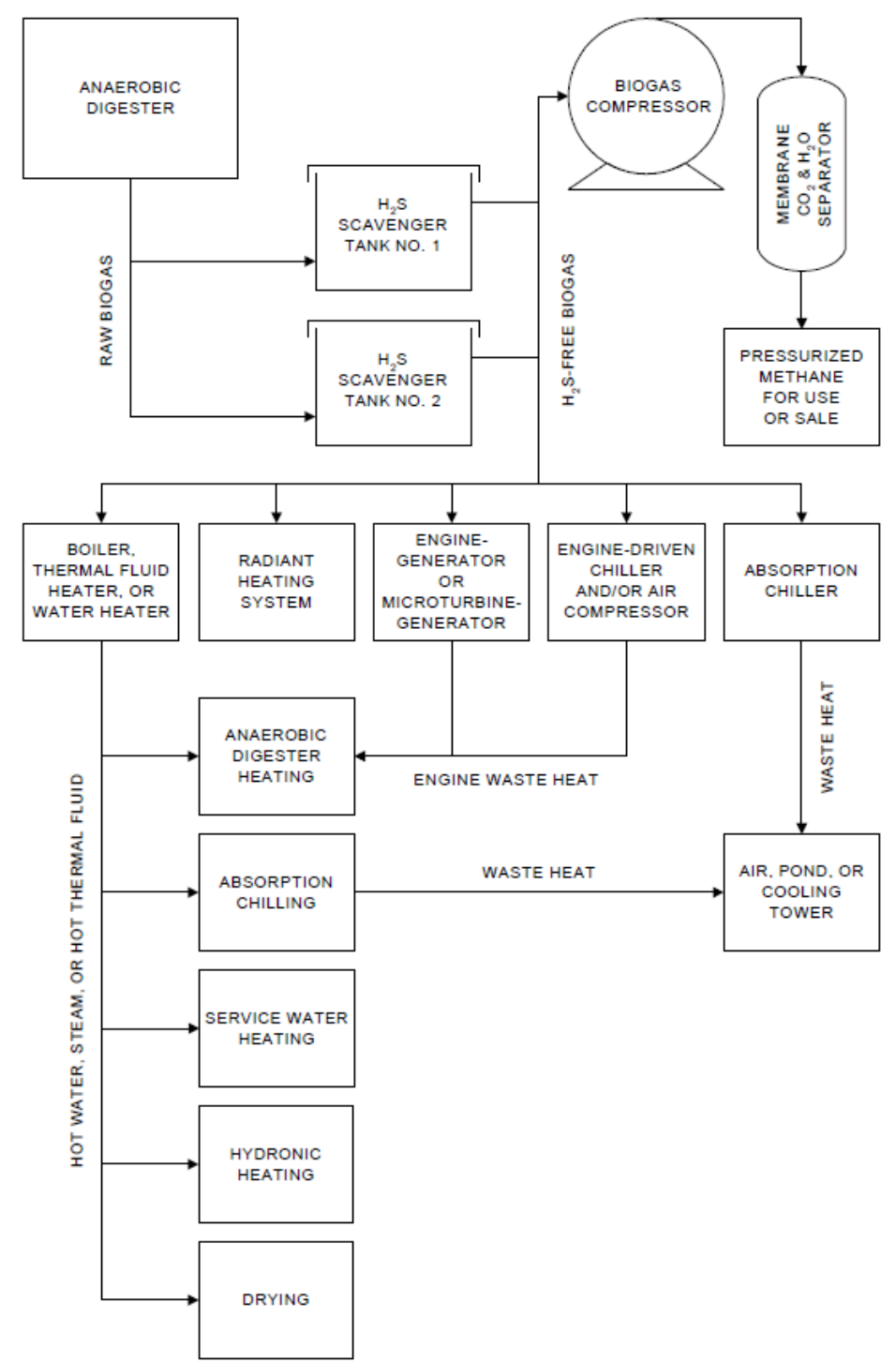

Figure 2.1 Range of biogas use options with particular reference to large scale dairy operations in the US (Mears, 2001). 
The majority of the existing biogas systems currently operating at Australian piggeries have adopted combined heat and power (CHP) systems which generate electricity for onfarm use and in some cases, export to the grid, in addition to hot water which is used to heat farrowing and weaner sheds (housing young pigs). Whilst the mix of different energy requirements would vary markedly between piggeries, some larger piggeries produce biogas in excess of the volume required to satisfy on-site electrical power use, particularly if they are not operating on-site feed mills. Rather than flaring the unutilised biogas, or generating more electrical power for export to the grid (at relatively low rates of return), the industry is currently examining the feasibility of adopting a range of alternative, on-farm uses of biogas which could potentially improve overall on-farm energy use efficiency and maximise economic returns. Current and existing biogas uses are briefly summarised below.

Flaring: Piggery biogas systems generally require the installation of a flare for safely burning excess biogas, or as an emergency measure for use when other biogas burning appliances, such as engines or boilers, require maintenance. However, the use of a flare as the sole biogas destruction method may be appropriate at small piggeries which do not generate sufficient biogas for economically viable electrical power generation, and where the primary objectives are GHG and/or odour mitigation. Life cycle assessment analyses demonstrated that the installation of a CAP and flare system at a conventional piggery could lower GHG emissions by $46 \%$ (Wiedemann et al., 2012). Raw piggery biogas does not generally require treatment prior to flaring, other than the removal of free water (e.g. via a knockout pot, Allan, 2012).

Boilers: On-farm boilers are used primarily for heating water circulated through under-floor heating pads and zone heating elements which heat creep areas in farrowing sheds and weaner accommodation (hydronic heating), and/or for heating air blown or circulated through finned tube convectors/radiators/heat exchangers to provide space heating in piggery sheds. As these applications generally require water heated to a maximum temperature of $90^{\circ} \mathrm{C}$, biogas-fired boilers used in piggeries do not have to produce steam; however, some large piggeries may use steam for pelletising of feed. Biogas may not need to be upgraded before being burnt in boilers (Table 1.1). However, at $\mathrm{H}_{2} \mathrm{~S}$ concentrations higher than $1000 \mathrm{ppm}$, the formation of sulphuric acid is likely to result in serious corrosion (Wellinger et al., 2013). Alternatively, boilers burning untreated biogas may use 
components fabricated using corrosion resistant materials. Removal of water vapour from the biogas prior to use in boilers is also recommended (Wellinger and Lindberg, 2005).

Radiant heaters: Radiant heaters develop their infrared thermal radiation via a ceramic body that is heated to $600-800^{\circ} \mathrm{C}$ (red-hot) by the biogas flame. Approximately $95 \%$ of the biogas energy content is converted to heat resulting in thermal power outputs ranging from 1.5 to $10 \mathrm{~kW}$ for typical small heaters (Werner et al., 1989). Care is required in managing the combustion by-products of radiant heaters $\left(\mathrm{CO}_{2}, \mathrm{CO}, \mathrm{SO}_{2}\right.$ and water vapour). Some radiant heaters may be fitted with a vent or flue to discharge the exhaust gases outside the piggery building to minimise harmful effects on livestock and worker health, and corrosion of metallic fittings.

Electricity: Biogas may be burnt in an internal combustion (IC) engine (compression or spark ignition) or a gas micro-turbine, to power a generator used to generate electricity for on-farm use or export to the electricity supply grid.

Sulphur dioxide $\left(\mathrm{SO}_{2}\right)$, formed from combustion of relatively high levels of $\mathrm{H}_{2} \mathrm{~S}$ in the piggery biogas, can produce highly corrosive sulphurous and sulphuric acid by reacting with condensed water that forms when combustion exhaust gases are cooled below their dew point. The lubricating oil used in gas reciprocating engines may also require more frequent changing as it becomes contaminated with sulphur, lowering the $\mathrm{pH}$ and adversely affecting its lubrication qualities. Consequently, reciprocating gas engines typically require a biogas $\mathrm{H}_{2} \mathrm{~S}$ concentration less than $200 \mathrm{ppm}$ to avoid excessive corrosion and lubrication issues (AMPC and MLA, 2013). Proper treatment of the biogas to remove contaminants will lead to extended engine overhaul intervals, longer spark plug life, extended oil change intervals, better component life and lower overall maintenance costs (Caterpillar, 2013).

In biogas micro-turbines, air is pressed into a combustion chamber at high pressure and mixed with biogas. The air-biogas mixture is burned resulting in a temperature increase and expansion of the gas mixture. The hot gases are then released through a turbine, connected to an electricity generator (typical electric capacity $<200 \mathrm{kWe}$ ). Biogas must be compressed to approximately $585 \mathrm{kPa}$ for use in a micro-turbine (Wiltsee and Emerson, 2004) which have shaft speeds as high as $96,000 \mathrm{rpm}$ and electrical efficiencies from 25 to $30 \%$. The cost of biogas micro-turbines is relatively high and research and development 
work is aiming to reduce costs for future models (Seadi et al., 2008). Micro-turbines can operate with gases having a wide range of energy contents, automatically adjusting to changing energy densities over time, and can accept high levels of contaminants such as $\mathrm{H}_{2} \mathrm{~S}$ (5000 - 70,000 ppm) (Capstone, 2009). This may avoid the need for $\mathrm{H}_{2} \mathrm{~S}$ removal from the biogas altogether, with associated benefits in capital and maintenance costs. However, micro-turbines are not tolerant of entrained free water and siloxanes, albeit that siloxanes are usually not an issue with straight manure digestion.

Cogeneration or combined heat and power (CHP): In addition to generating electricity, cogeneration or CHP systems use heat exchangers to recover otherwise wasted energy from the engine cooling and exhaust systems. The recovered energy is in the form of hot water at temperatures typically ranging from 70 to $80^{\circ} \mathrm{C}$. This hot water can be used for a range of productive uses, thereby further offsetting on-farm energy costs.

Trigeneration: In addition to the heat and power produced in cogeneration or CHP systems, trigeneration systems use a portion of the heat from the cooling water and/or flue gas produced by the engine (or turbine) driving the electrical generator, use an absorption chilling process to produce cooling energy, as shown in Figure 2.2. This cooling energy, generally in the form of chilled water, could potentially be used in applications such as shed cooling, snout cooling or for chilling of drinking water supplied to lactating sows, which has had demonstrated production benefits (Willis and Collman, 2007).
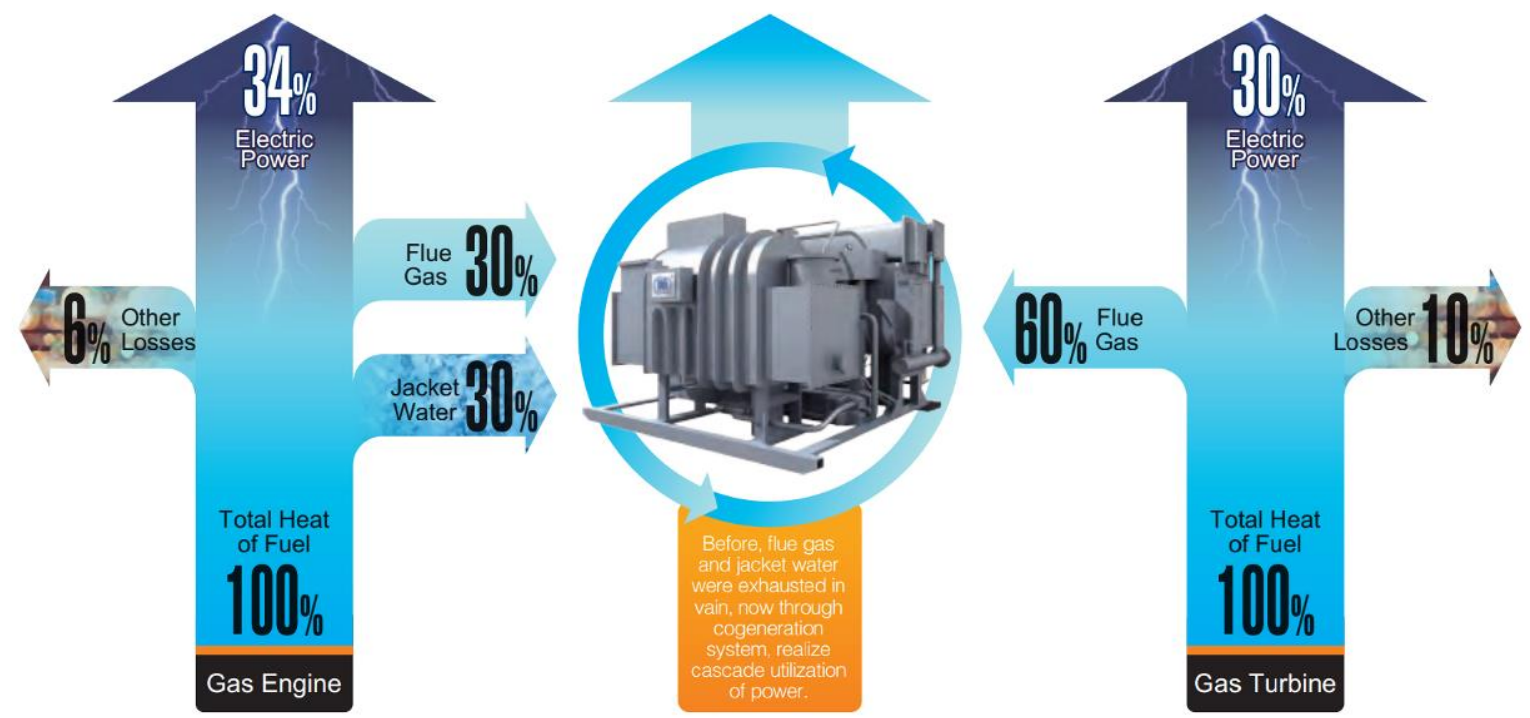

Figure 2.2 Trigeneration system schematic drawing showing heating, cooling and electrical energy potential from biogas (Simons Green Energy, 2014). 
Vehicle fuel: Raw biogas must be upgraded to natural gas quality for use in vehicles designed to run on natural gas. This means that $\mathrm{CO}_{2}, \mathrm{H}_{2} \mathrm{~S}$, ammonia, entrained particulates and water (and sometimes other trace compounds) have to be removed so that the treated gas has a high $\mathrm{CH}_{4}$ content of about $95-98 \%$ by volume (NSCA, 2006). Heavy-duty vehicles may be fitted with spark ignition dedicated gas engines or compression ignition dual-fuel engines which use diesel for pilot ignition purposes. High rates of substitution of compressed natural gas (CNG) or biomethane for diesel, sometimes up to $90 \%$, have been claimed; however, an average of $70 \%$ is representative of typical fleet operation (NSCA, 2006). It is envisaged that the main applications for using piggery biogas as vehicle fuel would be for farm machinery, such as tractors, and/or for trucks used to transport pigs between production units and/or to the abattoir. These applications may be economically feasible at piggeries where on-site energy usage is relatively low and there is excess biogas available after satisfying on-site electricity, heating and cooling needs. Depending on travel distances, vehicular storage of CNG may be limiting. Furthermore, the capital and ongoing operational costs involved in upgrading the raw biogas and converting existing vehicles may diminish the economic viability of this option.

\subsection{Hydrogen sulphide $\left(\mathrm{H}_{2} \mathrm{~S}\right)$, its formation, properties and impacts on biogas use}

$\mathrm{H}_{2} \mathrm{~S}$ is generally present in biogas at concentrations between 80 and 4,000 ppmv, depending on the feedstock (Allegue and Hinge, 2014). Pigs typically excrete $76 \pm 40 \mathrm{~g} \mathrm{~S} / \mathrm{d}$ per $1000 \mathrm{~kg}$ live weight in fresh manure (ASAE, 2003), which is equivalent to $3 \mathrm{~g} \mathrm{~S} / \mathrm{d}$ per standard pig unit (40 $\mathrm{kg}$ live weight). $\mathrm{H}_{2} \mathrm{~S}$ is primarily produced by sulphatereducing microorganisms which reduce sulphur-containing proteins, under the anaerobic conditions which exist in digesters and covered ponds (Trogisch et al., 2004). Increasing dietary protein content increases the excretion of sulphur-containing compounds capable of generating sulphide under anaerobic storage (Stevens et al,. 1993). Considerable amounts of $\mathrm{H}_{2} \mathrm{~S}$ can be produced by biochemical conversion of inorganic sulphur, particularly sulphate, which is the primary form of sulphur excreted in pig urine (Allegue and Hinge, 2014 and Spoelstra, 1980).

Equations 2.1 and 2.2 describe the reduction of sulphate (Muyzer and Stams, 2008, McVay, ND, respectively): 
$\mathrm{SO}_{4}{ }^{2-}+2 \mathrm{C}$ organic $+2 \mathrm{H}_{2} \mathrm{O}+$ microbial activity $\rightarrow \mathrm{H}_{2} \mathrm{~S}+2 \mathrm{HCO}^{3-}$ Equation 2.2

The polar nature of the $\mathrm{H}_{2} \mathrm{~S}$ molecule makes it highly soluble in water (or piggery effluent). $\mathrm{H}_{2} \mathrm{~S}$ enters the digester or covered pond head space by volatilization. The rate at which $\mathrm{H}_{2} \mathrm{~S}$ leaves the aqueous phase is governed by Henry's Law (Henry's constant: $2582 \mathrm{~mL}$ gas. L water ${ }^{-1} \mathrm{~atm}^{-1}$ at $20^{\circ} \mathrm{C}$, Noyola et al., 2006), the amount of turbulence in the water, $\mathrm{pH}$, temperature, wastewater constituents, and $\mathrm{H}_{2} \mathrm{~S}$ concentrations in the liquid and gas phases (Pomeroy and Parkhurst, 1977).

Sulphides occur in the aqueous phase as dissolved $\mathrm{H}_{2} \mathrm{~S}$, bisulphide ion (HS-) or sulphide ion $\left(\mathrm{S}^{-2}\right)$, depending on the $\mathrm{pH}$ of the liquid (Figure 2.3, McVay, ND). Dissolved $\mathrm{H}_{2} \mathrm{~S}$ and HS- dominate at near equal concentrations around $\mathrm{pH} 7$, which is a common operational $\mathrm{pH}$ in healthy anaerobic wastewater treatment (Noyola et al., 2006). Because only dissolved $\mathrm{H}_{2} \mathrm{~S}$ can transfer into the gaseous phase, the concentration of $\mathrm{H}_{2} \mathrm{~S}$ in biogas can be reduced by increasing $\mathrm{pH}$ which in turn converts dissolved $\mathrm{H}_{2} \mathrm{~S}$ into bisulphide ion.

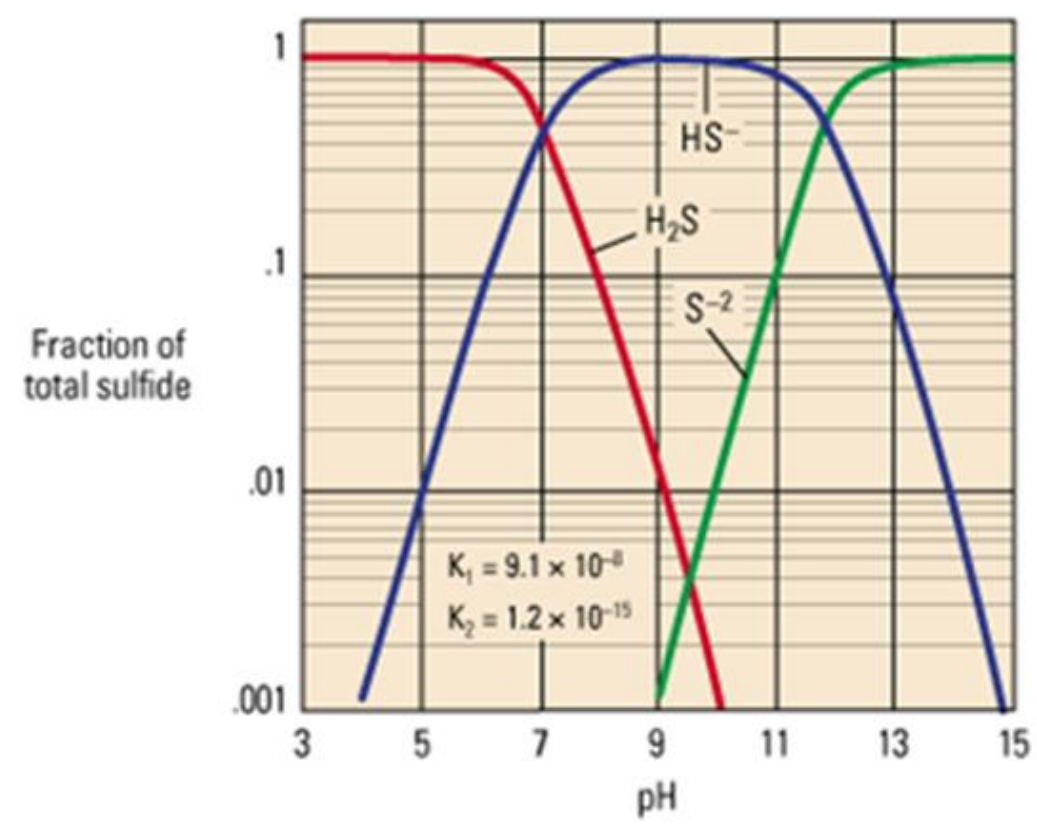

Figure 2.3. The distribution of sulphide species in water at a range of $\mathrm{pH}$ values. (McVay, ND)

The solubility of $\mathrm{H}_{2} \mathrm{~S}$ in water is also affected by temperature (Figure 2.4). Some further physical and chemical properties of $\mathrm{H}_{2} \mathrm{~S}$ are provided in Table 2.1. 


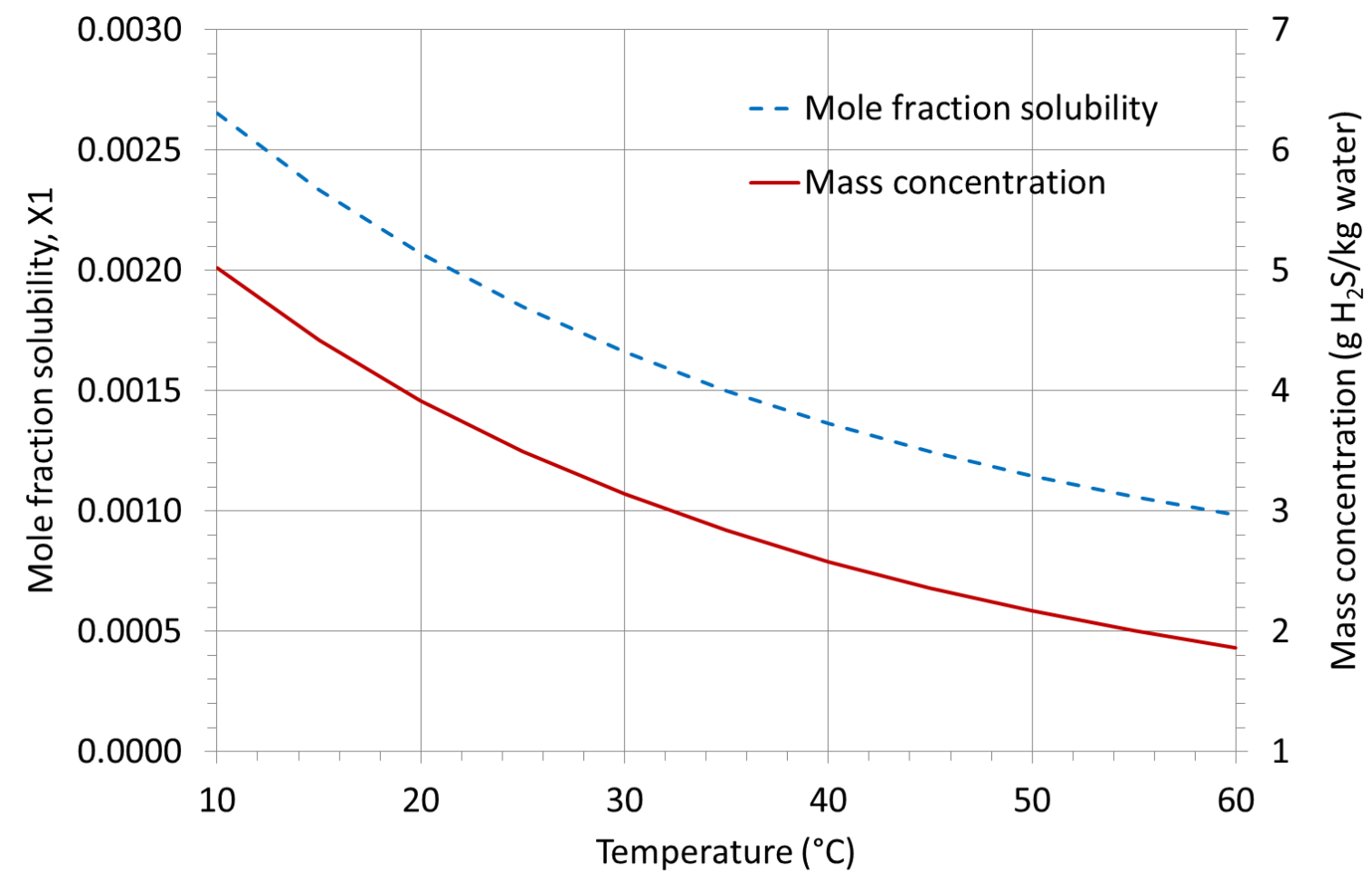

Figure 2.4. Solubility of $\mathrm{H}_{2} \mathrm{~S}$ in water over the relevant range of temperatures, for a partial gas pressure of 101.325 kPa (1 atm). Based on Gevantman in Haynes (2016).

Table 2.1. Selected physical and chemical properties of $\mathrm{H}_{2} \mathrm{~S}$ (adapted from Air Liquide, 2016 and 2012).

\begin{tabular}{|c|c|}
\hline Property & Value \\
\hline Physical state at $20^{\circ} \mathrm{C} / 101.3 \mathrm{kPa}:$ & Gas. \\
\hline Colour: & Colourless. \\
\hline Odour: & $\begin{array}{l}\text { Rotten eggs. Odour can persist. Poor warning } \\
\text { properties at low concentrations. }\end{array}$ \\
\hline Odour threshold: & $\begin{array}{l}\text { Odour threshold is subjective and inadequate to } \\
\text { warn for overexposure. }\end{array}$ \\
\hline Molecular weight: & $34.081 \mathrm{~g} / \mathrm{mol}$ \\
\hline Gas density $\left(1.013\right.$ bar and $\left.15^{\circ} \mathrm{C}\right)$ : & $1.4534 \mathrm{~kg} / \mathrm{m}^{3}$ \\
\hline Compressibility Factor $(\mathrm{Z})\left(1.013\right.$ bar and $\left.15^{\circ} \mathrm{C}\right)$ : & 0.99148 \\
\hline Specific gravity: & 1.19 \\
\hline Specific volume (1.013 bar and $\left.25^{\circ} \mathrm{C}\right)$ : & $0.7126 \mathrm{~m}^{3} / \mathrm{kg}$ \\
\hline Viscosity $\left(1.013\right.$ bar and $\left.0^{\circ} \mathrm{C}\right)$ : & 1.1298E-04 Poise \\
\hline Solubility in water $\left(1.013\right.$ bar and $\left.0^{\circ} \mathrm{C}\right)$ : & $4.67 \mathrm{vol} / \mathrm{vol}$ \\
\hline Solubility in water: & $3980 \mathrm{mg} / \mathrm{L}$ \\
\hline Auto ignition temperature: & $270^{\circ} \mathrm{C}$ \\
\hline Flammability range [vol\% in air]: & 4.3 to 45.5 \\
\hline Other data: & $\begin{array}{l}\text { Gas/vapour heavier than air. May accumulate in } \\
\text { confined spaces, particularly at or below ground } \\
\text { level. }\end{array}$ \\
\hline
\end{tabular}


$\mathrm{H}_{2} \mathrm{~S}$ is a colourless, toxic and flammable gas (Department of Sustainability, Environment, Water, Population and Communities, 2013). Although it primarily affects the nervous system, it is considered a broad-spectrum poison, because it can poison several different systems in the body. Further to the impacts on human health noted in Section 1.1, Table 2.2 summarises the range of physical reactions likely to result from exposure to $\mathrm{H}_{2} \mathrm{~S}$, at various concentrations (Aquafix, 2015). The severity of these reactions highlights the vital importance of ensuring that all on-farm biogas systems incorporate suitable control measures to eliminate the risk of human and livestock exposure to dangerous $\mathrm{H}_{2} \mathrm{~S}$ concentrations.

Table 2.2. Human physical reactions following exposure to $\mathrm{H}_{2} \mathrm{~S}$, at a range of concentrations (adapted from Aquafix, 2015).

\begin{tabular}{|c|c|}
\hline $\begin{array}{l}\mathrm{H}_{2} \mathrm{~S} \text { concentration } \\
(\mathrm{ppm})\end{array}$ & Physical Reaction \\
\hline 0.03 & Can smell. Exposure is safe for up to 8 hours. \\
\hline 4 & May cause eye irritation. Mask must be used, as it damages metabolism. \\
\hline 10 & $\begin{array}{l}\text { 10-minute maximum exposure. Kills smell in } 3-15 \text { min. Causes gas eye and throat } \\
\text { injury. Reacts violently with dental mercury amalgam fillings. }\end{array}$ \\
\hline 20 & Exposure for more than 1 min causes severe injury to eye nerves. \\
\hline 30 & Loss of smell, injury to blood brain barrier through olfactory nerves. \\
\hline 100 & $\begin{array}{l}\text { Respiratory paralysis in 30-45 min. Needs prompt artificial resuscitation. Will } \\
\text { become unconscious quickly ( } 15 \mathrm{~min} \text { max). }\end{array}$ \\
\hline 200 & Serious eye injury and permanent damage to eye nerves. Stings eye and throat. \\
\hline 300 & Loses sense of reasoning and balance. Respiratory paralysis in 30-45 min. \\
\hline 500 & $\begin{array}{l}\text { Asphyxia! Needs prompt artificial resuscitation. Will become unconscious in 3-5 } \\
\text { min. Immediate artificial resuscitation is required. }\end{array}$ \\
\hline 700 & $\begin{array}{l}\text { Breathing will stop and death will result if not rescued promptly, immediate } \\
\text { unconsciousness. Permanent brain damage may result unless rescued promptly. }\end{array}$ \\
\hline
\end{tabular}

\section{$2.3 \quad \mathrm{H}_{2} \mathrm{~S}$ removal Technologies}

This section categorises biogas treatment technologies into (a) methods where the biogas is treated directly in the digester vessel or covered anaerobic lagoon (CAL) or (b) methods where the biogas is treated in vessels or columns installed downstream of the digester or CAL. 


\subsection{1 $\quad \mathrm{H}_{2} \mathrm{~S}$ removal inside a digester or CAL}

This section outlines two existing technologies to remove $\mathrm{H}_{2} \mathrm{~S}$ while the biogas is still inside the digester or CAL.

\subsubsection{Biological oxidation inside the digester or covered lagoon}

For this treatment method, air is injected into the biogas headspace above the liquid inside the digester or CAL. Specialised sulphide oxidizing micro-organisms (Thiobacillus), which are naturally present inside the digester, then oxidise the $\mathrm{H}_{2} \mathrm{~S}$ to elemental sulphur (Ryckebosch et al., 2011) with the injected oxygen acting as the electron acceptor as follows:

$2 \mathrm{H}_{2} \mathrm{~S}+\mathrm{O}_{2} \rightarrow 2 \mathrm{~S}+2 \mathrm{H}_{2} \mathrm{O}$ Equation 2.3

These micro-organisms are autotrophic, using $\mathrm{CO}_{2}$ from the biogas to supply their carbon needs (Ryckebosch et al., 2011). In addition to elemental sulphur (a largely insoluble solid), some sulphate can be produced due to complete oxidation of $\mathrm{H}_{2} \mathrm{~S}$ as follows:

$\mathrm{H}_{2} \mathrm{~S}+2 \mathrm{O}_{2} \rightarrow \mathrm{SO}_{4}+2 \mathrm{H}+$ Equation 2.4

This sulphate has the potential to cause corrosive, acidic solutions in localised pools of water or condensate. However, with respect to the digester liquid bulk, alkalinity in the digester liquid (Staunton et al., 2015; Sell et al., 2011) would be expected to readily neutralize the acid that is formed, and so any influence on digester $\mathrm{pH}$ and operation would likely be insignificant.

Micro-aeration is said to reduce the $\mathrm{H}_{2} \mathrm{~S}$ concentration in biogas by as much as $95 \%$ to around 50 ppm (Wellinger and Lindberg, 2005), depending on factors such as temperature, reaction time and air placement/mixing. Such a reduction in $\mathrm{H}_{2} \mathrm{~S}$ concentration may be sufficient for the operation of most boilers and internal combustion engines used at piggeries, without requiring any further treatment of the biogas. Alternatively, if very low or consistently low levels of $\mathrm{H}_{2} \mathrm{~S}$ are required for the intended biogas use (Table 1.1), the biological oxidation could be followed by a secondary polishing step using a solid medium such as dry iron oxide (see Section 2.3.2.1 below). 
The major advantage of micro-aeration, especially for application at piggeries, is that no chemical additives are required and operating and capital costs can be very low. Only a very small amount of air is required, generally around 2 to $6 \%$ air in biogas (Wellinger and Lindberg, 2005), so if an air-pump is used, the parasitic power load would be negligible. The main concern of micro-aeration is the potential to create an explosive biogas-air mixture inside the digester or CAL, in the case where air addition is excessive. This risk can be further elevated on-farm because relatively remote biogas infrastructure would be infrequently inspected. Fortunately, a 2 to $6 \%$ air mixture in biogas is equivalent to a 94 to $98 \%$ biogas mixture in air, which is well above the upper explosive limit for typical piggery biogas (17 to $18 \%$ biogas in air mixture, Ross and Walsh, 1996). So, a more likely risk scenario would result from air being continuously added to a stagnant biogas headspace, such as in the case when downstream biogas equipment is shut-down for some reason. Automated safety measures can be cost-prohibitive, yet the possible consequences are obviously unacceptable. Other strategies have to be developed and implemented to prevent this risk scenario on-farm, such as, for example, an automatic safety interlock that only allows air addition when the metered flow of biogas from the digester or CAL exceeds a minimum value.

The amount of air required for successful micro-aeration (2 to $6 \%$ of air in biogas, Wellinger and Lindberg, 2005) is notably higher than the stoichiometric amount required for conversion of $\mathrm{H}_{2} \mathrm{~S}$ to elemental sulphur ( $0.7 \%$ by volume for $3000 \mathrm{ppm} \mathrm{H}_{2} \mathrm{~S}$ ). This is perhaps due to $\mathrm{O}_{2}$ scavenging requirements of heterotrophic carbon oxidation inside the digester (or CAL), or to accommodate varying biogas production and quality.

The available literature does not provide any clear guidance on how to achieve adequate mixing of air within the biogas headspace, especially for large CALs having large biogas headspace volumes. For example, is micro-aeration even feasible for CALs? Are multiple air injection points required for CALs? It is also unclear where the necessary biofilm grows in a CAL. Lastly, it is not known whether elemental sulphur just joins a stagnant pool of settling sludge in the CAL and is ultimately converted back into $\mathrm{H}_{2} \mathrm{~S}$ to exacerbate the overall sulphur loading. In mixed tank digesters, elemental sulphur is generally assumed to simply flow out with the treated digestate. 


\subsubsection{Chemical dosing of iron chloride into a digester}

Sulphide strongly binds with ferric $\left(\mathrm{Fe}^{3+}\right)$ or ferrous $\left(\mathrm{Fe}^{2+}\right)$ iron, forming insoluble iron precipitates by the following reactions (Ryckebosch et al., 2011):

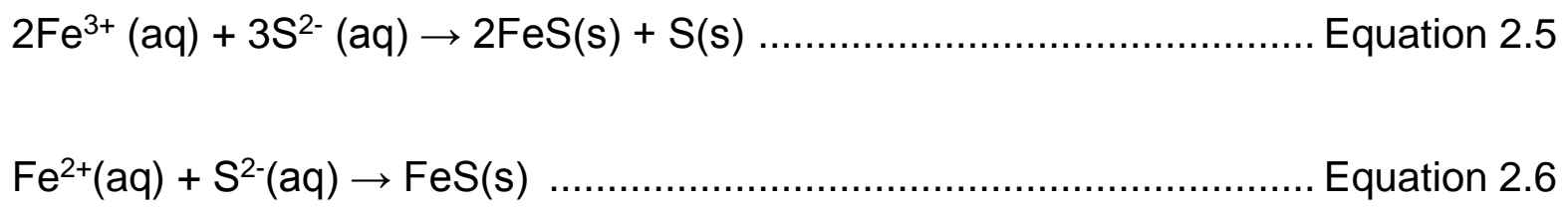

These reactions sequester sulphide from the digester liquid phase, to form suspended or settled solids. This ultimately discourages transfer of sulphide into the gas phase, resulting in a reduced $\mathrm{H}_{2} \mathrm{~S}$ concentration in the biogas. The normal dosing rate for ferrous chloride is 100 to $220 \mathrm{~g}$ iron/t substrate, depending on the nature of the substrate (Kronos, 2014); however, this dosage rate may be cost-prohibitive for piggery applications. Whilst this treatment method effectively reduces high concentrations of $\mathrm{H}_{2} \mathrm{~S}$, it is less efficient at achieving low and stable levels of $\mathrm{H}_{2} \mathrm{~S}$ (Krich, et al., 2005). A reduction of the biogas $\mathrm{H}_{2} \mathrm{~S}$ concentration down to $100 \mathrm{ppm}$ has been reported by Schomaker et al. (2000). The high chemical costs, relatively poor performance and material safety considerations associated with ferric chloride, are likely to limit the future use of this method at piggeries.

\subsubsection{Removal of $\mathrm{H}_{2} \mathrm{~S}$ downstream of a digester or CAL}

This section outlines a number of commercially available technologies for removing $\mathrm{H}_{2} \mathrm{~S}$ from extracted biogas, downstream of a digester or CAL.

\subsubsection{Chemisorption using iron oxide, iron hydroxide or zinc oxide}

In this treatment method, biogas is passed through a bed of solid media, with which the $\mathrm{H}_{2} \mathrm{~S}$ in the biogas reacts to form solid precipitates. The active ingredient is typically iron oxide $\left(\mathrm{Fe}_{2} \mathrm{O}_{3}\right)$, iron hydroxide $\left(\mathrm{Fe}(\mathrm{OH})_{3}\right)$ or zinc oxide $(\mathrm{ZnO})$, and their reaction products are iron (III) sulphide $\left(\mathrm{Fe}_{2} \mathrm{~S}_{3}\right)$ or zinc sulphide $(\mathrm{ZnS})$ precipitates, respectively.

Stoichiometrically, $1 \mathrm{~kg}$ of $\mathrm{Fe}_{2} \mathrm{O}_{3}, \mathrm{Fe}(\mathrm{OH})_{3}$ or $\mathrm{ZnO}$ removes $0.64,0.48$ or $0.42 \mathrm{~kg}$ of $\mathrm{H}_{2} \mathrm{~S}$, respectively. The relevant reactions are (Ryckebosch et al., 2011):

$\mathrm{Fe}_{2} \mathrm{O}_{3}(\mathrm{~s})+3 \mathrm{H}_{2} \mathrm{~S}(\mathrm{~g}) \rightarrow \mathrm{Fe}_{2} \mathrm{~S}_{3}(\mathrm{~s})+3 \mathrm{H}_{2} \mathrm{O}_{(\mathrm{l})}$ Equation 2.7

$2 \mathrm{Fe}(\mathrm{OH})_{3}(\mathrm{~s})+3 \mathrm{H}_{2} \mathrm{~S}(\mathrm{~g}) \rightarrow \mathrm{Fe}_{2} \mathrm{~S}_{3}(\mathrm{~s})+6 \mathrm{H}_{2} \mathrm{O}(\mathrm{l})$ Equation 2.8 
A variety of iron-rich media can be used as the solid contacting medium. A commonly applied commercial product is referred to as "iron sponge", which consists of iron-oxideimpregnated wood-chips, generally pine (Zicari, 2003; Abatzoglou and Boivin, 2009). Approximately $20 \mathrm{~g}$ of $\mathrm{H}_{2} \mathrm{~S}$ can be bound per $100 \mathrm{~g}$ of iron sponge (Krich et al., 2005).

In recent years, several commercial media have been offered as improved alternatives to iron sponge, to be used for $\mathrm{H}_{2} \mathrm{~S}$ removal across a range of industries (Zicari, 2003). Such commercial products have iron coatings on different supporting structures such as dried manure, ceramic beads, diatomaceous earth, or unspecified proprietary materials (Cherosky and Li, 2013), or consist of pelletised iron-oxide rich substrate, for example red mud, which is a waste product from aluminium production (Wellinger and Lindberg, 2005). At high $\mathrm{H}_{2} \mathrm{~S}$ concentrations ( 1,000 to $4,000 \mathrm{ppm}$ ), $100 \mathrm{~g}$ of red mud pellets is said to bind $50 \mathrm{~g}$ of sulphide; however, such pellets are likely to be more expensive than wood chips (Krich et al., 2005).

The sulphide binding capacity of a solid medium depends on the contact area-to-volume ratio and the available content of the active ingredient (iron and/or zinc). For example, rusted steel wool, whilst rich in iron, has a relatively small surface area and thus a low sulphide binding capacity (Krich et al., 2005).

The optimal temperature range for the iron binding reaction with sulphide is said to be between 25 and $50^{\circ} \mathrm{C}$ (Wellinger and Lindberg, 2005). The reaction requires water, so the biogas should not be dried prior to this treatment step; however, condensation may result in excess water coating or binding the pellets, thereby reducing the reactive surface area (Krich et al., 2005).

The iron-oxide in the chemisorption medium is eventually completely converted to sulphide minerals, and thus will not react any further. The resulting bed of spent media can then be regenerated to a limited extent by exposure to atmospheric oxygen, which converts the iron sulphide back into iron oxide, with elemental sulphur as a by-product, according to the following reaction (Zicari, 2003): 
In batch mode, this regeneration can be achieved by removing the medium from the chemisorption column and exposing it to air. The used iron sponge material is spread out into a $0.15 \mathrm{~m}$ thick layer which is kept continually wetted for 10 days (Zicari, 2003) to manage the heat build-up and prevent combustion by the highly exothermic oxidation reaction (Equation 2.10) (Revell, 1997). The Gas Processors Suppliers Association (2004) recommends that the entire bed should be wetted before beginning the change-out operation. The elemental sulphur that forms as a by-product (Equation 2.10) progressively coats the surface of the media, increasing the pressure drop across the bed and eventually blocking gas flow through the bed or into pores within the media (Kido et al., 1995). This build-up of elemental sulphur appears to result in a one third loss in $\mathrm{H}_{2} \mathrm{~S}$ removal capacity every time the media is regenerated (Abatzoglou and Boiuvin, 2009). Therefore, a medium cannot be regenerated indefinitely and eventually has to be replaced with fresh medium. Stochiometrically, $1 \mathrm{~kg}$ of $\mathrm{Fe}_{2} \mathrm{O}_{3}$ removes $0.64 \mathrm{~kg}$ of $\mathrm{H}_{2} \mathrm{~S}$, (Equation 2.7). Taylor (1956) suggests that only about $85 \%$ of this theoretical removal efficiency ( $0.56 \mathrm{~kg} \mathrm{H}_{2} \mathrm{~S} / \mathrm{kg} \mathrm{Fe}_{2} \mathrm{O}_{3}$ ) can be achieved in batch operation mode, because of the accumulated sulphur and a resulting progressive loss in chemisorption capacity. However, these statements may only apply to traditional iron sponge material, consisting of iron oxide impregnated wood chips, because some manufacturers of commercial media claim that their iron-based media can be regenerated several times before needing replacement (ADI International, 2009).

As an alternative to the batch regeneration noted above, it may be possible to regenerate iron sponge medium continuously by introducing a small amount of oxygen into the biogas stream. Removal rates as high as $2.5 \mathrm{~kg} \mathrm{H}_{2} \mathrm{~S} / \mathrm{kg} \mathrm{Fe}_{2} \mathrm{O}_{3}$ have been reported in continuousregeneration mode with a feed-gas stream containing only a few tenths of a percent of oxygen (Kohl and Neilsen, 1997).

Figure 2.5 is a schematic drawing of a single iron sponge-type $\mathrm{H}_{2} \mathrm{~S}$ chemisorption column for use with SULFATREAT®, a commercial medium (M-I SWACO, 2010). The chemisorption medium in the given vessel is supported on a mesh screen. The untreated biogas enters at the top of the vessel, moving down through the medium. Down-flow of biogas is recommended for maintaining bed moisture and so that the gas flows through the most fouled bed first (Zicari, 2003). The treated gas exits the vessel through an outlet 
pipe installed in the plenum. As shown in Figure 2.6, two vessels can be used in a lead/lag configuration so that change-outs of the medium can be carried out without interrupting the biogas flow. Furthermore, an overall improvement in the $\mathrm{H}_{2} \mathrm{~S}$ removal efficiency can be achieved by using the lead vessel as the main 'working unit' and the lag unit for polishing of the biogas quality, until the lead vessel requires change-out (M-I SWACO, 2010).

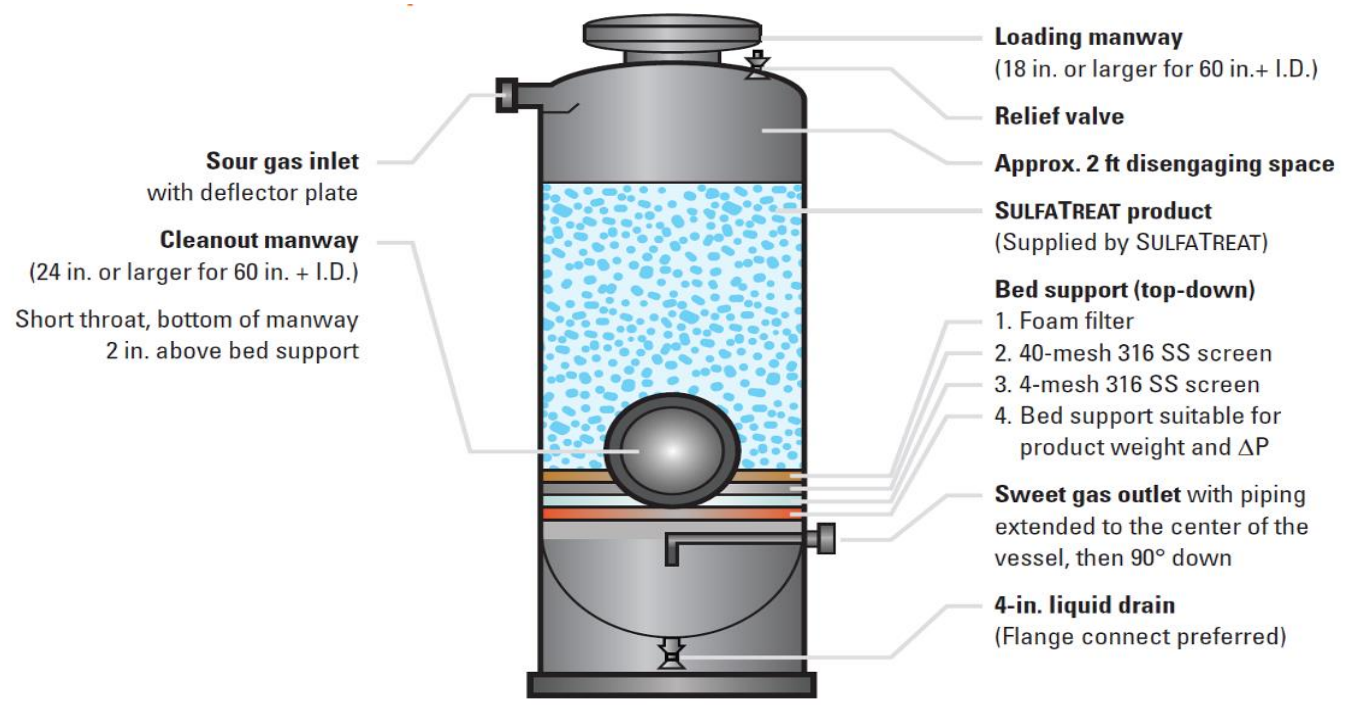

Figure 2.5. Schematic drawing showing standard SULFATREAT chemisorption column components (M-I SWACO, 2010).

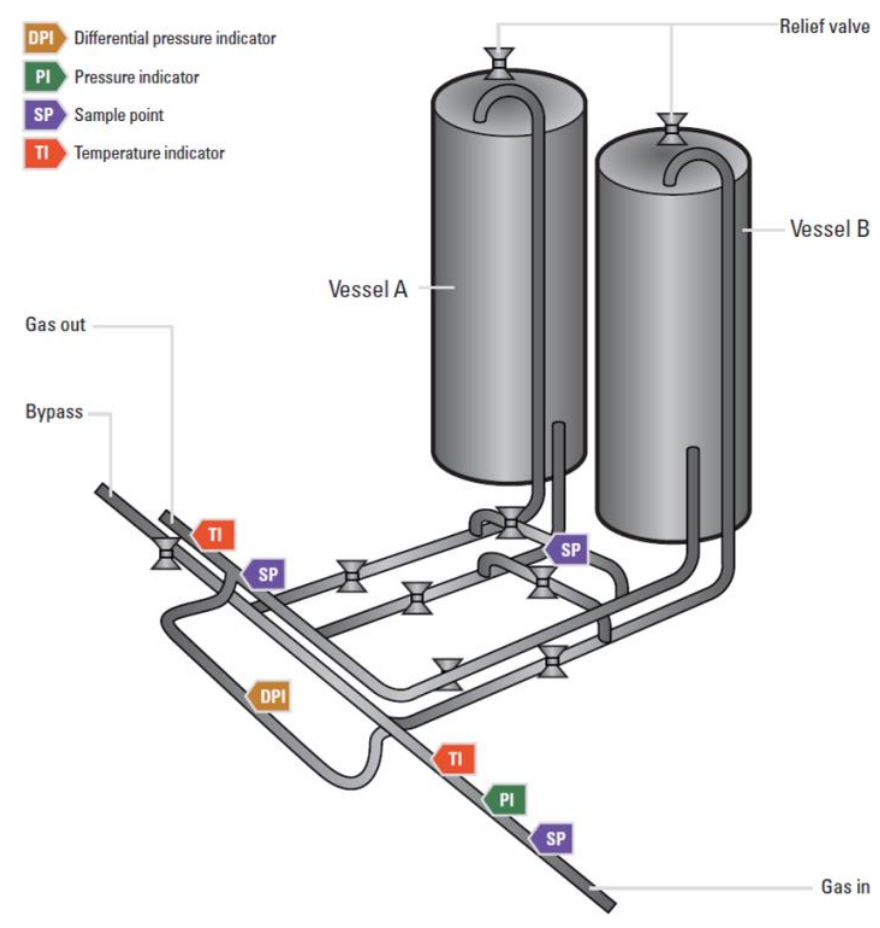

Figure 2.6 Schematic drawing of SULFATREAT vessels used in lead/lag configuration (M-I SWACO, 2010). 
The following general design recommendations for iron sponge systems have been adapted from Zicari (2003):

- Vessels should be fabricated from stainless-steel in box or tower geometries, to prevent corrosion and for ease of handling.

- Two vessels arranged in series (lead/lag) are suggested, to ensure sufficient bed depth and ease of handling.

- Down-flow of gas is recommended to maintain bed moisture and to direct the biogas through the most fouled bed first.

- A biogas residence time greater than 60 seconds is recommended, calculated using the empty bed volume and the total biogas flow rate (Revell, 2001).

- The temperature should be maintained between 18 and $46^{\circ} \mathrm{C}$ to enhance reaction kinetics without drying out the media (Kohl and Neilsen, 1997).

- A minimum bed height of $3 \mathrm{~m}$ has been recommended for optimum $\mathrm{H}_{2} \mathrm{~S}$ removal, while a $6 \mathrm{~m}$ bed is suggested if mercaptans are present (Anerousis and Whitman, 1985); however, a reasonably conservative bed height recommendation would be 1.2 to $3 \mathrm{~m}$ (Maddox and Burns, 1968).

- The optimum superficial gas velocity range is 0.6 to $3.0 \mathrm{~m} /$ minute (Anerousis and Whitman, 1985).

- The surface contaminant $S$ loading rate should be maintained below $10 \mathrm{~g} \mathrm{~S} / \mathrm{min} / \mathrm{m}^{2}$ bed (Maddox and Burns, 1968).

- The moisture content should be $40 \%( \pm 15 \%)$ to maintain reactivity. Saturating the inlet gas would therefore help to maintain this moisture content (Kohl and Neilsen, 1997), but raw biogas is usually already moisture saturated.

- The addition of sodium carbonate can maintain $\mathrm{pH}$ between 8 and 10, to increase $\mathrm{H}_{2} \mathrm{~S}$ removal, with the addition of $16 \mathrm{~kg}$ sodium carbonate per $\mathrm{m}^{3}$ of sponge initially ensuring an alkaline environment (Kohl and Neilsen, 1997).

- While not always practiced, $140 \mathrm{kPa}$ is the minimum pressure recommended for consistent operation (Anerousis and Whitman, 1985).

Some of these recommendations may not be entirely applicable for more recently developed commercial chemisorption media, and manufacturer's recommendations should be the default for such applications.

Some early adopters of biogas technology in the Australian pork industry have used commercial iron-oxide-based media to treat biogas. The chemisorption reactor vessels 
have typically been of a simple design to minimise capital cost. However, operational issues have been encountered, including managing the heat and hazardous off-gases $\left(\mathrm{SO}_{2}\right)$ generated by the exothermic regeneration reaction when media is removed from the chemisorption vessel to be regenerated in contact with air. Furthermore, the finite life of the chemisorption media and the relatively high $\mathrm{H}_{2} \mathrm{~S}$ concentration in raw piggery biogas, suggest that larger piggeries may incur an annual cost as high as $\$ 7000$ for the supply and replacement of purification media (Section 2.5, below). The ongoing costs associated with purchasing, regenerating and replacing commercial purification media, may be a significant burden on piggery operators. However, of interest is the fact that the active ingredients in commercial chemisorption media are present in naturally occurring materials, such as iron-rich soils, and other low-cost by-products such as granular steel furnace slag. For instance, iron-rich and zinc contaminated soils have been used to remove $\mathrm{H}_{2} \mathrm{~S}$ from coal derived natural gas (Ko, 2008; Ko, 2011; Ko and Hsueh, 2012). In the laboratory trials of Chapter 3 below, some of these alternative materials have been evaluated for potential use as on-farm biogas treatment media.

\subsubsection{Adsorption onto activated carbon}

Hydrogen sulphide can be removed from biogas by adsorption onto a bed of activated carbon (Hagen et al., 2001). This method is commonly used to clean a wide range of pollutants from industrial exhaust air, such as volatile organic compounds (VOCs), and also to remove $\mathrm{H}_{2} \mathrm{~S}$ and odours from municipal sewerage systems (TAPC, 2013). The gas to be treated might be pre-filtered, dehumidified or cooled, all of which assist the adsorption process. The carbon typically takes the form of small granules or extruded pieces. Very high rates of adsorption can be achieved, such that the treated exhaust air is essentially free of VOCs and/or $\mathrm{H}_{2} \mathrm{~S}$. Whilst the mechanisms are not yet well understood (Siefers, 2010), it is generally accepted that contaminant removal occurs by both physical and chemical means. The most common way for utilising activated carbon adsorption is without regeneration of the carbon (Hagen et al., 2001). However, the replacement costs of activated carbon can be significant, so regenerable systems have been used where a duty bed of activated carbon is adsorbing contaminants while a standby bed is being regenerated by steam stripping (TAPC, 2013).

The bed of activated carbon can be regenerated continuously with oxygen sourced from atmospheric air, resulting in biological oxidation similar to the process described in Equation 2.3 above (Hagen et al., 2001). The activated carbon may also be doped or 
impregnated with various compounds such as potassium iodide $(\mathrm{KI})$ to increase the reaction rate by combining physical sorption and chemical reaction pathways (Wellinger and Lindberg, 2005; Siefers, 2010; Abatzoglou and Boivin, 2009). Activated carbon impregnated with potassium iodide $(\mathrm{KI})$ is used in pressure-swing adsorption (PSA) systems (Krich et al., 2005). In these systems, $\mathrm{H}_{2} \mathrm{~S}$ molecules are selectively adsorbed by applying pressure to four carbon sieves, typically used in tandem. The release of pressure allows the contaminants to be desorbed and released from the carbon sieve. This process typically adsorbs carbon dioxide $\left(\mathrm{CO}_{2}\right)$ and water vapour in addition to $\mathrm{H}_{2} \mathrm{~S}$ and is often preceded by biological oxidation to convert the $\mathrm{H}_{2} \mathrm{~S}$ to elemental sulphur and water.

Activated carbon treatment could potentially be used to 'polish' biogas quality after some primary treatment step. However, it is unlikely to be widely used as a single biogas treatment step at piggeries, because of the high cost of batch replacement and the complexity of regenerative options.

\subsubsection{Absorption with liquids}

Water scrubbing is a well-established and simple technology that removes both $\mathrm{H}_{2} \mathrm{~S}$ and $\mathrm{CO}_{2}$ from biogas, as both of these gases are more soluble in water than $\mathrm{CH}_{4}$ (Krich et al., 2005; Tippayawong and Thanompongchart, 2010). Absorption of $\mathrm{H}_{2} \mathrm{~S}$ in liquids can be either physical, where the trace component $\left(\mathrm{H}_{2} \mathrm{~S}\right)$ is physically dissolved in water or an organic solvent; or chemical, where the dissolved $\mathrm{H}_{2} \mathrm{~S}$ is involved in a chemical reaction with the solvent (Ryckebosch et al., 2011). Water scrubbing generally involves introducing the biogas to the base of a cylindrical tower containing packing material (Raschig rings, spiral rings, or Berl saddles) to give a large surface area for contact with the water, which enters the top of the tower in a counter-current flow arrangement. Higgs (2006) suggests a typical superficial gas velocity through the packed bed of 120 to $150 \mathrm{~m}$. minute ${ }^{-1}$ and a typical irrigation rate of $250 \mathrm{~L}$. minute ${ }^{-1}$. $\mathrm{m}^{-2}$ of tower cross-sectional area. Figure 2.7 is a schematic drawing of a proposed counter-current, packed-bed water scrubber (Skerman et al., 2012).

Chemicals can be added to the water to improve the absorption process, resulting in lower water and energy consumption by virtue of reduced pumping. Diluted sodium hydroxide $(\mathrm{NaOH})$ solution and iron chloride $\left(\mathrm{FeCl}_{2}\right)$ solution can be used as chemical absorption liquids (Schomaker et al., 2000). 


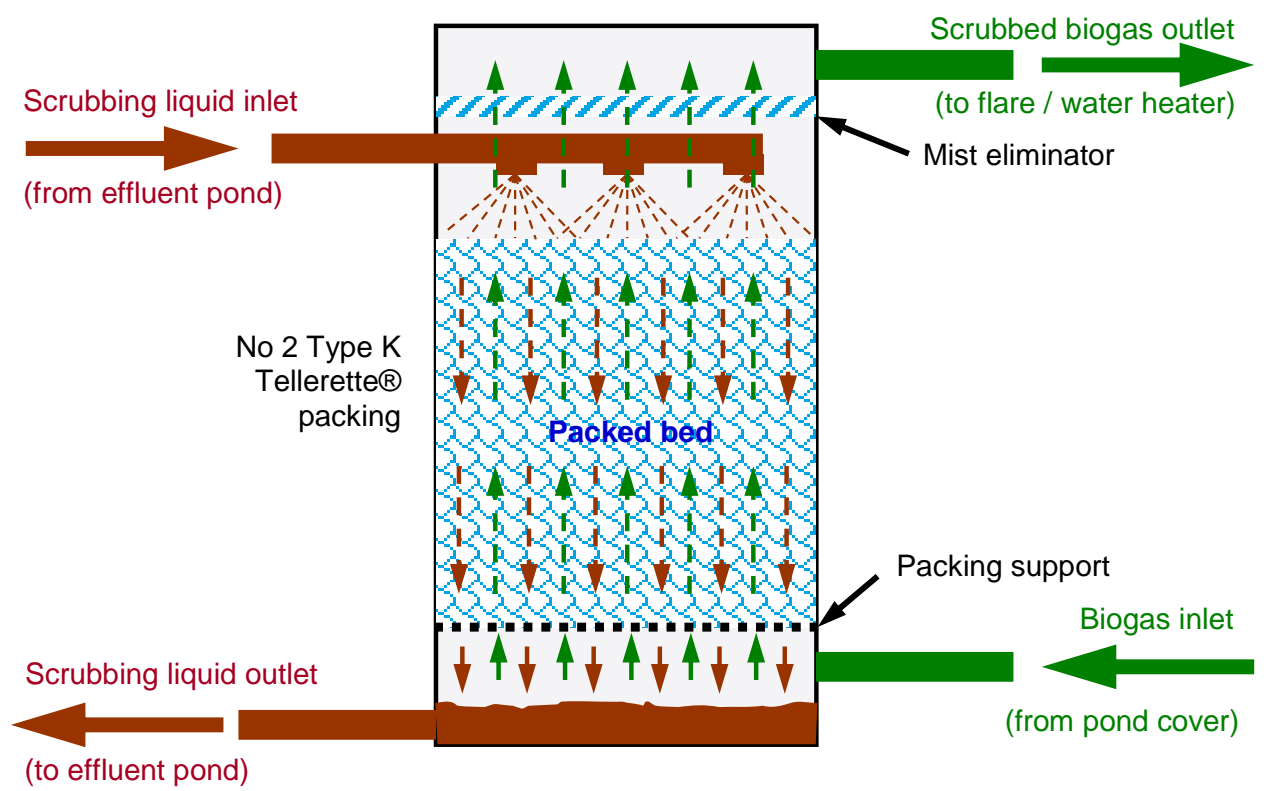

Figure 2.7 Schematic drawing of a counter-current flow, packed-bed water scrubber (Skerman, et al., 2012).

Selexol ${ }^{\mathrm{TM}}$, which is a solution of polyethylene glycol, may be used for the simultaneous removal of $\mathrm{CO}_{2}, \mathrm{H}_{2} \mathrm{~S}$ and water vapour from biogas (Krich et al., 2005). Selexol ${ }^{\mathrm{TM}}$ solvents are physical solvents that do not rely on a chemical reaction. Both $\mathrm{CO}_{2}$ and $\mathrm{H}_{2} \mathrm{~S}$ are more soluble (relative to $\mathrm{CH}_{4}$ ) in Selexol ${ }^{\mathrm{TM}}$ fluid than in water, resulting in lower solvent demand and reduced pumping energy. Figure 2.8 is a flow diagram for sulphur removal using Selexol ${ }^{\mathrm{TM}}$ (UOP, 2009).

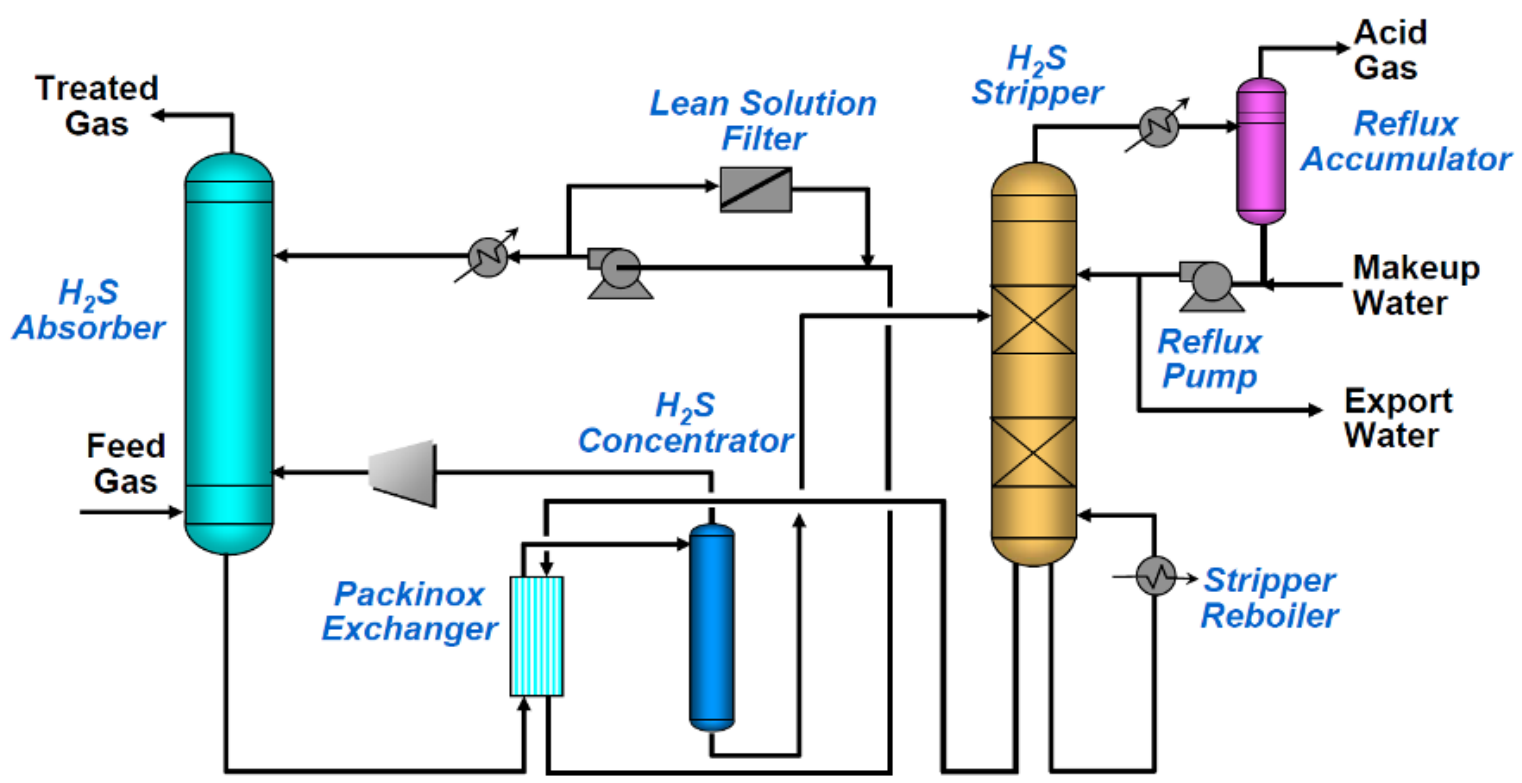

Figure 2.8 Selexol flow scheme for sulphur removal (UOP, 2009) 
The high pressure, requirement for steam for sulphur stripping in the Selexol ${ }^{\mathrm{TM}}$ process, and the complexity of this process, is likely to limit its applicability on-farm at piggeries.

In general, liquid-phase chemical absorption processes are not specific for $\mathrm{H}_{2} \mathrm{~S}$ removal, and also remove $\mathrm{CO}_{2}$ with $\mathrm{H}_{2} \mathrm{~S}$, adding seemingly unnecessary complexity for a piggery application. These technologies are unlikely to be adopted widely in Australian piggeries due to their relative complexity and ongoing chemical costs. The literature does not seem to advocate water scrubbing without added chemicals to treat biogas with high $\mathrm{H}_{2} \mathrm{~S}$ concentrations, so performance is unknown or assumed to be relatively poor compared to alternatives outlined above and below.

\subsubsection{Biological $\mathrm{H}_{2} \mathrm{~S}$ removal systems}

All biological $\mathrm{H}_{2} \mathrm{~S}$ removal systems rely on the biological oxidation of $\mathrm{H}_{2} \mathrm{~S}$ to elemental $\mathrm{S}$ and water, as described in Equation 2.3.

In single vessel systems, commonly referred to as bio-trickling filters, the contaminated gas typically passes in an upward flow direction through a packed, non-submerged column, where a liquid is continuously recirculated through the packing in a countercurrent, down-flow direction (Noyola et al., 2006). The pollutant is initially solubilised into the liquid film and is converted by microorganisms that grow on the packing medium. The liquid provides moisture, nutrients and $\mathrm{pH}$ control to the biofilm. Inert packing materials, such as plastic Raschig or Pall rings or saddles, are generally used (Noyola et al., 2006).

By adding 4 to $6 \%$ air to the biogas stream, the $\mathrm{H}_{2} \mathrm{~S}$ absorbed in the liquid film on the packing, can be oxidised to form elemental sulphur (Wellinger and Lindberg,2005). A temperature of approximately $35^{\circ} \mathrm{C}$ promotes the biological conversion of $\mathrm{H}_{2} \mathrm{~S}$ to elemental sulphur (Ryckebosch et al., 2011). The elemental sulphur is retained on the packing media and/or is sloughed off into the recirculated liquid which leaves the filter.

Biological filtration may be used to remove odour, ammonia and $\mathrm{H}_{2} \mathrm{~S}$ from biogas and is said to be generally more economical than chemical conditioning (Hagen et al., 2001). With the addition of air in biological filters, the $\mathrm{H}_{2} \mathrm{~S}$ content can be reduced from 2000 $3000 \mathrm{ppm}$ to $50-100 \mathrm{ppm}$. In other experiments the $\mathrm{H}_{2} \mathrm{~S}$ content was reduced from 800 ppm to 10 ppm (Hagen et al., 2001). 
A schematic drawing of a commercial 'Biogas Sweetener' (aerobic bio-trickling filter designed in a forced-draft, up-flow configuration) is provided in Figure 2.9 (BIOREM ${ }^{\circ}$, 2010).

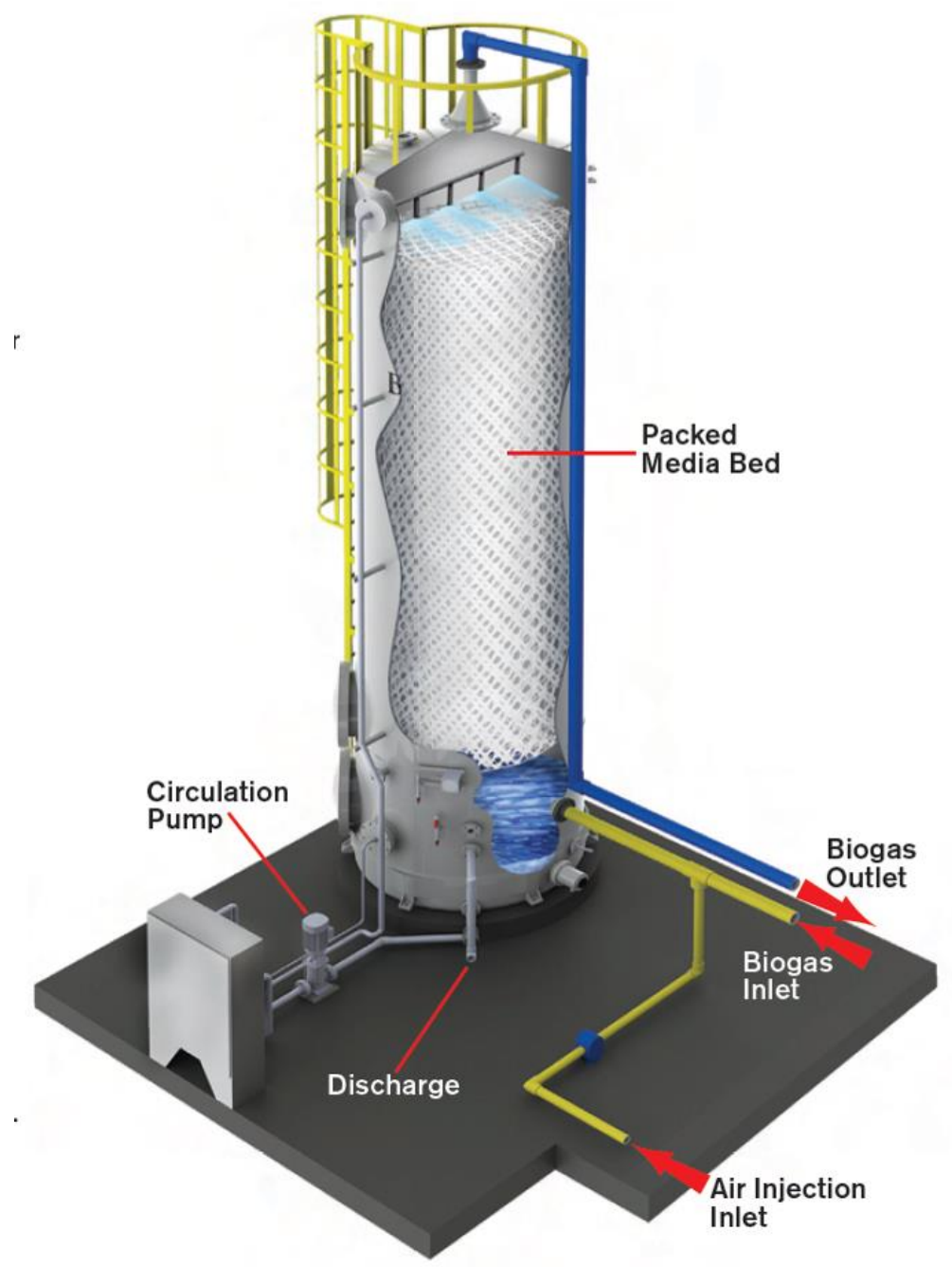

Figure 2.9 Schematic drawing of a 'Biogas Sweetener' aerobic bio-trickling filter (BIOREM®), 2010).

A comparison of several digester gas treatment methods (Kochaba, 2013) concluded that iron sponge or other chemisorption/adsorption media are economically attractive for smaller plants with gas flows up to approximately $100 \mathrm{cfm}(2832 \mathrm{~L} / \mathrm{min})$ and biogas $\mathrm{H}_{2} \mathrm{~S}$ concentrations less than $1000 \mathrm{ppmv}$; but that biological processes should be considered when $\mathrm{H}_{2} \mathrm{~S}$ concentrations are greater than $1000 \mathrm{ppmv}$ and/or become very competitive at $\mathrm{H}_{2} \mathrm{~S}$ concentrations greater than 2000 ppmv.

The above findings suggest that downstream biological oxidation (bio-trickling filter) systems may be an attractive option for treating Australian piggery biogas. In comparison to systems which involve biological oxidation of $\mathrm{H}_{2} \mathrm{~S}$ in the anaerobic digester or $\mathrm{CAL}$ headspace, bio-trickling filters have the advantage of injecting the oxygen/air into a 
smaller, more controlled space where more thorough mixing and contact between the biogas and biofilm could be achieved.

Bio-scrubbers employ a two-stage treatment process, which is more complex than singlevessel bio-trickling filter systems. With bio-scrubbers, the reactions that occur in a single column with bio-trickling filters, occur in two consecutive columns. Firstly, $\mathrm{H}_{2} \mathrm{~S}$ is absorbed from the biogas flowing up the scrubbing column, into a liquid flowing down the scrubbing column; and the liquid leaving the scrubbing column is then contacted with air in a separate bioreactor where the absorbed $\mathrm{H}_{2} \mathrm{~S}$ is biologically oxidised to elemental sulphur (Syed et al., 2006; Noyola et al., 2006). In this way, air/oxygen is isolated from the biogas being treated. A dilute alkaline solution is generally used as the washing liquid. A proprietary version of this process is known as the Shell-Paques process, or by its trade name of THIOPAQ®. Numerous systems of this type have been installed at facilities having biogas flows ranging from 50 to $2500 \mathrm{Nm} 3 / \mathrm{hr}$, and daily sulphur loads up to $600 \mathrm{~kg} \mathrm{~S} / \mathrm{d}$ (Paques, 2015). A schematic drawing of this process is provided in Figure 2.10 .

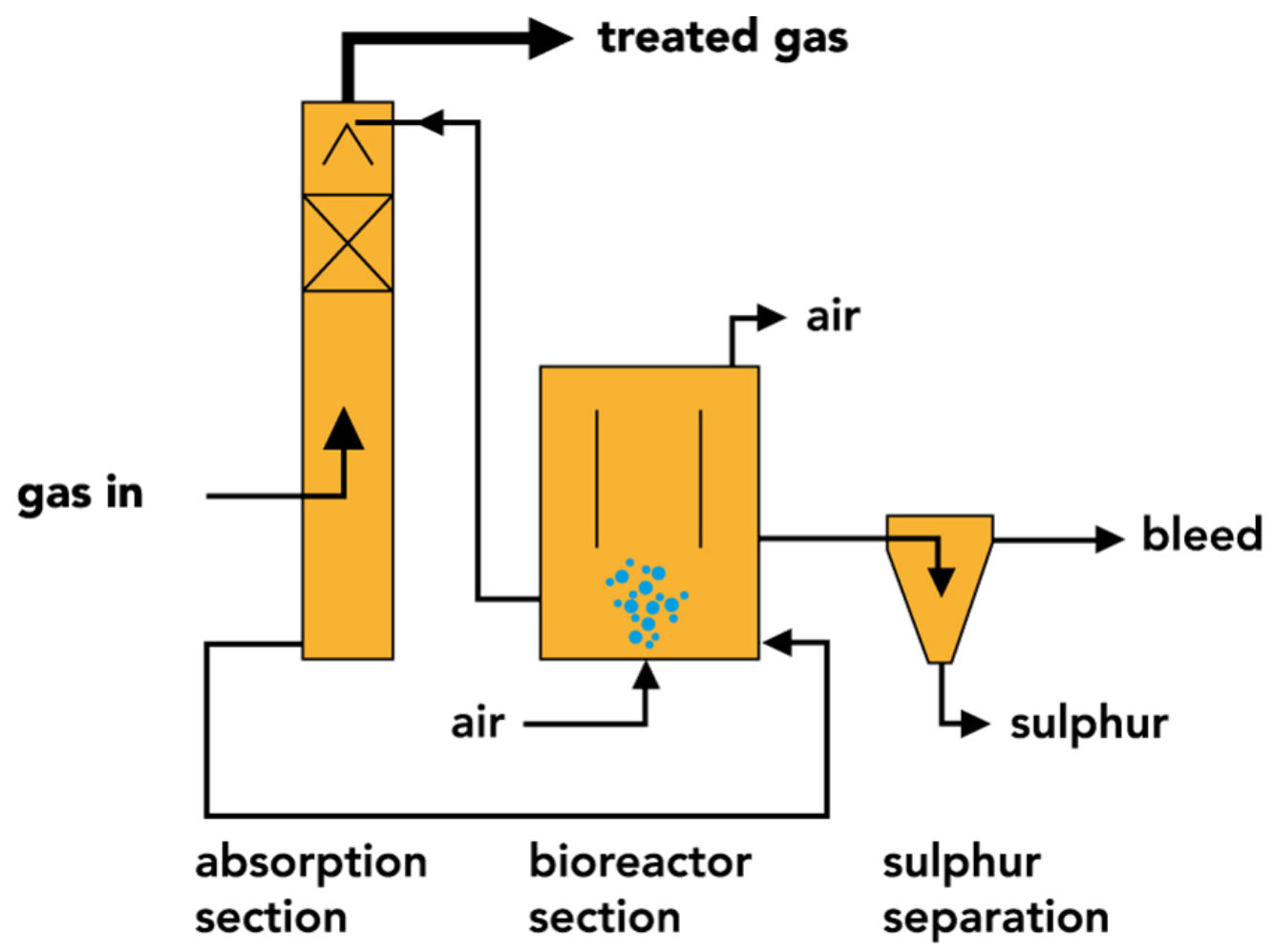

Figure 2.10 Schematic drawing showing the THIOPAQ® biogas scrubbing process (based on Paques, 2015),

In this process, the biogas entering the absorption column is washed by an alkaline scrubbing liquid that absorbs the hydrogen sulphide as described in Equation 2.11: 
$\mathrm{H}_{2} \mathrm{~S}$ gas $+\mathrm{OH}^{-} \rightarrow \mathrm{HS}^{-}$liquid $+\mathrm{H}_{2} \mathrm{O}$ Equation 2.11

The treated biogas exits the top of the absorber virtually free of hydrogen sulphide. The liquid containing dissolved sulphide flows to the bioreactor where it is oxidised by bacteria and converted to elemental sulphur to replenish the caustic, as described in Equation 2.12:

$\mathrm{HS}^{-}$liquid $+1 / 2 \mathrm{O}_{2} \rightarrow \mathrm{S}^{0}+\mathrm{OH}^{-}$ Equation 2.12

Bio-scrubbers generally require the use of chemicals to provide an alkaline washing medium. Consequently, it seems unlikely that the bio-scrubber approach would be widely adopted for treatment of piggery biogas in Australia.

Biofilters are three-phase bioreactors (gas, liquid, solid). The filter bed must have high porosity, high buffer capacity, high nutrient availability and high moisture retention capacity, to promote growth of the target microorganisms (Syed et al., 2006). The contaminated gas stream is continuously fed to the biofilter; however, the nutrient solution is added discontinuously. While biofilters are commonly used for odour control from contaminated air mixtures having relatively low contaminant concentrations, they would not generally be capable of treating the high $\mathrm{H}_{2} \mathrm{~S}$ concentrations and biogas flowrates commonly generated by on-farm digesters at commercial piggeries.

\subsubsection{Membrane separation}

Gas-liquid absorption using membranes has recently been developed for biogas upgrading (Wellinger and Lindberg, 2005). With this method, a micro-porous hydrophobic membrane separates a gas phase (the biogas that is being treated) and a liquid phase. The gaseous molecules diffuse through the membrane before being absorbed by the liquid flowing in a counter current direction. These absorption membranes operate at approximately atmospheric pressure (1 bar), resulting in relatively low construction costs.

Membrane separation technologies are considered complex and expensive in terms of operation and maintenance (Ryckebosch et al., 2011). Consequently, it seems unlikely that this biogas treatment technology will be widely adopted in the Australian pig industry in the foreseeable future. 


\subsection{Overall comparison of biogas treatment options}

Based on the criteria for selecting a $\mathrm{H}_{2} \mathrm{~S}$ removal method in Section 1.2, the options that appear to be most promising are outlined in Table 2.3, along with advantages, disadvantages and some unresolved issues. It is recommended that subsequent research focusses on trialling and developing a selection of these technologies.

Table 2.3 Summary of promising technologies for removing $\mathrm{H}_{2} \mathrm{~S}$ from biogas at Australian piggeries (adapted from Allan (2012), Ryckebosch et al. (2011) and Australian Pork Limited (2016)).

\begin{tabular}{|c|c|c|c|c|}
\hline Technology & Description & Advantages & Disadvantages & Unresolved issues \\
\hline $\begin{array}{l}\text { Biological } \\
\text { oxidation of } \mathrm{H}_{2} \mathrm{~S} \\
\text { in the digester. }\end{array}$ & $\begin{array}{l}\text { Air is injected into the } \\
\text { gas headspace above } \\
\text { the feedstock in the } \\
\text { digester. The target is } 2- \\
6 \% \text { air in the biogas. } \\
\text { Sulphur oxidising } \\
\text { bacteria consume air } \\
\text { derived oxygen to } \\
\text { convert } \mathrm{H}_{2} \mathrm{~S} \text { to elemental } \\
\text { sulphur }(\mathrm{S}) \text { and water. }\end{array}$ & $\begin{array}{l}\text { - Simple. } \\
\text { - No chemicals. } \\
\text { - Low operation and } \\
\text { maintenance cost. } \\
\text { - Can substantially } \\
\text { reduce } \mathrm{H}_{2} \mathrm{~S} \\
\text { concentrations. }\end{array}$ & $\begin{array}{l}\text { - Potential for } \\
\text { explosive gas } \\
\text { mixture. } \\
\text { - Performance may } \\
\text { be inconsistent. } \\
\text { - Partial } \mathrm{H}_{2} \mathrm{~S} \text { removal. } \\
\text { - } \mathrm{N}_{2} \text { and } \mathrm{O}_{2} \text { dilute } \\
\text { biogas. }\end{array}$ & $\begin{array}{l}\text { - Uniform injection of } \\
\text { air under large pond } \\
\text { cover. } \\
\text { - S accumulation in } \\
\text { CALs and potential } \\
\text { conversion back to } \\
\mathrm{H}_{2} \mathrm{~S} \text {. }\end{array}$ \\
\hline $\begin{array}{l}\text { Biological } \\
\text { oxidation in a } \\
\text { single } \\
\text { downstream } \\
\text { vessel (bio- } \\
\text { trickling filter) } \\
\text { using inorganic } \\
\text { packing media }\end{array}$ & $\begin{array}{l}\text { A small quantity of air } \\
\left(\mathrm{O}_{2}\right) \text { is injected into the } \\
\text { biogas stream which } \\
\text { passes through a tower } \\
\text { filled with inorganic } \\
\text { packing, where } \\
\text { microorganisms } \\
\text { biologically oxidise } \mathrm{H}_{2} \mathrm{~S} \\
\text { to elemental S. Liquid is } \\
\text { continuously sprayed } \\
\text { over the packing to } \\
\text { provide moisture and } \\
\text { nutrients to sustain the } \\
\text { microorganisms growing } \\
\text { on the biofilm formed on } \\
\text { the packing. }\end{array}$ & $\begin{array}{l}\text { - More precise control } \\
\text { of air injection / } \\
\text { mixing compared to } \\
\text { biological oxidation } \\
\text { in digesters / CALs. } \\
\text { - Simple } \\
\text { configuration, single } \\
\text { process reactor. } \\
\text { - Handles high } \mathrm{H}_{2} \mathrm{~S} \\
\text { concentrations. } \\
\text { - Diverse biogas } \\
\text { applications. }\end{array}$ & $\begin{array}{l}\text { - Water, "nutrient" } \\
\text { consumption. } \\
\text { - Down-time for } \\
\text { annual media } \\
\text { cleaning. } \\
\text { - } \mathrm{N}_{2} \text { and } \mathrm{O}_{2} \text { dilute } \\
\text { biogas. } \\
\text { - Potential for } \\
\text { explosive gas } \\
\text { mixture. } \\
\text { - Performance may } \\
\text { be inconsistent. }\end{array}$ & $\begin{array}{l}\text { - Use of recycled CAL } \\
\text { effluent as a } \\
\text { possible liquid } \\
\text { nutrient source. } \\
\text { - Packing cleaning } \\
\text { intervals. }\end{array}$ \\
\hline $\begin{array}{l}\text { Chemisorption } \\
\text { using solid iron } \\
\text { oxide or iron } \\
\text { hydroxide } \\
\text { based media. }\end{array}$ & $\begin{array}{l}\text { Biogas is passed } \\
\text { through a bed of iron } \\
\text { oxide or hydroxide based } \\
\text { media (e.g. pellets or } \\
\text { impregnated woodchips). } \\
\mathrm{H}_{2} \mathrm{~S} \text { reacts to form iron } \\
\text { sulphide. Some media } \\
\text { can be partially } \\
\text { regenerated by exposure } \\
\text { to air }\left(\mathrm{O}_{2}\right) \text {, but must } \\
\text { eventually be replaced. }\end{array}$ & $\begin{array}{l}\text { - } \text { Mature technology. } \\
\text { - Simple } \\
\text { configuration. } \\
\text { - Handles high } \mathrm{H}_{2} \mathrm{~S} \\
\text { concentration. } \\
\text { - Produces low } \mathrm{H}_{2} \mathrm{~S} \\
\text { concentration. } \\
\text { - Some media can be } \\
\text { partially } \\
\text { regenerated. } \\
\text { - Track record, } \\
\text { because actually } \\
\text { used at some } \\
\text { piggeries. }\end{array}$ & $\begin{array}{l}\text { - Regeneration costs. } \\
\text { - Frequency and cost } \\
\text { of media } \\
\text { regeneration or } \\
\text { replacement for high } \\
\mathrm{H}_{2} \mathrm{~S} \text { biogas. } \\
\text { - Disposal of used } \\
\text { media. } \\
\text { - Heat and hazardous } \\
\text { off-gas }\left(\mathrm{SO}_{2}\right) \\
\text { generated by } \\
\text { exothermic reaction } \\
\text { during replacement } \\
\text { of highly reactive } \\
\text { commercial media. }\end{array}$ & $\begin{array}{l}\text { - Feasibility of using } \\
\text { low cost industrial } \\
\text { by-products or } \\
\text { natural iron-rich } \\
\text { products rather than } \\
\text { commercial media. } \\
\text { - Managing emissions } \\
\text { of heat and } \\
\text { hazardous } \mathrm{SO}_{2} \text { off- } \\
\text { gas during medium } \\
\text { replacement. }\end{array}$ \\
\hline
\end{tabular}




\begin{tabular}{|c|c|c|c|c|}
\hline Technology & Description & Advantages & Disadvantages & Unresolved issues \\
\hline $\begin{array}{l}\text { Adsorption on } \\
\text { solid activated } \\
\text { carbon which } \\
\text { may be } \\
\text { impregnated } \\
\text { with potassium } \\
\text { iodide (KI). }\end{array}$ & $\begin{array}{l}\text { Biogas is passed } \\
\text { through an activated } \\
\text { carbon filter, often } \\
\text { impregnated with } \\
\text { potassium iodine }(\mathrm{KI}) \text { or } \\
\text { sulphuric acid }\left(\mathrm{H}_{2} \mathrm{SO}_{4}\right) \text {. } \\
\mathrm{H}_{2} \mathrm{~S} \text { is converted to } \\
\text { elemental sulphur }(\mathrm{S}) \text {. } \\
\text { May be used in } \\
\text { combination with and } \\
\text { subsequent to, biological } \\
\text { oxidation. }\end{array}$ & $\begin{array}{l}\text { - Mature technology. } \\
\text { - Simple } \\
\text { configuration. } \\
\text { - Removes other } \\
\text { trace compounds. }\end{array}$ & $\begin{array}{l}\text { - Frequency and cost } \\
\text { of media } \\
\text { replacement for high } \\
\mathrm{H}_{2} \mathrm{~S} \text { biogas. } \\
\text { - On-site regeneration } \\
\text { may be costly or } \\
\text { complex. }\end{array}$ & $\begin{array}{l}\text { - Use in combination } \\
\text { with, or following } \\
\text { biological oxidation. } \\
\text { - Pressure and } \\
\text { temperature } \\
\text { requirements for } \\
\text { efficient operation. }\end{array}$ \\
\hline $\begin{array}{l}\text { Water scrubber } \\
\text { (Physical } \\
\text { absorption on } \\
\text { water). }\end{array}$ & $\begin{array}{l}\text { The biogas passes } \\
\text { through a counter- } \\
\text { current scrubbing tower } \\
\text { where the } \mathrm{H}_{2} \mathrm{~S} \text { is } \\
\text { physically absorbed into } \\
\text { the liquid phase. }\end{array}$ & $\begin{array}{l}\text { - Removes both } \mathrm{H}_{2} \mathrm{~S} \\
\text { and } \mathrm{CO}_{2} \text {. } \\
\text { - No chemical } \\
\text { additives. }\end{array}$ & $\begin{array}{l}\text { - High water } \\
\text { consumption. } \\
\text { - High parasitic } \\
\text { energy } \\
\text { consumption. } \\
\text { - Clogging of } \\
\text { absorption column. } \\
\text { - Complex } \\
\text { regenerative } \\
\text { processes. }\end{array}$ & $\begin{array}{l}\text { - Suitability of } \\
\text { secondary pond } \\
\text { effluent as } \\
\text { scrubbing liquid. } \\
\text { - Operating pressure. } \\
\text { - Possibility and } \\
\text { impact of } \\
\text { discharging waste } \\
\text { water produced by } \\
\text { the scrubber into an } \\
\text { effluent pond. }\end{array}$ \\
\hline $\begin{array}{l}\text { Chemical } \\
\text { scrubber } \\
\text { (Chemical } \\
\text { absorption on } \\
\text { liquid chemical } \\
\text { solution) }\end{array}$ & $\begin{array}{l}\text { To improve the } \\
\text { absorption process, } \\
\text { chemicals such as } \\
\mathrm{NaOH}, \mathrm{FeCl}_{2} \text { or } \mathrm{Fe}(\mathrm{OH})_{3} \\
\text { are added to the } \\
\text { scrubbing water } \\
\text { circulated through the } \\
\text { counter-current } \\
\text { scrubbing tower. }\end{array}$ & $\begin{array}{l}\text { - Removes } \mathrm{H}_{2} \mathrm{~S} \text { and } \\
\mathrm{CO}_{2} \text {. } \\
\text { - Lower scrubbing } \\
\text { liquid flow rate and } \\
\text { energy than water } \\
\text { scrubber. }\end{array}$ & $\begin{array}{l}\text { - Requires caustic } \\
\text { chemical additive. } \\
\text { - Not regenerative } \\
\text { - Waste disposal. }\end{array}$ & $\begin{array}{l}\text { - Recirculation of } \\
\text { chemical solution. } \\
\text { - The potential to use } \\
\text { CAL effluent as a } \\
\text { slightly alkaline } \\
\text { scrubbing solution. }\end{array}$ \\
\hline
\end{tabular}

\subsection{Practical options for $\mathrm{H}_{2} \mathrm{~S}$ removal from piggery biogas}

The calculations summarised in Table 2.4 illustrate the cost of using a commercial chemisorption medium to remove $\mathrm{H}_{2} \mathrm{~S}$ from the biogas generated from a typical 1000 sow farrow to finish piggery in Australia. The resulting $\mathrm{H}_{2} \mathrm{~S}$ removal cost of $\$ A U 7.94 / \mathrm{kg} \mathrm{H}_{2} \mathrm{~S}$ removed is towards the lower end of the range reported for German biogas plants employing active carbon-based $\mathrm{H}_{2} \mathrm{~S}$ removal systems (€4.46-€12.82 EUR/kg H $\mathrm{H}_{2} \mathrm{~S}$ removed $=\$ A U 7.08-\$ A U 20.34 / \mathrm{kg} \mathrm{H} 2 \mathrm{~S}$ removed, Reinhold, 2005). However, assuming a typical piggery biogas $\mathrm{H}_{2} \mathrm{~S}$ concentration of 2,000 ppm', biogas treatment costs in Australia could represent up to $5 \%$ of the electricity cost savings from biogas use.

\footnotetext{
1 The following analysis assumed a raw biogas primary energy content of $6.0 \mathrm{kWh} / \mathrm{m}^{3}$ biogas and an internal combustion generator electrical efficiency of $30 \%$, giving chemisorption system supply and operating costs of $2.2 \mathrm{cents} / \mathrm{m}^{3}$ biogas treated or 1.2 cents per $\mathrm{kWh}$ biogas derived electricity. The assumed average electricity supply cost was 25 cents/kWh.
} 
This could significantly impact on the economic feasibility of on-farm biogas use, highlighting the need for more cost-effective options.

Table 2.4. Calculations used to estimate typical hydrogen sulphide removal costs for a 1000 sow farrow-to-finish $(10,000$ standard pig unit) piggery.

\begin{tabular}{|c|c|c|}
\hline Parameter & Units & Value \\
\hline Piggery operating capacity & SPU & 10,000 \\
\hline Volatile solids (VS) production & $\mathrm{kg} \mathrm{VS/SPU/y}$ & 90 \\
\hline Piggery volatile solids (VS) production & $\mathrm{kg} \mathrm{VS/d}$ & 2,464 \\
\hline Volatile solids removal in solids separator & $\%$ & $25 \%$ \\
\hline Biogas production rate & $\mathrm{m}^{3} / \mathrm{kg}$ VS added & 0.43 \\
\hline Daily biogas production & $\mathrm{m}^{3}$ biogas $/ \mathrm{d}$ & 795 \\
\hline Biogas methane \% & $\%$ & $65 \%$ \\
\hline Methane production rate & $\mathrm{m}^{3} / \mathrm{kg} \mathrm{VS}$ added & 0.28 \\
\hline Daily methane collection & $\mathrm{m}^{3} \mathrm{CH}_{4} / \mathrm{d}$ & 517 \\
\hline Annual methane collection & $\mathrm{m}^{3} \mathrm{CH}_{4} / \mathrm{yr}$ & 188,663 \\
\hline Methane energy value & $\mathrm{MJ} / \mathrm{m}^{3} \mathrm{CH}_{4}$ & 33.35 \\
\hline Energy value & $\mathrm{MJ} / \mathrm{d}$ & 17,226 \\
\hline Total primary energy potential & $\mathrm{kWh} / \mathrm{d}$ & 4,785 \\
\hline \multicolumn{3}{|l|}{ Electricity generation potential } \\
\hline Generator electrical efficiency & $\%$ & $30 \%$ \\
\hline Daily electricity generation & $\mathrm{kWh} / \mathrm{d}$ & 1,436 \\
\hline Annual electricity generation & $\mathrm{kWh} / \mathrm{y}$ & 524,325 \\
\hline Average electricity cost & $\$ / k W h$ & $\$ 0.25$ \\
\hline Value of generated electricity & $\$ / y$ & $\$ 131,081$ \\
\hline \multicolumn{3}{|l|}{ Hydrogen sulphide chemisorption } \\
\hline Biogas $\mathrm{H}_{2} \mathrm{~S}$ concentration & $\mathrm{ppm}$ & 2000 \\
\hline $\mathrm{H}_{2} \mathrm{~S}$ volume & $\mathrm{m}^{3} \mathrm{H}_{2} \mathrm{~S} / \mathrm{d}$ & 1.589 \\
\hline Mass S & $\mathrm{g} \mathrm{S} / \mathrm{d}$ & 2,118 \\
\hline Chemisorption medium & & $\operatorname{cg} 5$ \\
\hline S chemisorption at breakthrough & $\mathrm{g}$ S/g medium & 0.200 \\
\hline Medium use mass & $\mathrm{kg}$ medium/d & 10.592 \\
\hline Medium use mass & t medium/y & 3.869 \\
\hline Medium cost & $\$ / t$ & $\$ 1,210$ \\
\hline Annual medium cost & $\$ / y$ & $\$ 4,681$ \\
\hline$\%$ electricity savings & $\%$ & $3.6 \%$ \\
\hline \multicolumn{3}{|l|}{$\mathrm{H}_{2} \mathrm{~S}$ chemisorption column operation } \\
\hline Column capacity & $\mathrm{L}$ & 300 \\
\hline Column ID & $\mathrm{m}$ & 0.600 \\
\hline Medium depth & $\mathrm{m}$ & 1.061 \\
\hline Medium density & $\mathrm{kg} / \mathrm{m}^{3}$ & 699 \\
\hline Medium mass & $\mathrm{kg}$ & 210 \\
\hline S chemisorption at breakthrough & g S & 41,940 \\
\hline Medium replacement interval & d & 19.80 \\
\hline Labour & person.hr/replacement & 4 \\
\hline Labour cost & $\$ /$ person.hr & $\$ 25$ \\
\hline Annual labour cost & $\$ / y$ & $\$ 1,845$ \\
\hline Total medium replacement cost & $\$ / y$ & $\$ 6,526$ \\
\hline$\%$ electricity savings & $\%$ & $4.98 \%$ \\
\hline
\end{tabular}


Technologies for biological removal of $\mathrm{H}_{2} \mathrm{~S}$ are now increasingly being considered, because of their high efficiency and low operating costs compared with physio-chemical biogas cleaning (Abatzoglou and Boivin, 2009; Weiland, 2010). Primary biological treatment could reduce $\mathrm{H}_{2} \mathrm{~S}$ concentrations from 2000-3000 ppm down to 50-100 ppm (Hagen et al., 2001) placing a much lower load on any subsequent polishing step. Secondary treatment using a relatively simple, reliable method such as chemisorption by solid iron-oxide media, could then remove any residual $\mathrm{H}_{2} \mathrm{~S}$ to address any concerns regarding possible inconsistent performance of an upstream biological treatment system. Compared with using chemisorption as the sole treatment process, this stepped approach with biological treatment followed by chemisorption could substantially reduce the solid medium supply, replacement and regeneration costs. Also biogas quality can be made consistently suitable for common on-farm uses, such as CHP systems utilising reciprocating biogas engines. Further, chemisorption column capacities could be limited to manageable and cost effective dimensions and the safety of change out of chemisorption medium could be better managed, especially noting that biogas combustion devices are often located in close proximity to pig sheds. With biological oxidation, a practical, costeffective and safe means of air injection is required, and with an external packed tower system, a nutrient liquid is also required to support the growth of micro-organisms and keep $\mathrm{pH}$ balanced for adequate $\mathrm{H}_{2} \mathrm{~S}$ mass transfer. Because synthetic nutrient solutions are unlikely to be cost feasible on-farm (especially at smaller piggeries) it is of particular interest to determine whether treated effluent from a covered anaerobic lagoon (CAL) could be used as the necessary nutrient source. To date, there have been no reports of this concept being tested on-farm at a piggery.

For a subsequent chemisorption step, it was of particular interest to note that the active compounds enabling chemisorption of $\mathrm{H}_{2} \mathrm{~S}$ seem to be relatively common in natural materials such as soils and even in some agricultural and industrial waste and byproducts. Consequently, a range of other low-cost materials - such as biodegradable wastes - may also be useful for $\mathrm{H}_{2} \mathrm{~S}$ removal (Cherosky and $\mathrm{Li}$, 2013). For example, ironrich and zinc contaminated soils have effectively removed $\mathrm{H}_{2} \mathrm{~S}$ from coal derived natural gas (Ko, 2008; Ko, 2011; Ko and Hsueh, 2012). Trials have also been previously carried out on a variety of other media, including soil, peat, compost, sludge, pig manure/sawdust, wood bark, activated carbon, rock wool, lava rock, poly-propylene rings, calcium-alginate beads, fuyolite and ceramics (referenced in Zicari, 2003). While these references suggest that $\mathrm{H}_{2} \mathrm{~S}$ removal can, at least in principle, be supported by many natural and waste 
materials, there is a lack of clarity around the performance of some alternative media for treating biogas having high $\mathrm{H}_{2} \mathrm{~S}$ concentrations, as is the case for piggery biogas. There is also some uncertainty surrounding the need for oxygen addition and optimal operating pressures for media such as biochar and activated carbon which may offer both physical and chemical reactive removal of $\mathrm{H}_{2} \mathrm{~S}$. These factors could potentially affect the practical and economic viability of on-farm use of these media. The possibility and practicality of regenerating the various media on-farm is also unknown. Comprehensive laboratory trials are needed to investigate these aspects.

Previous laboratory-scale biogas $\mathrm{H}_{2} \mathrm{~S}$ removal trials have typically used cylinders of specially prepared gas having a range of $\mathrm{H}_{2} \mathrm{~S}$ concentrations, often in $\mathrm{N}_{2}$, to address some of the safety concerns associated with using $\mathrm{CH}_{4}$-rich gases such as biogas in a laboratory (White, 2010 and Wang, 2008). The test gases have commonly been hydrated by bubbling through a water bath prior to treatment by various media such as biochar (White, 2010) and the commercial iron oxide based media, cg4 (Wang, 2008) and Sulfatreat 410-HP® (Truong and Abatzoglou, 2005), contained in small-scale (1 to $6 \mathrm{~cm}$ dia) glass, PVC or stainless steel reactor columns. Gas flows through the columns have typically been regulated using mass flow controllers, and in some cases, the flowrates, flow velocities and gas composition have been varied throughout the experiments. The concentrations of $\mathrm{H}_{2} \mathrm{~S}$ in the gases entering and exiting the test columns are usually measured using various methods such as gas chromatography (Wang, 2008), commercial $\mathrm{H}_{2} \mathrm{~S}$ detectors with electro-chemical cells (Gas Badge Pro, White, 2010) or precision detector tube colorimetric method (Truong and Abatzoglou, 2005). From such tests, breakthrough curves are typically obtained to determine the sulphur sorption capacity corresponding to various constant inlet $\mathrm{H}_{2} \mathrm{~S}$ concentrations and particular $\mathrm{H}_{2} \mathrm{~S}$ concentrations in the treated gas outflow. While such laboratory trials can provide valuable indications of the expected performance of a range of media, full-scale on-farm trials are considered important to confirm media performance under real-life operating conditions and to address a range of practical operating issues. For example, in their raw form, the porosity, physical homogeneity and chemical properties of alternative media are unlikely to match those of specially engineered commercial media. Consequently, the pressure drop through alternative media may be higher, unless a relatively simple pre-treatment method can be applied (e.g. mixing with a low-cost bulking agent). Further, inconsistent physical properties or scale issues may result in short-circuiting, tunnelling and/or the development of preferential flow paths through solid chemisorption media at full-scale, which may also 
affect chemisorption performance. Lastly, the $\mathrm{H}_{2} \mathrm{~S}$ loading from biogas produced in onfarm CALs and digesters is likely to vary given the dynamic nature of the pond/digester chemistry and microbiology, while biogas flowrates through the treatment system will fluctuate considerably in response to on-farm electrical and heating loads, ambient climatic conditions with unheated covered lagoons and other operational conditions. These aspects necessitate on-farm testing of chemisorption using alternative low-cost media.

\subsection{Conclusion}

In summary, the literature review has highlighted a range of issues that need to be addressed with regard to on-farm biogas treatment. While biological oxidation of $\mathrm{H}_{2} \mathrm{~S}$ by injection of air into the digester or CAL appears to be a simple and attractive option for removal of bulk $\mathrm{H}_{2} \mathrm{~S}$ from piggery biogas, unresolved issues include the feasibility of safely achieving adequate mixing of injected air under the pond cover and the potential for the $S$ which accumulates in the liquid effluent to be converted back to $\mathrm{H}_{2} \mathrm{~S}$. Downstream biological oxidation in a single packed vessel addresses some of these issues, but it is of interest to see whether recycled CAL effluent could be used as a more cost-effective liquid nutrient source. With regard to the use of solid iron-based chemisorption media to remove $\mathrm{H}_{2} \mathrm{~S}$ from piggery biogas, the performance of low cost industrial by-products or natural iron-rich products should be tested, initially in laboratory trials and subsequently in on-farm trials. The potential for regenerating media on-farm and for managing the emission of heat and hazardous $\mathrm{SO}_{2}$ off-gas during medium replacement, also require further consideration. The two research objectives outlined in Section 1.2 of Chapter 1 were developed to address these identified gaps in current knowledge. 


\section{Low-cost filter media for removal of hydrogen sulphide from piggery biogas}

This Chapter was accepted, in part, in the journal Process Safety and Environmental Protection as: Skerman, A.G., Heubeck, S., Batstone, D.J., Tait, S. (2016a). Low-cost filter media for removal of hydrogen sulphide from piggery biogas.

\subsection{Introduction}

This chapter presents carefully designed laboratory experiments that tested and compared $\mathrm{H}_{2} \mathrm{~S}$ removal by a commercial iron-based medium ( $\left.\mathrm{cg}_{5}\right)$ with that of low-cost alternative iron-based solid media (granulated steel furnace slag and red soil) and granular activated carbon, biochar, compost and composted beef feedlot manure. The study also sought to determine whether one of the alternative media, namely iron-rich red soil, could be regenerated by exposure to air for reuse as a filter medium. These experiments were carried out to address Research Objective 1 in Section 1.2.

\subsection{Materials and methods}

Lab-scale experiments measured single-pass $\mathrm{H}_{2} \mathrm{~S}$ removal from a pre-humidified standard gas onto solid filter media contained in a cylindrical plastic column.

\subsubsection{Materials}

To simulate a typical piggery biogas, a cylinder containing 2000 ppm $\mathrm{H}_{2} \mathrm{~S}$ in high purity nitrogen was sourced from Encore Automation Pty Ltd (Balcatta WA) for use as the test gas. Nitrogen was used as the $\mathrm{H}_{2} \mathrm{~S}$ carrier in the test gas (instead of the main biogas components methane and carbon dioxide) for safety reasons, but was not expected to influence the test results (Wang, 2008). Deionized water was used to humidify the test gas mixture. Oxygen $\left(\mathrm{O}_{2}\right)$, sourced from BOC Ltd Toowoomba, was used to dilute the test gas prior to measurements of $\mathrm{H}_{2} \mathrm{~S}$ by an electro-chemical sensor. Since $\mathrm{H}_{2} \mathrm{~S}$ is toxic and potentially lethal, appropriate control strategies were in place to manage the associated health risks. 
The following iron and carbon-based media were tested in the experiments: $\mathrm{cg}_{5}$ iron oxide $\mathrm{H}_{2} \mathrm{~S}$ scavenger material (Shanxi Clean Company of Catalysis and Purification

Technologies Development), granular steel furnace slag (GSFS $<5 \mathrm{~mm}$, Cement Australia, Darra, Qld), granular steel furnace slag (GSFS M21-coarse, Wagners, Toowoomba, Qld), naturally-occurring red soil excavated from just below the soil surface (A horizon) at 203 Tor Street, Toowoomba QId (S $27^{\circ} 32^{\prime} 05^{\prime \prime}$, E $151^{\circ} 55^{\prime \prime} 46^{\prime \prime}$ ), naturally-occurring red soil excavated from a road cutting (B horizon) at Ravensbourne, Qld (S $27^{\circ} 22^{\prime} 18^{\prime \prime}, \mathrm{E} 152^{\circ} 10^{\prime}$ 05"), granular activated carbon (GAC, Calgon BPL 4x10), compost (Naturegrow, Amgrow Pty Ltd), composted beef feedlot manure (Kerwee feedlot, Jondaryan, Qld) and biochar (Green waste 550, Pacific Pyrolysis Pty Ltd, Somersby NSW). The red soil, compost, composted beef feedlot manure and biochar samples were prepared for testing by sieving through a $2 \mathrm{~mm}$ sieve to remove coarse fragments. A further sample of the Ravensbourne red soil) was also tested as a finer textured product by sieving through a $500 \mu \mathrm{m}$ sieve. Sugar cane mulch (SCM, Rocky Point Mulching, Woongoolba Qld) was added to the Tor Street red soil, as a bulking agent, to evaluate its effectiveness for reducing the pressure drop through these soils. This SCM was mechanically ground using a Retsch SM 100 Cutting Mill and then mixed with the red soil in proportions $20 \% \mathrm{v} / \mathrm{v} \mathrm{SCM}$ or $40 \% \mathrm{v} / \mathrm{v} \mathrm{SCM}$.

The analytical methods described in Section 3.2.6 (below) were used to determine the Total solids (TS) and Volatile solids (VS) content, bulk density, particle density and porosity values (including interstitial voids), and Aluminium (Al), Iron (Fe), Phosphorus (P) and Sulphur (S) elemental concentrations, for each test medium.

\subsubsection{Apparatus}

Figure 3.1 provides a schematic of the experimental apparatus. The outlet pressures on the cylinders of test gas and $\mathrm{O}_{2}$ were set at approximately $200 \mathrm{kPa}$, and the gas flow rates were controlled by Alicat MCS-1SLPM-D/5M and MC-100SCCM-DX-0.25VCR/5M mass flow controllers (Alicat Scientific, Tucson AZ 85743 USA), respectively. To emulate raw piggery biogas which is usually saturated with moisture, the test gas was pre-humidified by bubbling through a $150 \mathrm{~mm}$ depth of deionised water and the resulting relative humidity of the gas was confirmed to be $>95 \%$ using a humidity sensor (HOBO® Pro v2 U23-002). A cylindrical test column was fabricated from PVC pressure pipe (nominal diameter DN $25 \mathrm{~mm}$, internal diameter $29.8 \mathrm{~mm}$, PN 12 - 1.2 MPa maximum working pressure) with Polythene end caps and a stainless steel mesh base-plate to support the solid test 
medium. A 3-way manual valve (MV1) was used to direct the test gas through either the test column or a bypass line. The gas exiting the column passed through a particulate filter (Swagelok SS-4F-2) to protect the downstream $\mathrm{H}_{2} \mathrm{~S}$ sensors. Oxygen was mixed with the test gas using the MFCs noted above at a volumetric proportion of 1:9, based on the sensor manufacturer's recommendations. After this, the gas mixture was directed by electrical solenoid valves (SMC VDW21-6G-2-01-G) to one of two $\mathrm{H}_{2} \mathrm{~S}$ sensors (Alphasense H2S-BE, Great Notley, CM77 7AA, UK) or to an external chimney. These Alphasense $\mathrm{H}_{2} \mathrm{~S}$ sensors are three electrode amperometric electrochemical cells. The working electrode oxidises the $\mathrm{H}_{2} \mathrm{~S}$ with the counter electrode balancing the generated current while the reference electrode anchors the working electrode at the correct potential to ensure that it stays in the transport limited current plateau of the current-voltage curve (Alphasense Application Note AAN 104 - How Electrochemical Gas Sensors Work, Issue 12, ND). The solenoid valves were activated by solid-state relays, switched by a HYTEK iUSBDA6-U120816 data acquisition module (HYTEK Automation Inc) that was controlled using LabVIEW Base Development System software (National Instruments Australia).

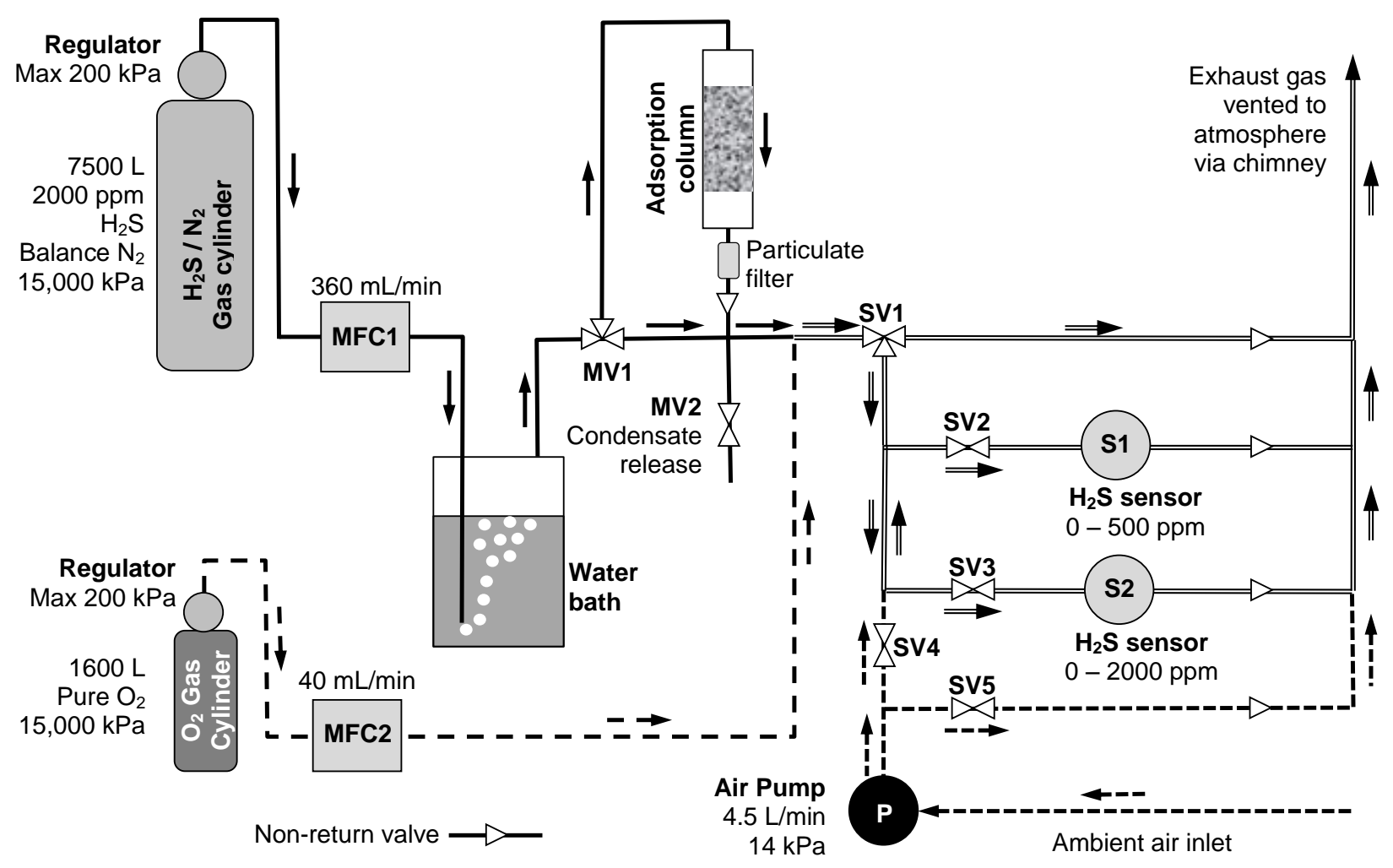

Figure 3.1 Schematic drawing of the apparatus used during the hydrogen sulphide sorption experiments. 
The measurement ranges of the sensors were 0-500 ppm $\mathrm{H}_{2} \mathrm{~S}$ (S1) and 0-2000 ppm $\mathrm{H}_{2} \mathrm{~S}$ (S2). The sensors were fitted with digital transmitter boards producing 4-20 mA outputs, which were converted to $0.48-2.40 \mathrm{~V}$ signals using $120 \Omega$ resistors installed in parallel with each sensor. To meet the manufacturer's requirement for minimum gas flow velocity across the sensor, the entire test gas flow was directed to only one of the two sensors, depending on the relevant measurement range. To prolong the operating life of the sensors, a domestic aquarium aeration pump (Sera air $275 \mathrm{R}$ plus air pump, $4.5 \mathrm{~L} / \mathrm{min}$, $\geq 14 \mathrm{kPa}$ ) was used to purge the sensors with ambient air between measurement events. The durations of sampling and purging times, the sensor data logging frequency and the voltage output at which flow was switched from sensor S1 to S2, were all nominated inputs in the LabVIEW user interface. All the components of the test apparatus were connected with perfluoroalkoxy (PFA) tubing and Swagelok ${ }^{\circledR} 1 / 4$ inch $(6.35 \mathrm{~mm})$ OD 316 stainless steel tube fittings.

\subsubsection{Batch $\mathrm{H}_{2} \mathrm{~S}$ removal studies}

The various chemisorption media (Section 3.2.1) were added directly to the test column. The $\mathrm{H}_{2} \mathrm{~S}$ chemisorption capacities of the SCM and red soil+SCM mixtures were not evaluated in the experiments described in this Thesis. As outlined in Table 3.2, the media masses, volumes, depths and test gas residence times varied due to bulk density differences between the different media (Table 3.1). However, column geometries were maintained within the recommended range, having depth to diameter ratios of $3: 1$ to $6: 1$ (ACP Technologies, 2012) in all cases. After connecting the test column to the experimental rig, the $\mathrm{H}_{2} \mathrm{~S}$ in $\mathrm{N}_{2}$ and $\mathrm{O}_{2}$ mass flow controllers were set at flow rates of 360 and $40 \mathrm{~mL} / \mathrm{min}$, respectively, with gas flow initially by-passing the test column and sensors, and discharging via the chimney. At the commencement of a test, the gas flow was redirected to the test column and the automatic test sequence was initiated using the LabVIEW software. The superficial gas flow velocity through the test column was $0.52 \mathrm{~m} / \mathrm{min}$, resulting in a medium residence time ranging from 15 to 17 seconds (depending on bed depth). The operating sequence alternated between five minutes of purging, where the gas flow from the column was directed to the chimney and the sensors were purged with air, followed by five minute sampling/measurement cycles, where flow from the column was directed to one of the $\mathrm{H}_{2} \mathrm{~S}$ sensors. This purge/sampling sequence was repeated until the measured $\mathrm{H}_{2} \mathrm{~S}$ concentration at the sensor approached $1800 \mathrm{ppm}$, indicating that the test medium was approaching saturation. During the test sequence, the 
lower-range sensor ( $\mathrm{S} 1$ ) was protected from exposure to $\mathrm{H}_{2} \mathrm{~S}>500 \mathrm{ppm}$ by diverting gas flow to the higher-range sensor (S2) when measured $\mathrm{H}_{2} \mathrm{~S}$ concentrations exceeded 300 ppm.

Throughout the test sequence, the voltage output from the data acquisition module was recorded at 10 second intervals. Calibration curves were used to convert the sensor signals into $\mathrm{H}_{2} \mathrm{~S}$ concentrations at the outlet of the test column. These measured concentrations were plotted over time to produce breakthrough curves. Generalised logistic curves (Equation 3.1) were fitted to the data, using the function lsqcurvefit in Matlab R2013b:

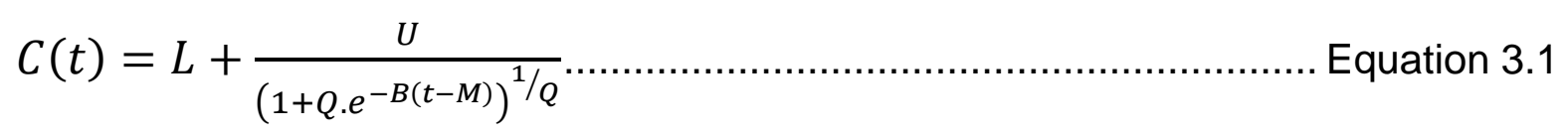

where $C(t)$ is the column outlet $\mathrm{H}_{2} \mathrm{~S}$ concentration (ppm) at time, $t(\mathrm{hr}), L$ is the lower asymptote $(0 \mathrm{ppm}), U$ is the upper asymptote $(2000 \mathrm{ppm}), B$ is the growth rate and $Q$ and $M$ are empirical fit parameters. This equation therefore contains 3 contestable parameters. The logistic curves allowed consistent interpolation over the entire breakthrough curve and identification of consistent breakthrough points. In some cases, the measured data exhibited two distinctly different responses over the test period. In such cases, two different logistic curves were added (Equation 3.2) to fit the entire test dataset, as follows:

$C(t)=L_{1}+\frac{U_{1}}{1+e^{-B_{1}\left(\ln (t)-M_{1}\right)}}+L_{2}+\frac{U_{2}}{1+e^{-B_{2}\left(\ln (t)-M_{2}\right)}} \ldots \ldots \ldots \ldots \ldots \ldots \ldots \ldots . .$. Equation 3.2 where $C(t)$ is the measured $\mathrm{H}_{2} \mathrm{~S}$ concentration (ppm) at the column outlet at time $t(\mathrm{hr}), L_{1}$ and $L_{2}$ are lower asymptotes ( $0 \mathrm{ppm}$ ), $U_{1}$ and $U_{2}$ are upper asymptotes, $B_{1}$ and $B_{2}$ are growth rates and $M 1$ and $M 2$ are empirical fit parameters. This equation therefore contains 5 contestable parameters.

The following four time events on the breakthrough curves were recorded, because they were of particular practical interest from an application perspective:

(i) $\mathrm{T}_{10}$ : the first occurrence of $\mathrm{H}_{2} \mathrm{~S}>10 \mathrm{ppm}$, approximating the breakthrough time, and representing the Safe Work Australia (2013) 8-hour average exposure limit;

(ii) $\mathrm{T}_{200}$ : the first occurrence of $\mathrm{H}_{2} \mathrm{~S}>200 \mathrm{ppm}$, a common upper limit for internal combustion engine generators (Wellinger and Lindberg, 2005); 
(iii) $\mathrm{T}_{1000}$ : the first occurrence of $\mathrm{H}_{2} \mathrm{~S}>1000$ ppm, a common upper limit for boilers burning biogas (Wellinger and Lindberg, 2005); and

(iv) $\mathrm{T}_{1950}$ : the first occurrence of $\mathrm{H}_{2} \mathrm{~S}>1950$ ppm, approximating saturation i.e. when $\mathrm{H}_{2} \mathrm{~S}$ concentration is approximately the same at the inlet and outlet of the test column. Note that the $T_{1950}$ value is indicative only, because most of the experiments were not run to saturation. Hence, the $T_{1950}$ value was only a model prediction, noting that empirical models have very limited predictive capability.

Model prediction curves, including confidence intervals, were generated using the Matlab function $n l p r e d c i$ using the jacobian generated by lsqcurvefit. This was then used to determine values including $95 \%$ confidence intervals for $T_{10}-T_{1950}$ from model and upper and lower confidence arrays, using the Microsoft Excel Lookup function.

The modelled column outlet $\mathrm{H}_{2} \mathrm{~S}$ concentrations were used to calculate the cumulative $\mathrm{S}$ removal masses at the $T_{10}, T_{200}, T_{1000}$ and $T_{1950}$ times (Table 3.2). Henry equation calculations, using a Henry's law solubility constant $\left(\mathrm{H}^{\mathrm{cp}}\right)$ of $0.10 \mathrm{M} \mathrm{atm}^{-1}$ for $\mathrm{H}_{2} \mathrm{~S}$ in water (Sander, 2015), suggested that the dissolution of $\mathrm{H}_{2} \mathrm{~S}$ in the water bath, prior to passing through the chemisorption column, would have been relatively minor (maximum $0.04 \mathrm{~g} \mathrm{~S}$ ). Consequently, no adjustments were made to the chemisorption removal masses reported below to account for this effect.

For a subset of replicate tests, average results were calculated along with $95 \%$ confidence limits. Genstat software (Payne et al., 2011) was used to perform an Analysis of Variance (ANOVA) to assess the variance between treatments $\left(\mathrm{H}_{2} \mathrm{~S}\right.$ concentrations) and the residual variances and a repeatability coefficient were calculated.

\subsubsection{Pressure drop experiments}

The pressure drop across a bed of the $\mathrm{cg}_{5}$ and red soil (Tor St, Toowoomba) media was assessed by passing high-purity $\mathrm{N}_{2}$ gas at a range of flowrates through approximately $100 \mathrm{~mL}$ of each medium (for a consistent bed depth) housed in the test column (Figure 3.1). The gas flowrates were regulated using an Alicat MC-5SLPM-D-DB15/5M mass flow controller and the pressure drop was measured between tapping points directly upstream and downstream of the test column, using a TSI Model 8705 DP-CALC ${ }^{\text {TM }}$ micromanometer. The experimental results were used to derive graphical plots of the pressure 
drop per unit depth of medium versus flow velocity, for comparison with values calculated using the Ergun equation (Equation 3.3, Ergun, 1952).

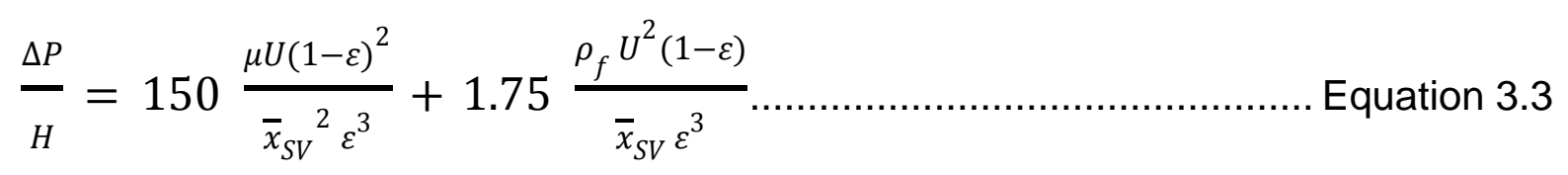

where $\Delta P$ is the measured pressure drop $(\mathrm{Pa}), H$ is the bed depth $(\mathrm{m}), \mu$ is the gas dynamic viscosity $\left(1.76 \times 10^{-5}\right.$ Pa.s at $20^{\circ} \mathrm{C}$, interpolated from Haynes, 2016), $U$ is the superficial gas velocity $(\mathrm{m} / \mathrm{s}), \varepsilon$ is the bed void fraction, $\bar{x} s V$ is the surface-volume mean diameter of the packed bed particles (the mean diameter of a sphere that has the same surface area to volume ratio as the test media particles, $\mathrm{m}$ ) and $\rho_{f}$ is the gas density $\left(1.165 \mathrm{~kg} / \mathrm{m}^{3}\right.$ at $20^{\circ} \mathrm{C}$, interpolated from Haynes, 2016). The values of the surface-volume mean diameters for the $\mathrm{cg}_{5}$ and red soil particles were estimated using the Microsoft

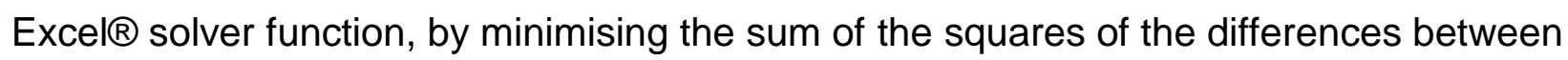
the measured values and the values calculated using the Ergun equation. Linear regression analyses were performed on the measured vs. predicted data plots, and simultaneous F-tests for slope $=1$ and intercept $=0$ were carried out.

In an attempt to reduce pressure drop associated with the use of red soil, further experiments were performed with pressure drop measurements on red soil mixed with ground SCM as a bulking agent at $20 \%$ and $40 \%$ SCM (by volume).

\subsubsection{Media regeneration studies}

A separate test examined the ability to regenerate a low-cost iron-rich medium by exposure to air. For this, a $\mathrm{H}_{2} \mathrm{~S}$ removal test was first performed on a sample of Tor St red soil as described in Section 3.2.3. Following the test, the soil sample was removed from the test column and spread in a thin layer across the base of a shallow Pyrex dish to promote exposure to ambient air over a period of approximately one week. After this, the sample was loaded back into the test column and another $\mathrm{H}_{2} \mathrm{~S}$ removal test was performed, again as described in Section 3.2.3. This use-regenerate-reuse was repeated three times on the same sample, resulting in a total of four uses. 


\subsubsection{Analytical methods}

The TS concentrations of the media were measured in triplicate using the methods recommended by Greenberg et al. (1992). Bulk density was measured in triplicate by a simplified tapping density technique based on ASTM D7481-09. For this, a known mass of test medium was placed in a $100 \mathrm{~mL}$ measuring cylinder which was then manually tapped on a laboratory bench until no further settlement of the medium was observed (typically within 30 seconds). At this point the final tapped volume was recorded to calculate the associated density. The particle densities of each of the media (pre-dried at $80^{\circ} \mathrm{C}$ and ground into a fine powder using a mortar and pestle) were measured using an AccuPyc II 1340, Helium Pycnometer based on methods described by Dane and Topp (2002). Each sample was purged with helium 20 times in the pycnometer to remove air and moisture. The particle density was then determined as an average of 10 measurements on each individual sample. The porosity of each medium was then calculated from the bulk density and particle density values [Porosity $(\%)=(1-$ (bulk density/particle density) $) \times 100$ ] (Dane and Topp, 2002). The elemental concentrations of $\mathrm{Al}, \mathrm{Fe}$ and $\mathrm{S}$ were determined by inductively coupled plasma optical emission spectroscopy (ICP-OES) based on methods described by Greenberg et al. (1992). For this, the media samples were digested with a 6:2:2 ratio of $\mathrm{HCl}, \mathrm{HNO}_{3}$ and $\mathrm{HF}$ using a Milestone Ethos-1 microwave digester, prior to analysis using a Varian Vista Pro ICP-OES instrument.

\subsection{Results and discussion}

\subsubsection{Media properties}

Table 3.1 summarises properties of the various tested media. The commercial medium $\mathrm{cg}_{5}$ had the highest iron content, which is one of the known active ingredients for chemisorption (Section 2.3.2.1). The red soils and GSFS (fine fraction) also had high iron contents. The carbon-based media (with low iron contents) had relatively high porosities in comparison to the other tested media, except $\mathrm{cg}_{5}$. Higher porosities would likely offer larger contact areas between the medium and $\mathrm{H}_{2} \mathrm{~S}$, and thus the high porosity of $\mathrm{cg}_{5}$ reflects the engineered nature of this commercial medium.

The two red soils tested in this experiment were both classified as krasnozems (Great Soil Group, Stace et al., 1968) or red ferrosols (Australian Soil Classification, Isbell, 1996). By 
definition, ferrosols have free iron oxide contents greater than $5 \% \mathrm{Fe}$ in the fine earth fraction (<2 mm) of the B2 horizon (Isbell, 1996). The iron contents determined by the ICP analyses for the samples of the Tor Street and Ravensbourne soils passing the $2 \mathrm{~mm}$ sieve were similar, at 14.1 to $15.5 \%$ (w/w), respectively; however, the Ravensbourne red soil was a slightly brighter red colour compared with the Tor Street red soil. These colour differences could reflect different crystalline structures of the iron oxide minerals present in the two soils (Schwertmann and Cornell, 2000). The largest proportion of soil total iron is in the form of oxide minerals such as hematite, goethite, lepidocrocite and ferrihydrite (Loeppert and Inskeep, 1996). The morphology of the two soils was also expected to be influenced by the degree of weathering. In this regard, the Ravensbourne red soil was likely to be a more mature, more deeply weathered soil, containing more strongly crystalline iron oxide minerals that would be less reactive than the weakly crystalline amorphous iron-oxide minerals in the younger Tor St red soil. Ko (2008) found that the $S$ sorption capacities of various oxisol (USDA soil taxonomy) soils was strongly correlated with the amounts of dithionite-citrate-bicarbonate (DCB) extractable iron oxides in the soils, indicating an effect of availability of iron on the reactivity with sulphide.

Table 3.1 Selected test media properties (mean values \pm error as $95 \%$ confidence interval in the mean values).

\begin{tabular}{|c|c|c|c|c|c|c|c|}
\hline Medium & $\begin{array}{c}\text { TS } \\
\text { (\% mass) }\end{array}$ & $\begin{array}{l}\text { Bulk density } \\
\qquad(\mathrm{g} / \mathrm{mL})\end{array}$ & $\begin{array}{c}\text { Particle } \\
\text { density } \\
(\mathrm{g} / \mathrm{mL})\end{array}$ & $\begin{array}{c}\text { Porosity } \\
(\%)^{e}\end{array}$ & $\begin{array}{c}\mathbf{F e} \\
\text { (\% dry } \\
\text { mass) }\end{array}$ & $\begin{array}{c}\text { Al } \\
\text { (\% dry } \\
\text { mass) }\end{array}$ & $\begin{array}{c}\mathbf{S} \\
\text { (\% dry } \\
\text { mass) }\end{array}$ \\
\hline \multicolumn{8}{|l|}{ Iron-based media } \\
\hline $\operatorname{cg}_{5}$ & $95.61 \pm 0.07$ & $0.699 \pm 0.024$ & $2.885 \pm 0.002$ & 75.8 & 20.32 & 0.12 & 5.61 \\
\hline GSFS $(<5 \mathrm{~mm})^{a}$ & $99.02 \pm 0.02$ & $2.122 \pm 0.111$ & $3.289 \pm 0.002$ & 35.5 & 16.22 & 2.58 & 0.14 \\
\hline GSFS (M21 - coarse) & $99.93 \pm 0.02$ & $1.332 \pm 0.065$ & $2.719 \pm 0.001$ & 51.0 & 0.07 & 0.64 & 0.94 \\
\hline Red soil ${ }^{b}$ Tor St & $87.29 \pm 0.08$ & $1.110 \pm 0.055$ & $2.701 \pm 0.001$ & 58.9 & $14.07 \pm 0.10$ & $5.61 \pm 0.12$ & $0.05 \pm 0.00$ \\
\hline $\begin{array}{l}\text { Red soil b } \\
\text { Ravensbourne }\end{array}$ & $82.90 \pm 0.13$ & $1.257 \pm 0.010$ & $2.764 \pm 0.001$ & 54.5 & 15.54 & 6.10 & 0.09 \\
\hline $\begin{array}{l}\text { Red soil c } \\
\text { Ravensbourne }\end{array}$ & $84.04 \pm 0.96$ & $1.256 \pm 0.033$ & $2.771 \pm 0.001$ & 54.7 & 16.29 & 5.69 & 0.11 \\
\hline \multicolumn{8}{|l|}{ Carbon-based media } \\
\hline GAC $^{d}$ & $93.02 \pm 0.19$ & $0.557 \pm 0.002$ & $2.138 \pm 0.155$ & 73.9 & 0.18 & 0.46 & 1.06 \\
\hline Compost ${ }^{b}$ & $66.09 \pm 0.13$ & $0.597 \pm 0.014$ & $2.023 \pm 0.001$ & 70.5 & 2.25 & 2.21 & 0.66 \\
\hline Composted manure ${ }^{b}$ & $64.38 \pm 0.64$ & $0.738 \pm 0.013$ & $1.871 \pm 0.002$ & 60.6 & 2.01 & 0.55 & 1.31 \\
\hline Biochar ${ }^{b}$ & $90.21 \pm 0.32$ & $0.208 \pm 0.007$ & $1.664 \pm 0.027$ & 87.5 & 0.20 & 0.14 & 0.06 \\
\hline
\end{tabular}

a GSFS, Granulated steel furnace slag; ${ }^{b}$ Samples prepared by sieving at $2 \mathrm{~mm}$;

c Sample prepared by sieving at $500 \mu \mathrm{m}$; ${ }^{\mathrm{d}} \mathrm{GAC}$, Granular activated carbon;

e Porosity $(\%)=(1-($ bulk density/particle density $)) \times 100$ 


\subsubsection{Media performance/capacity}

Figure 3.2 presents typical data from a $\mathrm{H}_{2} \mathrm{~S}$ removal test (a breakthrough curve, in this case for GAC 2) and indicates the four time events ( $T_{10}, T_{200}, T_{1000}$ and $\left.T_{1950}\right)$ that were of particular practical interest in characterising the tested media (Section 3.2.3). Calculations determined the corresponding masses of sulphur removed from the test gas at each of these times (Table 3.2). The cumulative amounts of sulphur removed at $\mathrm{T}_{200}$ (200ppm $\mathrm{H}_{2} \mathrm{~S}$ downstream of test column) and $\mathrm{T}_{1000}$ (1000ppm $\mathrm{H}_{2} \mathrm{~S}$ downstream of test column) are probably of greatest practical importance, because these correspond to the recommended upper $\mathrm{H}_{2} \mathrm{~S}$ levels for internal combustion engines and boilers, respectively (Section 2.1). Figure 3.3 presents data for a repeatability analysis performed on three separate samples of granulated activated carbon, giving average values for sulphur removal capacity together with errors estimated at the $95 \%$ confidence limit. The repeatability coefficient was found to be 0.98 , indicating that the experimental results were reproducible.

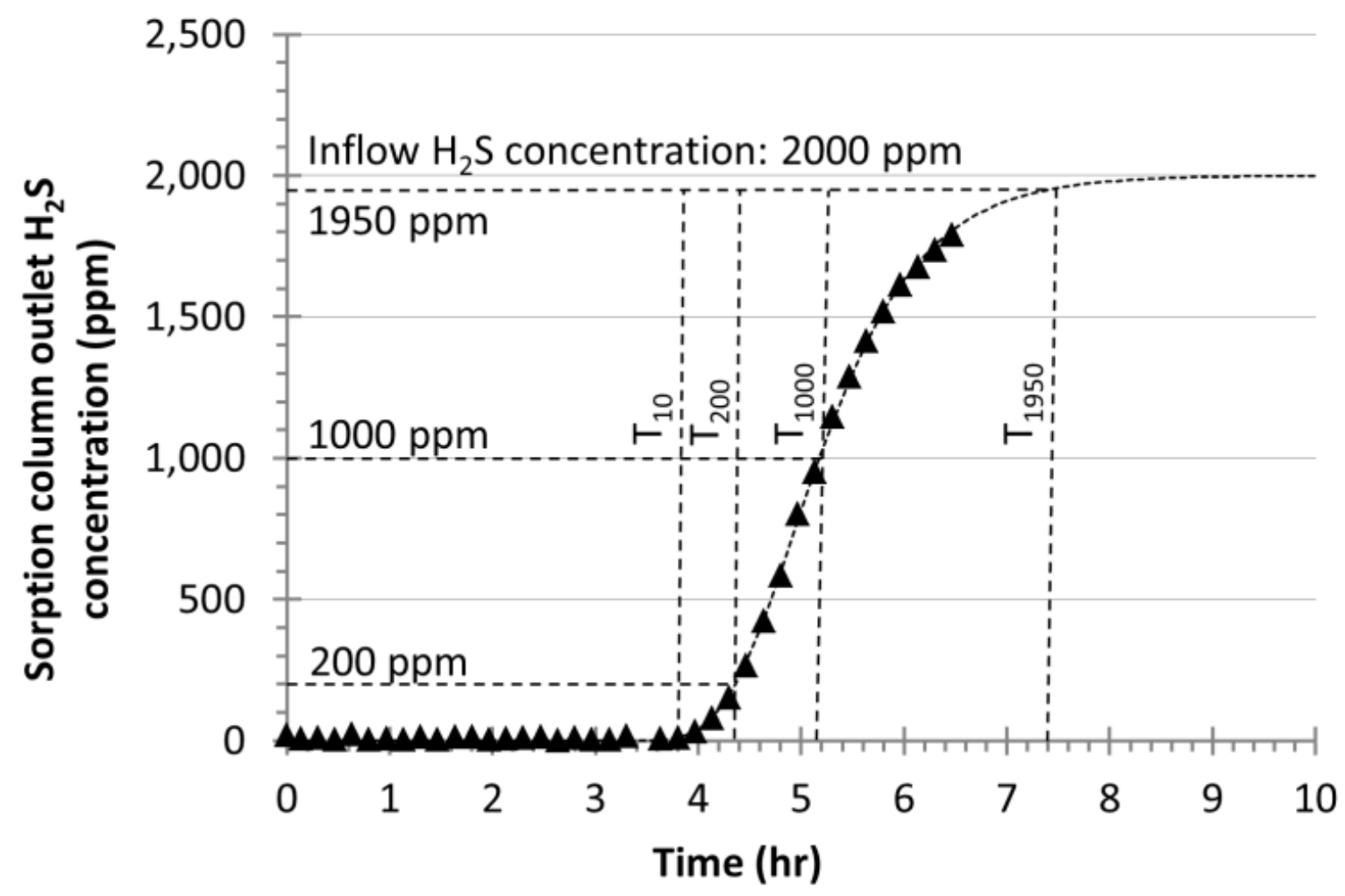

Figure 3.2 A typical breakthrough curve for GAC plotted from the experimental data, showing the key times of interest ( $T_{10}$ at breakthrough, $\mathrm{H}_{2} \mathrm{~S} \approx 10 \mathrm{ppm} ; \mathrm{T}_{200}, \mathrm{H}_{2} \mathrm{~S}=200 \mathrm{ppm} ; \mathrm{T}_{1000}, \mathrm{H}_{2} \mathrm{~S}=$ 1000 ppm; $T_{1950}$ at saturation, $\left.\mathrm{H}_{2} \mathrm{~S}=1950 \mathrm{ppm}\right)$. The dashed curve is a fit of Equation 3.1. 


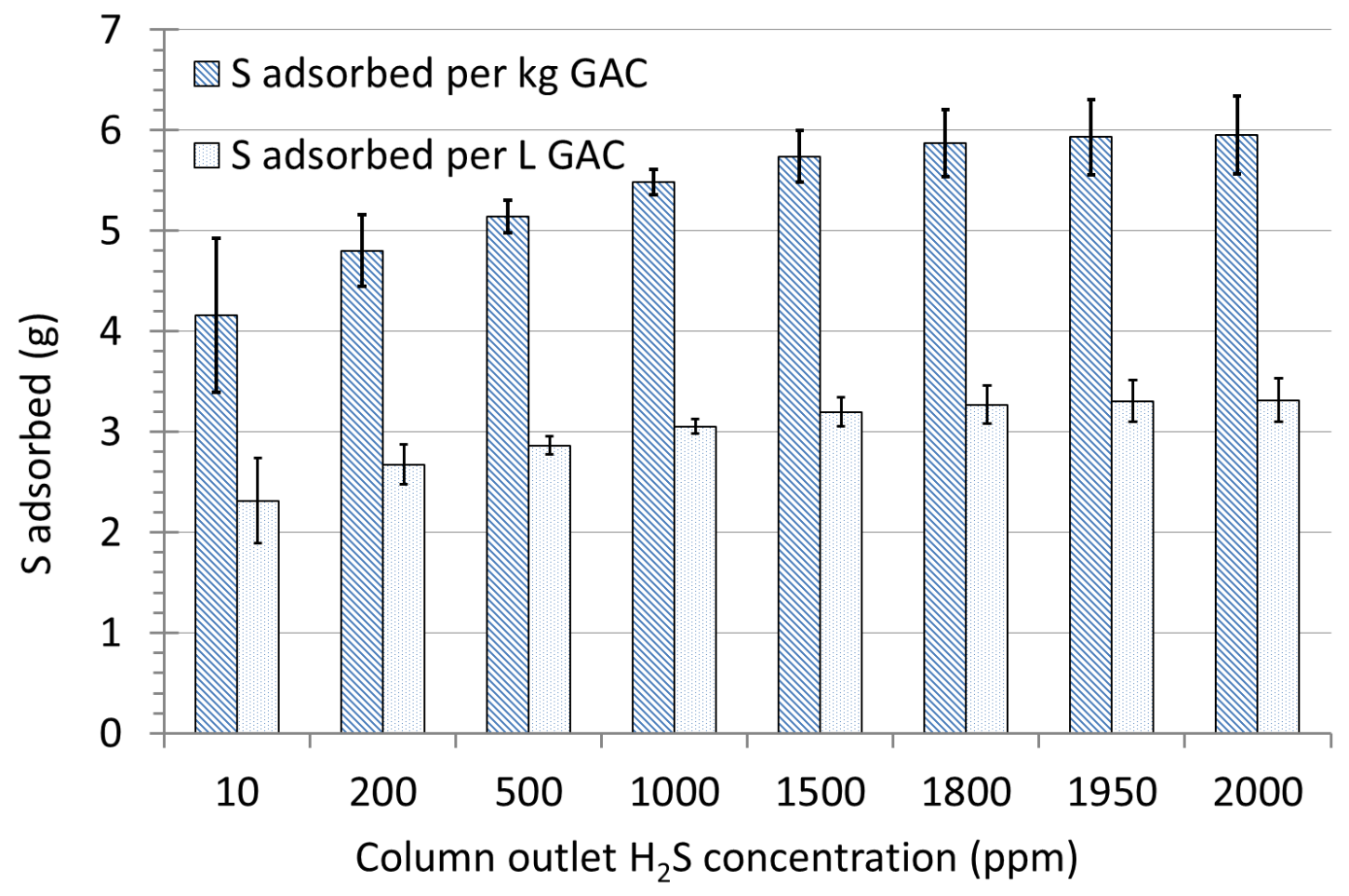

Figure 3.3 Results from a reproducibility analysis performed on three separate samples of GAC showing mean sulphur removal capacities, with error bars estimated at the $95 \%$ confidence level.

Figure 3.4 presents breakthrough curves for various tested media (measured data together with lines fitted using Equations 3.1 and 3.2). Table 3.2 also presents the corresponding masses of sulphur removed (the chemisorption capacities). The $\mathrm{H}_{2} \mathrm{~S}$ removal capacity of the $\mathrm{cg}_{5}$ pellets was observed to be vastly superior compared to all of the other tested media (Table 3.2). The extrapolated $\mathrm{H}_{2} \mathrm{~S}$ removal capacity at saturation (260 $\mathrm{g} \mathrm{S} / \mathrm{kg}$ medium) agreed well with the supplier's claimed performance of $250 \mathrm{~g} \mathrm{~S} / \mathrm{kg}$ medium (ACP Technologies Inc, 2012). However, it was unclear whether this performance claimed by the supplier corresponded to complete saturation or to breakthrough. The measured $\mathrm{H}_{2} \mathrm{~S}$ removal capacity at breakthrough for $\mathrm{cg}_{5}$ ( $143 \mathrm{~g} \mathrm{~S} / \mathrm{kg}$ medium) also agreed well with that reported elsewhere for a similar material called $\mathrm{cg}_{4}$ (Wang et al., 2008, $141 \mathrm{~g} \mathrm{~S} / \mathrm{kg}$ medium). The high performance of $\mathrm{cg}_{5}$ (Table 3.1) was expected to be the result of its engineered high porosity and high iron content that would provide greater contact area and more chemisorption sites. 


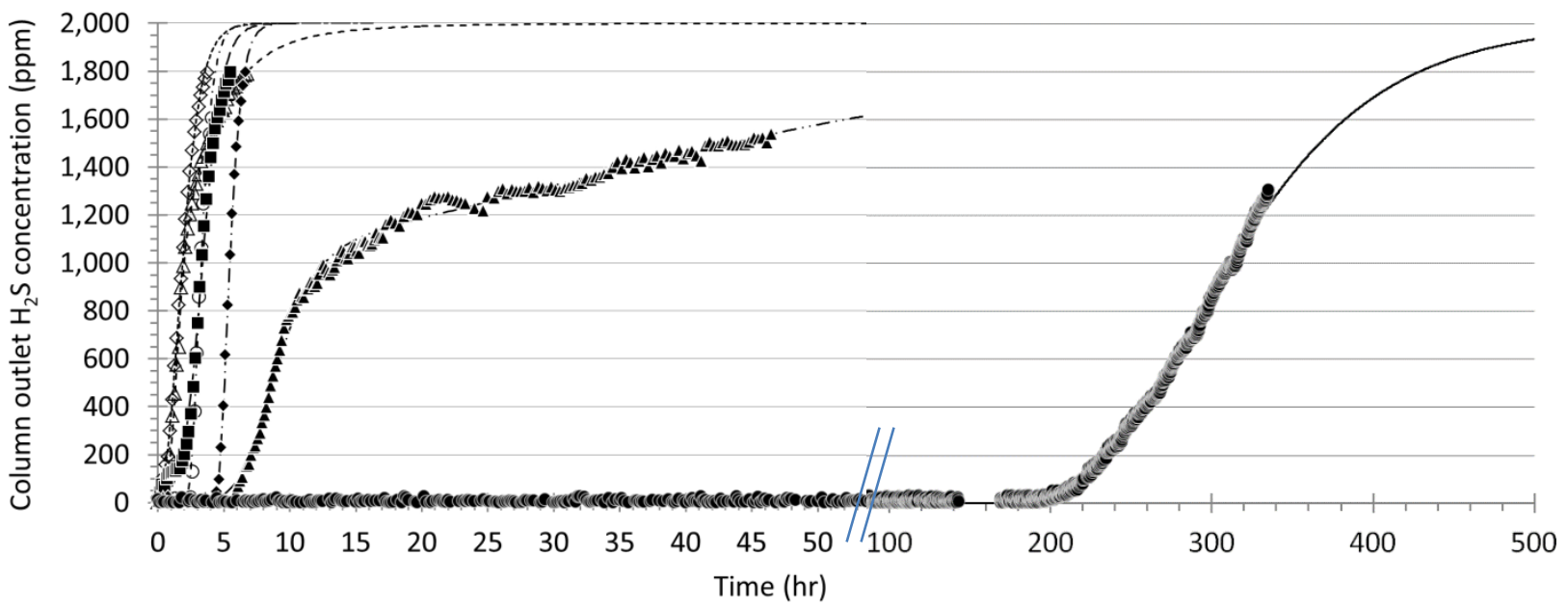

Figure 3.4 Breakthrough curves (column outlet $\mathrm{H}_{2} \mathrm{~S}$ concentrations vs. time) for the tested media. Data is presented for cg5 $(\bullet)$, composted feedlot manure $(\diamond)$, GSFS $(\Delta)$, biochar $(O)$, compost $(\square)$, GAC $(\diamond)$ and Tor Street red soil $(\Delta)$. Note the break in scale/change of scale on the time axes. Lines represent data extrapolated beyond the measured datasets, using the fitted logistic curves (Equations 3.1 and 3.2). 
Table 3.2 Data for masses of sulphur removed (means $\pm 95 \%$ confidence intervals), corresponding to times of interest, $T_{10}$ (breakthrough $\mathrm{H}_{2} \mathrm{~S}>10 \mathrm{ppm}$ ), $\mathrm{T}_{200}$ (when $\mathrm{H}_{2} \mathrm{~S}=200 \mathrm{ppm}$ ), $\mathrm{T}_{1000}$ (when $\mathrm{H}_{2} \mathrm{~S}=1000 \mathrm{ppm}$ ) and $\mathrm{T}_{1950}(\approx$ saturation).

\begin{tabular}{|c|c|c|c|c|c|}
\hline \multirow{2}{*}{$\begin{array}{l}\text { Test medium } \\
{[\text { [mass }(\mathrm{g}) \text {, volume }(\mathrm{mL})} \\
\text { depth }(\mathrm{mm}) \text {, res time }(\mathrm{s})]\end{array}$} & \multirow{2}{*}{$\begin{array}{l}\text { Outlet } \\
\mathrm{H}_{2} \mathrm{~S} \text { conc } \\
\text { (ppm) }\end{array}$} & \multirow{2}{*}{$\begin{array}{l}\text { Elution } \\
\text { time } \\
\text { (hr) }\end{array}$} & \multicolumn{3}{|c|}{$\begin{array}{l}\text { Cumulative sulphur removed (capacity) } \\
\text { at the designated elution times }\end{array}$} \\
\hline & & & (g S/kg Fe) & (g S/kg med) & (g S/L med) \\
\hline $\operatorname{cg}_{5}$ & 10 & $177 \pm 1$ & $737 \pm 0$ & $143 \pm 0$ & $100 \pm 0$ \\
\hline \multirow{3}{*}{$\begin{array}{l}{[71.2 \mathrm{~g}, 101.9 \mathrm{~mL}} \\
147.0 \mathrm{~mm}, 17.0 \mathrm{sec}]\end{array}$} & 200 & $237 \pm 0$ & $976 \pm 0$ & $190 \pm 0$ & $132 \pm 0$ \\
\hline & 1000 & $312 \pm 0$ & $1,199 \pm 0$ & $233 \pm 0$ & $163 \pm 0$ \\
\hline & 1950 & $505 \pm 2$ & $1,338 \pm 2$ & $260 \pm 0$ & $182 \pm 0$ \\
\hline GSFS (<5mm) & 10 & $0.4 \pm 0.1$ & $0.9 \pm 0.0$ & $0.1 \pm 0.0$ & $0.3 \pm 0.0$ \\
\hline \multirow{3}{*}{$\begin{array}{l}{[161.9 \mathrm{~g}, 76.3 \mathrm{~mL}} \\
110.1 \mathrm{~mm}, 12.7 \mathrm{sec}]\end{array}$} & 200 & $1.0 \pm 0.0$ & $2.1 \pm 0.0$ & $0.3 \pm 0.0$ & $0.7 \pm 0.0$ \\
\hline & 1000 & $2.0 \pm 0.0$ & $3.7 \pm 0.0$ & $0.6 \pm 0.0$ & $1.2 \pm 0.0$ \\
\hline & 1950 & $12.9 \pm 2.4$ & $6.9 \pm 0.4$ & $1.1 \pm 0.1$ & $2.3 \pm 0.1$ \\
\hline Red soil (Tor St) & 10 & $3.0 \pm 0.9$ & $3 \pm 0$ & $1.6 \pm 0.0$ & $1.7 \pm 0.0$ \\
\hline \multirow{3}{*}{$\begin{array}{l}{[109.9 \mathrm{~g}, 99.0 \mathrm{~mL}} \\
142.9 \mathrm{~mm}, 16.5 \mathrm{sec}]\end{array}$} & 200 & $7.0 \pm 0.1$ & $29 \pm 0$ & $3.6 \pm 0.0$ & $4.0 \pm 0.0$ \\
\hline & 1000 & $12.6 \pm 0.2$ & $45 \pm 0$ & $5.6 \pm 0.0$ & $6.2 \pm 0.0$ \\
\hline & 1950 & $199.9 \pm 9.0$ & $153 \pm 9$ & $18.8 \pm 1.1$ & $20.9 \pm 1.2$ \\
\hline $\mathrm{GAC}^{\mathrm{a}}$ & 10 & $3.8 \pm 1.0$ & $2,260 \pm 415$ & $4.2 \pm 0.8$ & $2.3 \pm 0.4$ \\
\hline \multirow{3}{*}{$\begin{array}{l}{[52.1 \pm 4.0 \mathrm{~g}, 93.6 \pm 7.1 \mathrm{~mL}} \\
135.2 \pm 10.1 \mathrm{~mm}, 15.5 \pm 1.6 \mathrm{sec}]\end{array}$} & 200 & $4.5 \pm 0.6$ & $2,611 \pm 195$ & $4.8 \pm 0.4$ & $2.7 \pm 0.2$ \\
\hline & 1000 & $5.3 \pm 0.4$ & $2,981 \pm 68$ & $5.5 \pm 0.1$ & $3.1 \pm 0.1$ \\
\hline & 1950 & $7.7 \pm 1.4$ & $3,225 \pm 204$ & $5.9 \pm 0.4$ & $3.3 \pm 0.2$ \\
\hline Compost & 10 & $0.3 \pm 0.6$ & $17 \pm 0$ & $0.3 \pm 0.0$ & $0.2 \pm 0.0$ \\
\hline \multirow{3}{*}{$\begin{array}{l}{[58.9 \mathrm{~g}, 98.7 \mathrm{~mL}} \\
142.4 \mathrm{~mm}, 16.4 \mathrm{sec}]\end{array}$} & 200 & $1.9 \pm 0.1$ & $121 \pm 2$ & $1.8 \pm 0.0$ & $1.1 \pm 0.0$ \\
\hline & 1000 & $3.4 \pm 0.1$ & $1918 \pm 3$ & $2.8 \pm 0.1$ & $1.7 \pm 0.0$ \\
\hline & 1950 & $6.4 \pm 0.3$ & $226 \pm 7$ & $3.4 \pm 0.1$ & $2.0 \pm 0.1$ \\
\hline Composted feedlot manure & 10 & $0.1 \pm 0.1$ & $3 \pm 0$ & $0.0 \pm 0.0$ & $0.0 \pm 0.0$ \\
\hline \multirow{3}{*}{$\begin{array}{l}{[70.6 \mathrm{~g}, 95.7 \mathrm{~mL}} \\
138.1 \mathrm{~mm}, 15.9 \mathrm{sec}]\end{array}$} & 200 & $0.7 \pm 0.0$ & $44 \pm 0$ & $0.6 \pm 0.0$ & $0.4 \pm 0.0$ \\
\hline & 1000 & $1.8 \pm 0.0$ & $94 \pm 1$ & $1.2 \pm 0.0$ & $0.9 \pm 0.0$ \\
\hline & 1950 & $5.1 \pm 0.1$ & $129 \pm 2$ & $1.7 \pm 0.0$ & $1.2 \pm 0.0$ \\
\hline Biochar & 10 & $2.1 \pm 0.1$ & $3,583 \pm 1$ & $6.5 \pm 0.0$ & $1.3 \pm 0.0$ \\
\hline \multirow{3}{*}{$\begin{array}{l}{[18.8 \mathrm{~g}, 90.3 \mathrm{~mL}} \\
130.4 \mathrm{~mm}, 15.1 \mathrm{sec}]\end{array}$} & 200 & $2.6 \pm 0.1$ & $4,352 \pm 15$ & $7.9 \pm 0.0$ & $1.6 \pm 0.0$ \\
\hline & 1000 & $3.3 \pm 0.0$ & $5,188 \pm 39$ & $9.4 \pm 0.1$ & $1.9 \pm 0.0$ \\
\hline & 1950 & $5.2 \pm 0.1$ & $5,741 \pm 81$ & $10.4 \pm 0.1$ & $2.2 \pm 0.0$ \\
\hline
\end{tabular}

a Mean values for GAC 1, 2 and $3 \pm 95 \%$ confidence intervals.

b $95 \%$ confidence intervals generated by model confidence intervals.

The green waste-derived biochar showed the second highest breakthrough capacity (6.5 g S/kg medium, Table 3.2). While this value was within a wide range of values reported by Shang et al. (2012) (1.1 to $114 \mathrm{~g} \mathrm{~S} / \mathrm{kg}$ medium) for camphor-derived biochar, it was considerably lower than the capacities reported elsewhere by Shang et al. (2013) (109 to $383 \mathrm{~g} \mathrm{~S} / \mathrm{kg}$ medium) for biochars derived from agricultural/forestry waste products, such as camphor, rice hulls and bamboo. Others have reported on engineered GAC which has been impregnated with caustic compounds (Siefers, 2010; Abatzoglou and Boivin, 2009) such as sodium hydroxide $(\mathrm{NaOH})$ or potassium hydroxide $(\mathrm{KOH})$, sodium bicarbonate $\left(\mathrm{NaHCO}_{3}\right)$ and sodium carbonate $\left(\mathrm{Na}_{2} \mathrm{CO}_{3}\right)$, or strong oxidising agents such 
as potassium permanganate $\left(\mathrm{KMnO}_{4}\right)$. These media then give substantial $\mathrm{H}_{2} \mathrm{~S}$ removal by chemisorption. For example, typical $\mathrm{H}_{2} \mathrm{~S}$ removal capacities for unimpregnated and impregnated activated carbons can be quite different at 20 and $150 \mathrm{~g} \mathrm{H}_{2} \mathrm{~S} / \mathrm{kg}$ medium, respectively (Abatzoglou and Boivin, 2009). All carbon-based substrates tested during the present study showed low $\mathrm{H}_{2} \mathrm{~S}$ absorption capacities compared to the iron-based substrates, most probably because these were not impregnated and operating test pressures were near atmospheric. Comparing the test results for GAC and biochar to literature values (Abatzoglou and Boivin, 2009) indicates that impregnation with a reactive ingredient, rather than the neat carbon structure itself, is responsible for the majority of $\mathrm{H}_{2} \mathrm{~S}$ removal at near-atmospheric pressures.

The GSFS material crushed to a particle size $<5 \mathrm{~mm}$ gave reasonable $\mathrm{H}_{2} \mathrm{~S}$ removal performance (Table 3.2). In contrast, tests carried out on the M21 coarse GSFS material showed near-instantaneous breakthrough, most likely due to a low iron content $(<0.1 \%$, Table 3.1).

While the Tor Street soil was effective at removing $\mathrm{H}_{2} \mathrm{~S}$, both of the Ravensbourne soil samples (passing the $2 \mathrm{~mm}$ and $500 \mu \mathrm{m}$ sieves) showed near instantaneous breakthrough of $\mathrm{H}_{2} \mathrm{~S}$ (low removal capacity). This was despite the fact that these two red soils (Tor Street and Ravensbourne) had similar iron contents and porosities (Table 3.1). Overall, these findings suggested that the $\mathrm{H}_{2} \mathrm{~S}$ removal capacity of red soils could also be influenced by other factors, such as mineralogy (Section 3.3.1), rather than simply by iron content, porosity or particle size.

The results noted above suggested that the Tor street red soil was a worthwhile candidate for further investigation. Therefore, pressure drop experiments (Section 3.3.3) and regeneration experiments (Section 3.3.4) were performed on this material for comparison with the commercial cg5 medium results.

\subsubsection{Pressure drop}

Figure 3.5 presents results of the pressure drop experiments (Section 3.2.4). Tor St red soil was also tested with and without added sugar cane mulch (SCM) as a bulking agent, to investigate bulking as a practical means to reduce pressure drop (albeit at reduced volumetric $\mathrm{H}_{2} \mathrm{~S}$ removal capacity). The regression fits of Equation 3.3 (the Ergun equation) 
are also presented. The best fit values for the surface-volume mean diameter $\left(\bar{x}_{S V}\right)$ were found to be $73,62,71$ and $93 \mu \mathrm{m}$ for the red soil, $20 \%$ SCM bulked red soil, $40 \%$ SCM bulked red soil and $\operatorname{cg}_{5}$ media, respectively. Table 3.3 provides results of regression analyses of measured vs predicted (Ergun equation) pressure drop data for the combined and four individual sorption media. High $\mathrm{R}^{2}$ values $(\geq 0.99)$ indicated that the fits of Equation 3.3 were significant and appropriate $(P<0.05)$, while the high modelling efficiency $(E F)$ values indicate that the Ergun equation accurately predicted the experimental results. This outcome is consistent with the findings of Wang et al. (2011) for the CG sorbent. Despite good reproducibility, the simultaneous $\mathrm{F}$ test for slope $=1$ and intercept $=0$ indicated significant departures from the $y=x$ line for three of the five analyses performed (all, cg5 and red soil+40\% SCM).

Table 3.3. Results of regression analyses of measured vs predicted (Ergun equation) pressure drop data for the combined and four individual sorption media.

\begin{tabular}{|c|c|c|c|c|c|}
\hline Parameter & All & $\operatorname{cg}_{5}$ & $\begin{array}{l}\text { Red soil + } \\
20 \% \text { SCM }\end{array}$ & $\begin{array}{l}\text { Red soil + } \\
40 \% \text { SCM }\end{array}$ & Red soil \\
\hline $\mathrm{EF}$ a & 0.996 & 0.998 & 0.996 & 0.990 & 0.996 \\
\hline $\mathrm{R}^{2}$ & 0.996 & 1.000 & 0.997 & 0.995 & 0.997 \\
\hline \multicolumn{6}{|l|}{ Linear Regression } \\
\hline Slope & 0.979 & 1.032 & 0.980 & 0.936 & 0.976 \\
\hline Intercept & 0.195 & -0.112 & 0.310 & 0.306 & 0.404 \\
\hline \multicolumn{6}{|c|}{ Simultaneous $\mathrm{F}$ test for slope $=1$ and intercept $=0$} \\
\hline $\mathrm{F}$ & 4.097 & 14.440 & 1.925 & 6.402 & 2.175 \\
\hline$F_{\text {prob }}$ & 0.0217 & 0.0008 & 0.1850 & 0.0098 & 0.1530 \\
\hline Significant difference & ${ }^{*}(P<0.05)$ & $* * *(P<0.001)$ & ns & ${ }^{* *}(\mathrm{P}<0.01)$ & ns \\
\hline
\end{tabular}

At any given flow velocity, the pressure drop per unit bed depth was approximately ten times higher for the red soil than for the $\mathrm{cg}_{5}$ commercial medium. The relatively low pressure drop of the $\mathrm{cg}_{5}$ medium is reflective of its engineered characteristics (Section 3.3.1). In contrast, the results indicated that a relatively high upstream pressure would be required with the red soil media, consuming substantially more energy than with the cg5 medium, and potentially increasing the risk of tunnelling and uneven migration of the biogas through the packed column, which could lead to inferior $\mathrm{H}_{2} \mathrm{~S}$ removal. Bulking with $40 \%$ SCM decreased the pressure drop by $50 \%$ compared to red soil only, which would substantially reduce energy costs on-farm, but would obviously require a larger vessel for similar $\mathrm{H}_{2} \mathrm{~S}$ removal performance because of dilution of the active ingredient (the red soil). Chapter 4 assesses whether these laboratory results are scalable to full-scale, on-farm installations. 


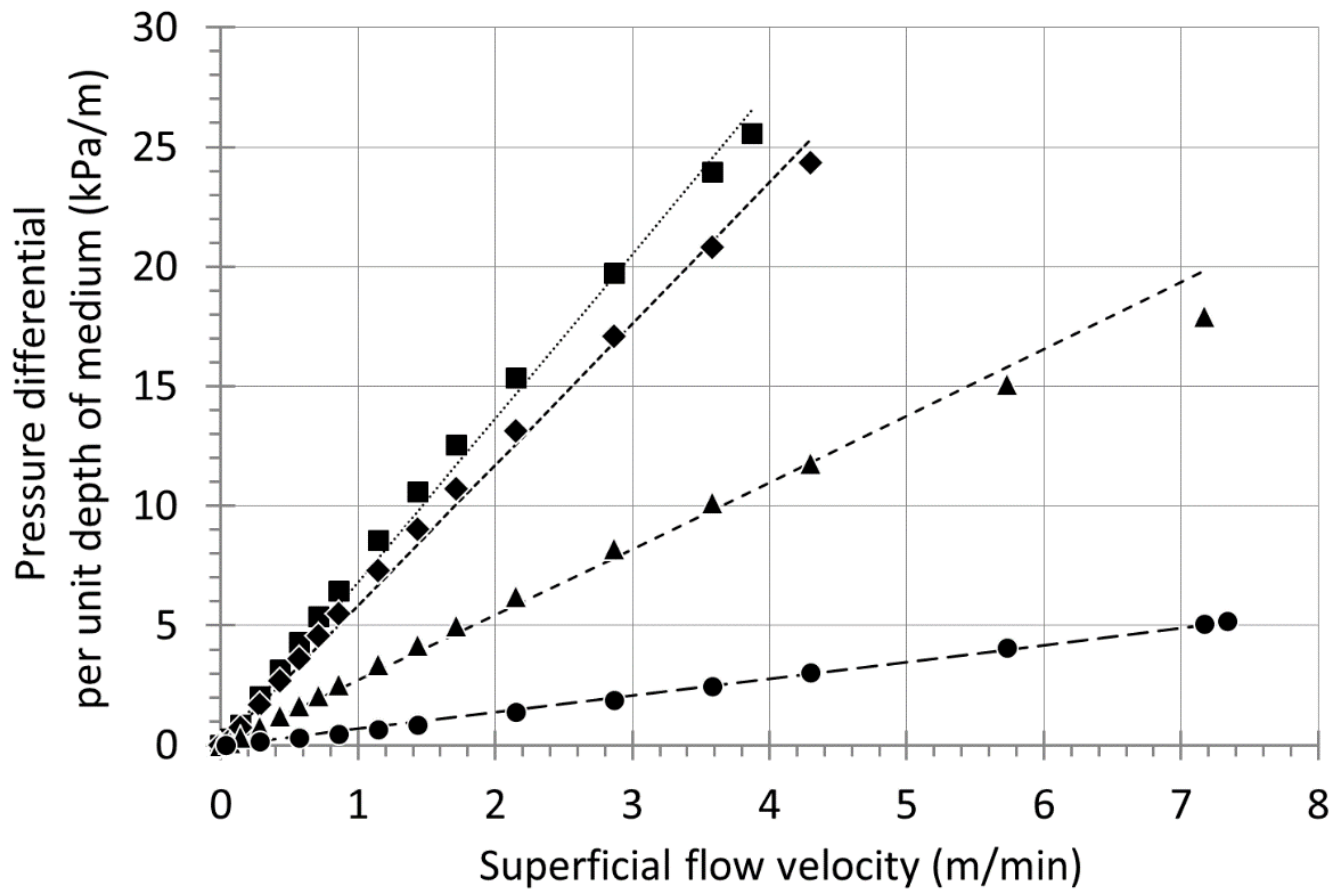

Figure 3.5 Pressure drop per unit depth of the red soil ( $\square$ ), red soil bulked with $20 \%$ SCM v/v $(\diamond)$, red soil bulked with $40 \% \mathrm{SCM} v / v(\Delta)$ and $\mathrm{cg}_{5}(\bullet)$ media, measured in the test column. Lines are regression fits with the Ergun equation (Equation 3.2) over a range of $\mathrm{N}_{2}$ flow velocities.

\subsubsection{Media regeneration}

Figure 3.6 presents breakthrough curves for a red soil sample (Tor Street, Toowoomba) tested in consecutive media regeneration trials (Runs 1 to 4 , Section 3.2.5). Table 3.4 outlines the elution times and sulphur removal capacities at a range of outlet $\mathrm{H}_{2} \mathrm{~S}$ concentrations for the four consecutive media regeneration tests (Runs 1 to 4 ). The results suggested that the $\mathrm{H}_{2} \mathrm{~S}$ removal performance of the medium (at least for removal up to breakthrough) improved with regeneration, which was somewhat unexpected. Usually, the use-regenerate-reuse of an iron-based medium would be expected to cause a progressive loss in capacity due to the build-up of elemental sulphur (Section 2.3.2.1). It is possible that in the present case, mechanical disturbance or chemical alternation by the reactive regeneration could have exposed previously inaccessible reactive surface area in the soil structure. This could have exposed additional active ingredient and/or decreased diffusion limitations by increasing pore size. However, these hypotheses require further testing in future works outside the scope of the present thesis (Section 5.4). 


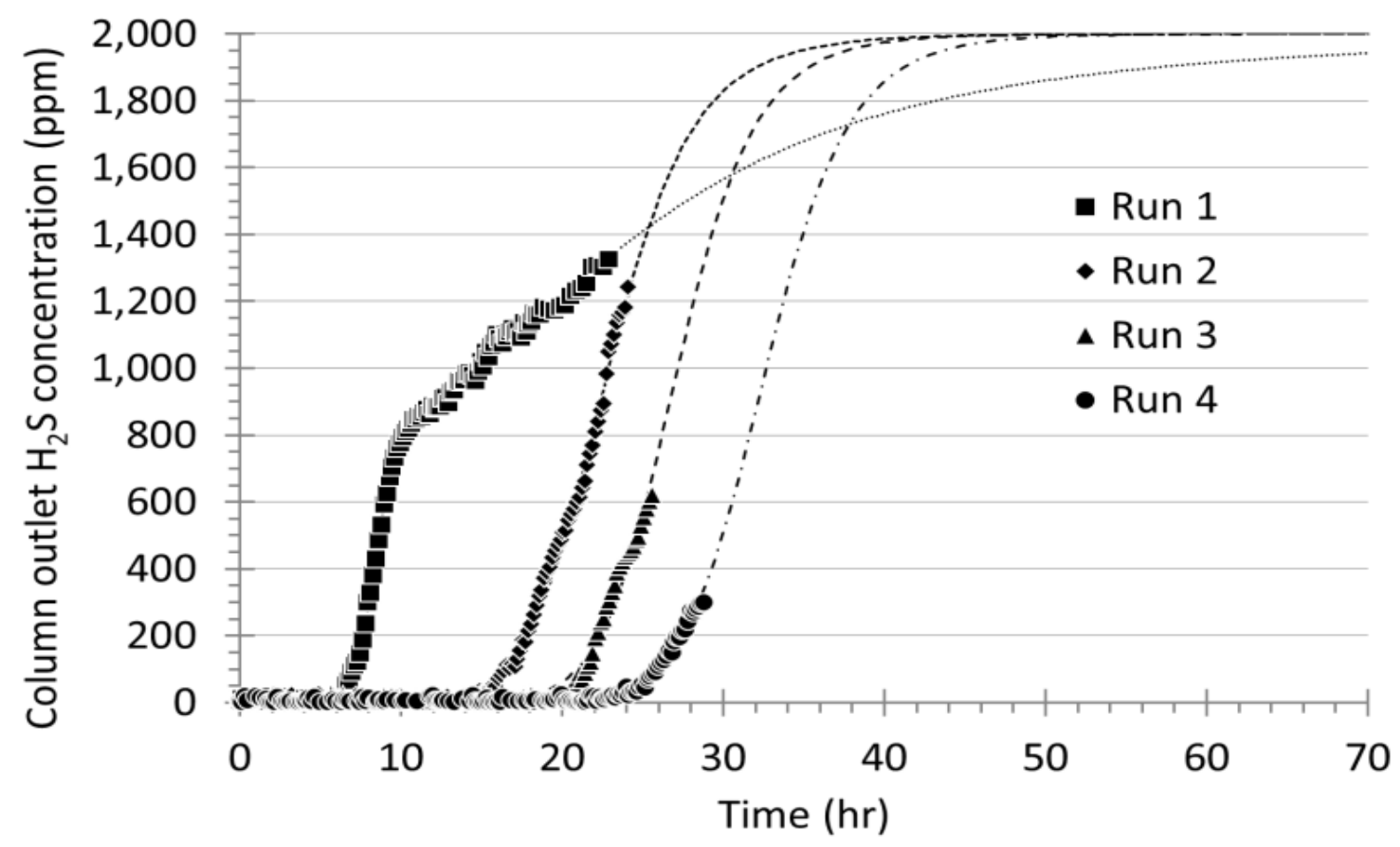

Figure 3.6 Breakthrough curves for a red soil (Tor St) sample tested in consecutive media regeneration trials. Lines represent data extrapolated beyond the measured datasets, using the fitted logistic curves (Equations 3.1 and 3.2).

Table 3.4 Masses of sulphur removed (capacity) for four consecutive media regeneration tests on the Tor Street red soil (Section 3.2.5).

\begin{tabular}{|c|c|c|c|c|c|}
\hline \multirow{2}{*}{$\begin{array}{l}\text { Run No } \\
\text { [mass }(\mathrm{g}) \text {, volume }(\mathrm{mL}) \\
\text { depth }(\mathrm{mm}) \text {, res time }(\mathrm{s})]\end{array}$} & \multirow{2}{*}{$\begin{array}{c}\text { Outlet } \\
\mathrm{H}_{2} \mathrm{~S} \text { conc } \\
\text { (ppm) }\end{array}$} & \multirow[t]{2}{*}{$\begin{array}{l}\text { Elution time } \\
\quad(\mathrm{hr})\end{array}$} & \multicolumn{3}{|c|}{$\begin{array}{l}\text { Cumulative sulphur removed (capacity) at the } \\
\text { designated elution times }\end{array}$} \\
\hline & & & (g S/kg Fe) & (g S/kg med) & (g S/L med) \\
\hline Run 1 & 10 & 4.36 & 17.41 & 2.45 & 2.42 \\
\hline \multirow{3}{*}{$\begin{array}{l}{[98.8 \mathrm{~g}, 99.9 \mathrm{~mL},} \\
144.2 \mathrm{~mm}, 16.6 \mathrm{sec}]\end{array}$} & 200 & 7.66 & 30.66 & 4.31 & 4.26 \\
\hline & 1000 & 14.75 & 48.15 & 6.77 & 6.70 \\
\hline & 1950 & 73.81 & 84.61 & 11.90 & 11.77 \\
\hline Run 2 & 10 & 12.51 & 50.77 & 7.14 & 7.04 \\
\hline \multirow{3}{*}{$\begin{array}{l}{[98.4 \mathrm{~g}, 99.8 \mathrm{~mL}} \\
144.1 \mathrm{~mm}, 16.6 \mathrm{sec}]\end{array}$} & 200 & 17.81 & 71.85 & 10.11 & 9.96 \\
\hline & 1000 & 22.89 & 86.83 & 12.21 & 12.04 \\
\hline & 1950 & 34.78 & 95.21 & 13.39 & 13.20 \\
\hline Run 3 & 10 & 16.97 & 68.92 & 9.69 & 9.61 \\
\hline \multirow{3}{*}{$\begin{array}{l}{[98.9 \mathrm{~g}, 99.7 \mathrm{~mL},} \\
143.9 \mathrm{~mm}, 16.6 \mathrm{sec}]\end{array}$} & 200 & 22.34 & 89.92 & 12.65 & 12.54 \\
\hline & 1000 & 27.16 & 103.96 & 14.62 & 14.50 \\
\hline & 1950 & 37.61 & 111.67 & 15.71 & 15.57 \\
\hline Run 4 & 10 & 21.50 & 88.20 & 12.40 & 12.57 \\
\hline \multirow{3}{*}{$\begin{array}{l}{[97.9 \mathrm{~g}, 96.7 \mathrm{~mL}} \\
139.5 \mathrm{~mm}, 16.1 \mathrm{sec}]\end{array}$} & 200 & 27.46 & 111.41 & 15.67 & 15.87 \\
\hline & 1000 & 32.66 & 127.14 & 17.88 & 18.11 \\
\hline & 1950 & 43.61 & 135.25 & 19.02 & 19.27 \\
\hline
\end{tabular}




\subsection{Applications}

The present laboratory results suggested that, at $\mathrm{H}_{2} \mathrm{~S}$ breakthrough, the volumetric $\mathrm{S}$ chemisorption capacity of the cg5 commercial medium was approximately 8 to 59 times that of the Tor Street red soil (Tables 3.2 and 3.4, respectively). Consequently, the medium replacement interval for a cg5 column would be 8 to 59 times longer than for a red soil column with a similar volume and $\mathrm{H}_{2} \mathrm{~S}$ loading. At certain locations where suitable krasnozem/red ferrosol soils are available at a piggery site or within close proximity, the supply cost of the red soil may be negligible. However, the availability and low supply cost would need to be weighed up against increased labour costs for more frequent medium replacement because of the lower $\mathrm{H}_{2} \mathrm{~S}$ removal capacity of the red soil (Section 3.3.2). In this work, only two red soils were tested, as obtained from the local area. There are likely to be other naturally occurring red soils with different (and perhaps superior) $\mathrm{H}_{2} \mathrm{~S}$ removal capacities. Future work should test the $\mathrm{H}_{2} \mathrm{~S}$ removal capacity of other iron-rich soils (Section 5.4).

The increasing $\mathrm{H}_{2} \mathrm{~S}$ removal capacities observed in four successive red soil regeneration trials (Section 3.3.4) suggested that on-site regeneration at a piggery could extend the life of red soil filter media. Such regeneration could potentially be done inside the chemisorption column or in batch mode outside the column (Section 2.3.2.1). Future work could explore such regeneration options.

In comparison to the commercial cg5 medium, the relatively high pressure drop through the red soil (Section 3.3.3) would require the installation of a higher pressure blower driven by a more powerful motor consuming more energy. The addition of the ground SCM bulking agent to the red soil substantially reduced the pressure drop (and energy consumption). However, $\mathrm{H}_{2} \mathrm{~S}$ chemisorption capacity was reduced because of the dilution of the active ingredient (red soil), and the SCM may be prone to combustion during the exothermic regeneration process. Further in-field testing could assess the structural stability of the SCM following extended exposure to biogas saturated with moisture. The use of alternative heat and moisture resistant bulking agents may address such issues.

Alternative filter media, such as the red soil, could also instead provide polishing treatment after a primary biological $\mathrm{H}_{2} \mathrm{~S}$ removal step (Section 2.5). In this way, the bulk of the sulphur load could be removed by the biological step and then an alternative medium with 
low chemisorption capacity (such as red soil) could be used with manageable column volumes and longer medium replacement intervals. The performance of a biological treatment system is further explored in Chapter 4.

\subsection{Conclusions}

In the laboratory-scale study reported in this Chapter, the performance of several commercial and alternative $\mathrm{H}_{2} \mathrm{~S}$ sorption media was evaluated. Conclusions from this study can be summarised as follows:

- A superior performance of the commercial medium (cg5 pellets) reflected its engineered high porosity and high iron content.

- All carbon based materials, including granular activated carbon and biochar, showed poor $\mathrm{H}_{2} \mathrm{~S}$ removal, indicating that pure physi-sorption is not of primary importance at low pressures, such as in typical on-farm biogas installations.

- A red soil was the most promising alternative medium with reasonable chemisorption capacity (2 to $12 \mathrm{~g} \mathrm{~S} / \mathrm{kg}$ medium at breakthrough) and likely low cost and ready availability, at least at some localities.

- The crystalline structure of the iron-oxide minerals in red soil appeared to strongly influence its $\mathrm{H}_{2} \mathrm{~S}$ removal capacity.

- Pressure drop was generally high with the red soils (10 times that of the commercial $\mathrm{cg}_{5}$ pellets) but could be effectively reduced with a bulking agent, albeit at a loss of active treatment volume.

- An unexpected increase in $\mathrm{H}_{2} \mathrm{~S}$ sorption capacity was observed with regeneration of used red soil media in air, perhaps due to mechanical disruption or chemical reaction.

In summary, certain red soils appeared to be promising alternative $\mathrm{H}_{2} \mathrm{~S}$ sorption media, but require full-scale testing on-farm. Such full-scale trials were performed as outlined in Chapter 4 of the thesis. 


\section{On-farm trials of low-cost options for hydrogen sulphide removal from piggery biogas}

\subsection{Introduction}

The laboratory study in Chapter 3 identified naturally-occurring red soil as a potentially attractive chemisorption option to bind $\mathrm{H}_{2} \mathrm{~S}$ from piggery biogas. However, chemisorption performance measured in the laboratory could differ greatly from that at full-scale on-farm. For example, differences in reactor vessel dimensions may result in variable wall effects or more pronounced development of preferential flow paths with sub-optimal gas-solid contact in either the laboratory or on-farm scenarios. Furthermore, the on-farm biogas composition and flowrates are likely to vary widely. For these reasons, it was deemed necessary to test the performance of the red soil on-farm as presented in this present Chapter 4.

As noted in Section 2.3.2.4, biological oxidation on-farm could provide an effective means to reduce the bulk of the $\mathrm{H}_{2} \mathrm{~S}$ load on a subsequent chemisorption step. Biological oxidation requires the addition of a small quantity of oxygen into the biogas being treated, and also a nutrient source to support the growth and activity of the microorganisms removing the $\mathrm{H}_{2} \mathrm{~S}$ (Section 2.3.2.4). The feasibility of using treated effluent from a covered anaerobic lagoon (CAL) as the necessary nutrient source has also been examined in this present Chapter 4.

\subsection{Materials and methods}

\subsubsection{Chemisorption trials at Piggery A}

The $\mathrm{H}_{2} \mathrm{~S}$ chemisorption trials were carried out at piggery $(\mathrm{A})$, which is a breeder unit $(700$ sow capacity) previously described by Skerman and Collman (2012), located in south-east Queensland. At this piggery, the entire raw effluent stream discharged from the pig housing sheds is treated in an on-site anaerobic lagoon. Biogas produced by this treatment is captured and recovered by a self-supported floating cover over about $50 \%$ of the lagoon liquid surface area. The biogas produced and captured is directed through an experimental chemisorption column to a hot water boiler. The hot water from the boiler is circulated through underfloor heating pads, installed in the farrowing sheds, to provide 
optimal growing conditions for piglets up to weaning age. The biogas blower used to pressurise the captured biogas produces a maximum pressure of $3.5 \mathrm{kPa}$ on the upstream side of the test column.

The trials compared the on-farm $\mathrm{H}_{2} \mathrm{~S}$ removal performance of a red soil with that of a commercial medium. The properties of the red soil (Tor St, Toowoomba) and the commercial medium, cg5 iron oxide scavenger material, are described in Section 3.3.1. To ensure that the blower supply pressure noted above would be adequate to overcome the higher pressure loss of the red soil (Section 3.3.3), the red soil was mixed with ground sugar cane mulch (SCM, Rocky Point Mulching, Woongoolba Qld 4207) in the proportion $40 \%$ SCM by volume, prior to testing.

Figure 4.1 is a schematic drawing of the test apparatus at piggery (A). The chemisorption column was constructed from DN 300 mm UPVC pipe (ID $305 \mathrm{~mm}$ ) with solvent weld fittings (Fabfit, Stapylton Qld). The chemisorption media were contained in the lower section of the column, suspended above a plenum formed from stainless steel mesh, supported on a bed of DN $20 \mathrm{~mm}$ Class 12 UPVC pressure pipe, cut into $40 \mathrm{~mm}$ lengths, and randomly placed in the base of the column. This plenum had a total depth of approximately $250 \mathrm{~mm}$. A sheet of geotextile fabric was placed on top of the stainless steel mesh to minimise the potential for any fine media material to migrate into the underlying plenum. The upper and lower sections of the column were connected with a UPVC flanged joint, secured with stainless steel bolts and an insertion rubber gasket to provide a gastight seal. The flanged joint provided access for placement and removal of the media. Polyethylene pipe (NB $25 \mathrm{~mm}$ ) and BSP threaded fittings were used to connect the test column to the upstream and downstream 2" (NB $50 \mathrm{~mm}$ ) stainless steel pipelines. Pressurized by the upstream biogas blower near the anaerobic lagoon, the raw biogas entered the top of the column, passing through the media bed in a downward flow direction. Down-flow of biogas has been previously recommended for maintaining bed moisture and so that the biogas flows through the most heavily loaded section of the bed first (Section 2.3.2.1). The treated biogas was collected at the plenum in the base of the column, where a manually operated condensate drain prevented water blocking the outlet pipeline exiting the column through the plenum wall. 


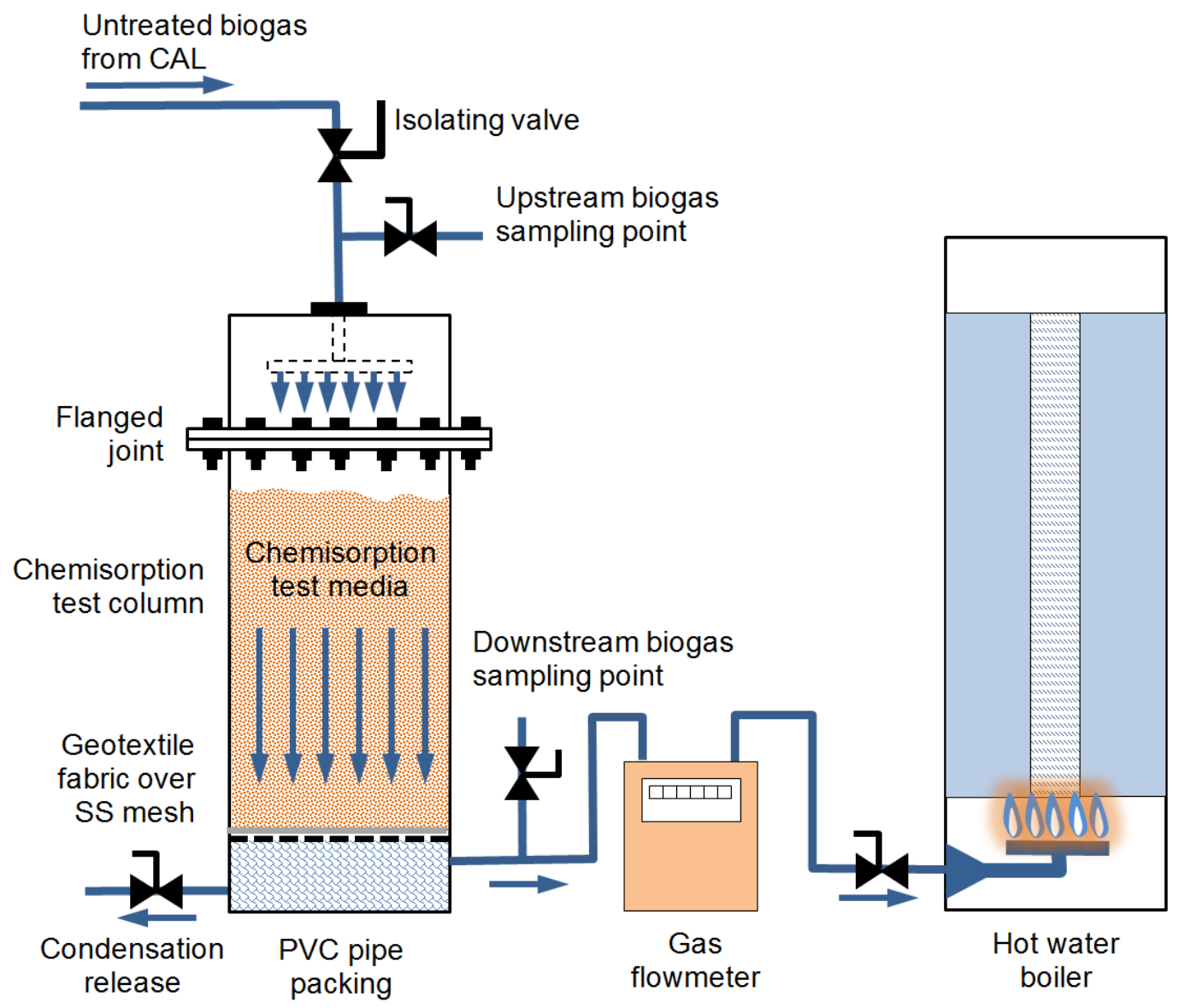

Figure 4.1 Schematic drawing of the test column and hot water boiler installed at piggery (A), as used in the on-farm trials.

A Landis+Gyr Model 750 gas meter, fitted with an Elster IN-Z61 pulse output kit, was installed to measure biogas flow through the test column and into the downstream hot water boiler. The pulse output from this meter was logged at 5 minute intervals using a HOBO UX120 4-channel data logger installed on the adjacent piggery shed wall. The composition of the biogas was measured upstream and downstream of the chemisorption column, using a Geotech Biogas 5000 portable analyser (Geotech, Leamington Spa, Warwickshire CV31 3JR, UK). This analyser measured the concentrations of the methane $\left(\mathrm{CH}_{4}\right)$, carbon dioxide $\left(\mathrm{CO}_{2}\right)$, oxygen $\left(\mathrm{O}_{2}\right)$, hydrogen sulphide $\left(\mathrm{H}_{2} \mathrm{~S}\right)$ and balance gases (assumed to be primarily nitrogen $\left(\mathrm{N}_{2}\right)$ and water vapour) in the biogas streams. The instrument was calibrated against two standard gas mixtures, one containing $60 \% \mathrm{CH}_{4}$ /

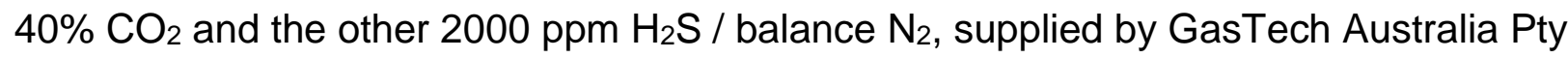
Ltd (Wangara WA 6065), in accordance with the manufacturer's procedures. Typical accuracies of the Biogas 5000 instrument were $\mathrm{CH}_{4} \pm 0.5 \%, \mathrm{CO}_{2} \pm 0.5 \%, \mathrm{O}_{2} \pm 1.0 \%$ and $\mathrm{H}_{2} \mathrm{~S} \pm 100 \mathrm{ppm}$ over a $0-5000 \mathrm{ppm}$ range, according to the manufacturer's 
specifications. A TSI Model 8705 DP-CALC ${ }^{\text {TM }}$ micro-manometer was used to measure pressure drop across the test column.

The three media (cg5, red soil+SCM 1 and red soil+SCM 2) were tested over three discrete tests carried out independently. To perform a test, the medium was loaded into the test column, with the upstream biogas line isolated and the biogas blower turned off. The total medium depths in the column, bed void fractions, biogas contact volumes and residence times during the two red soil+SCM trials and the single cg5 trial, are summarised in Table 4.1.

Once the media was loaded, the biogas blower was turned on, the isolating valve upstream from the test column was opened, the pipeline system was purged of air via the condensate release line, a leak check was performed using soapy water, the isolating valve downstream from the test column was opened, and the hot water boiler was started. The hot water boiler operated continuously throughout the red soil+SCM trials and intermittently during the cg5 trial because of a period of interruption for about one month when the anaerobic lagoon was being desludged (Section 4.3.1). During the two red soil+SCM trials and the single cg5 trial, the average biogas flowrates were 41, 44 and $37 \mathrm{~L} / \mathrm{min}$, respectively. Table 4.1 shows the basic physical characteristics of the media and the test conditions during the on-farm trials.

Table 4.1 Basic physical characteristics and test conditions for the on-farm trials carried out on the two red soil+sugar cane mulch (SCM) mixtures and cg5 media.

\begin{tabular}{lllll}
\hline Parameter & Units & Red soil+SCM 1 & Red soil+SCM 2 & cg5 \\
\hline Mass & $\mathrm{kg}$ & 22.34 & 36.14 & 34.22 \\
Volume & $\mathrm{L}$ & 29.96 & 48.36 & 48.95 \\
Depth & $\mathrm{m}$ & 0.41 & 0.66 & 0.67 \\
Bulk density & $\mathrm{kg} / \mathrm{m}^{3}$ & 750 & 750 & 700 \\
Bed void fraction & $\%$ & 69 & 69 & 76 \\
Pore volume & $\mathrm{L}$ & 20.55 & 33.08 & 37.11 \\
Depth / diameter & & 1.3 & 2.2 & 2.2 \\
Mean biogas flowrate & $\mathrm{L} / \mathrm{min}$ & 40.8 & 44.1 & 37.2 \\
Mean superficial flow velocity & $\mathrm{m} / \mathrm{min}$ & 0.58 & 0.60 & 0.51 \\
Mean biogas residence time & $\mathrm{sec}$ & 42 & 66 & 79 \\
\hline
\end{tabular}

Biogas composition was measured in triplicate, upstream and downstream of the test column, and biogas flow meter readings were also recorded during regular site visits, 
generally on a daily basis for the cg5 trial and approximately hourly during the red soil+SCM trials. The flow meter data logger recorded at a 5-minute frequency and the data were downloaded at the end of each media trial.

The resulting $\mathrm{H}_{2} \mathrm{~S}$ concentration and biogas flow data were used to calculate the mass of $S$ removed by chemisorption for each medium, on a volumetric and mass basis. The $S$ chemisorption mass was plotted against the downstream $\mathrm{H}_{2} \mathrm{~S}$ concentrations for comparison with the laboratory trial data outlined in Chapter 3.

For the cg5 medium, two phase exponential curves (Equations 4.1 and 4.2) were empirically fitted to the on-farm and laboratory data using Genstat software (Payne et al., 2011) and the solver function in Microsoft Excel® to minimise the sum of the squares of the differences between measured and modelled values:

$R=A 1+B 1 \cdot K 1^{x}$ when $\mathrm{x}<\mathrm{C}$ Equation 4.1

$R=A 2+B 2 \cdot K 2^{(x-C)}$ when $\mathrm{x}<\mathrm{C}$ Equation 4.2

Where: $R=$ Downstream $\mathrm{H}_{2} \mathrm{~S}$ concentration; $A 1, A 2, B 1, B 2, K 1, K 2$ and $C$ are empirical fitted parameter values and $x=$ Mass of $S$ chemisorbed ( $\mathrm{g} \mathrm{S} / \mathrm{kg}$ medium).

For the red soil+SCM medium, erratic results did not permit any meaningful curve fitting, so the raw data were instead directly quantitatively interpreted.

The pressure drop across the column was measured at the start, end and at various times throughout the trials. These pressure drop readings were compared with the values measured in the laboratory trials (Section 3.3.3) to assess any difference at full-scale. The Ergun equation (Equation 3.3) was also used to calculate pressure drops across the column.

$\frac{\Delta P}{H}=150 \frac{\mu U(1-\varepsilon)^{2}}{\bar{x}_{S V}{ }^{2} \varepsilon^{3}}+1.75 \frac{\rho_{f} U^{2}(1-\varepsilon)}{\bar{x}_{S V} \varepsilon^{3}}$ Equation 3.3

where $\mu$ in this case is the biogas dynamic viscosity $\left(1.22 \times 10^{-5} \mathrm{~Pa} . \mathrm{s}\right.$ at $20^{\circ} \mathrm{C}$ and $104,825 \mathrm{~Pa}$, interpolated from Haynes, 2016, based on a biogas composition of $67 \% \mathrm{CH}_{4}$ 
and $\left.33 \% \mathrm{CO}_{2}\right)$, and $\rho_{f}$ in this case is the biogas density $\left(1.086 \mathrm{~kg} / \mathrm{m}^{3}\right.$ at $20^{\circ} \mathrm{C}$ and $104,825 \mathrm{~Pa}$, interpolated from Haynes, 2016, based on a similar biogas composition). The values of the surface-volume mean diameters for the $\mathrm{cg}_{5}$ and red soil+SCM particles were estimated using the Microsoft Excel${ }^{\circledR}$ solver function, by minimising the sum of squares of the differences between measured values and values calculated using the Ergun equation.

\subsubsection{Biological $\mathrm{H}_{2} \mathrm{~S}$ removal trials at Piggery (B)}

The biological $\mathrm{H}_{2} \mathrm{~S}$ removal trial was performed at a grower-finisher piggery (B) located in the south-west slopes region of NSW (Australia), near Young, and accommodating 15,000 weaner to finisher pigs ( $8-100 \mathrm{~kg}$ live weight). A covered anaerobic lagoon (CAL) installed at this piggery treats raw effluent flushed from the sheds, supplying sufficient biogas to fuel two $80 \mathrm{~kW}$ Combined Heat and Power (CHP) generators. Some residual biogas is also flared. Prior to the installation of the biological $\mathrm{H}_{2} \mathrm{~S}$ removal system, biogas was solely treated using chemisorption with commercial iron oxide pellets in $2 \times 500 \mathrm{~L}$ parallel vessels, each holding about $300 \mathrm{~L}$ of filter medium. At this piggery, the owners aimed to install and operate a biological $\mathrm{H}_{2} \mathrm{~S}$ removal system to reduce the bulk of the $\mathrm{H}_{2} \mathrm{~S}$ in the biogas, with the downstream chemisorption then further polishing the biogas of any remaining $\mathrm{H}_{2} \mathrm{~S}$. The biological $\mathrm{H}_{2} \mathrm{~S}$ removal system was largely designed by the piggery owners and was fabricated and installed using local and on-farm labour. A series of five tests was carried out to assess the operational performance of the system over a 2-day intensive monitoring period. However, the system had been operating for some months prior to this, treating the entire biogas flow onsite to an unmeasured extent.

The biological oxidation vessel (Figure 4.2) was a 10,000 L fibreglass (FRP) rainwater tank (Tankworld, dia $2.56 \mathrm{~m}$ at mid-height, total height $2.2 \mathrm{~m}$ ) sourced from a local supplier. Approximately $7.7 \mathrm{~m}^{3}$ of general plastic packing (PALL-Rings, dimensions $25 \times 25 \mathrm{~mm}$ ) was sourced from Pingxiang Naike Chemical Industry Equipment Packing Co Ltd, China, providing an approximate packing depth of $1.5 \mathrm{~m}$ in the biological oxidation vessel. The packing was supported on plastic milk crates (approximate height $0.4 \mathrm{~m}$ ) placed on the base of the vessel, forming a plenum or underdrain, to allow uniform distribution of the inlet biogas across the entire cross-section of the packed column. A layer of plastic mesh was placed over the crates to retain the packing elements. The biogas inlet was installed on the side of the vessel, just above the base, so that biogas flowed up through the packing, exiting through an outlet at the top of the vessel. A 1 m diameter flanged cover on the side 
wall of the vessel allowed easier removal of the packing material for cleaning, at approximately 10-monthly intervals; however, the packing material was not cleaned directly before or during the trial. The biogas inlet and outlet pipelines were $100 \mathrm{~mm}$ DN UPVC pressure pipe (SWJ). A single nozzle installed through the roof of the vessel sprayed effluent, recycled from the nearby CAL outlet, reasonably evenly over the plastic packing, at a measured flow rate of $0.17 \pm 0.01 \mathrm{~L} / \mathrm{sec}$. This resulted in counter-current flow of liquid and biogas. The liquid effluent gradually drained through the packing and was collected from the base of the vessel before being pumped to an on-site Sedimentation and Evaporation Pond System (SEPS).

Normal operation of the biological oxidation system relied on air being passively drawn into the biogas stream through a tapping saddle installed in the biogas delivery pipeline, just upstream from the biological oxidation vessel. The biogas blower installed downstream from the vessel created a small negative pressure at the air injection point. A valve was provided on the air injection line to allow adjustment of the air injection rate. However, prior to the commencement of the trial, this passive air injection system was found to be unreliable/poorly controlled. Consequently, a refurbished positive displacement compressor, provided by the piggery operators, was connected to the inlet tapping saddle to positively inject air into the flowing biogas stream at a near-constant measured flowrate of $3.6 \pm 0.1 \mathrm{~m}^{3} / \mathrm{h}$ (Figure 4.2). This air flowrate resulted in $2.3-6.0 \%$ air (by volume) in the biogas stream, which is within the recommended range to support the biological oxidation of $\mathrm{H}_{2} \mathrm{~S}$ (2 to $6 \%$, Section 2.3.1.1).

The composition of the biogas upstream and downstream from the biological oxidation vessel was measured from tapping saddles with sampling valves, using the same Geotech Biogas 5000 portable analyser used in the chemisorption $\mathrm{H}_{2} \mathrm{~S}$ removal trials described in Section 4.2.1.

The upstream sampling point was located directly upstream from the air injection port (measuring the raw biogas as extracted from the CAL before mixing with air). A rotating vane anemometer (TSI VelociCalc Plus, Model 8324-M-GB, Rev 2.3, USA) was installed in the biogas pipeline, downstream of the biological oxidation vessel, to measure biogas flowrate during the trial, but was removed after the trial for normal operation. 


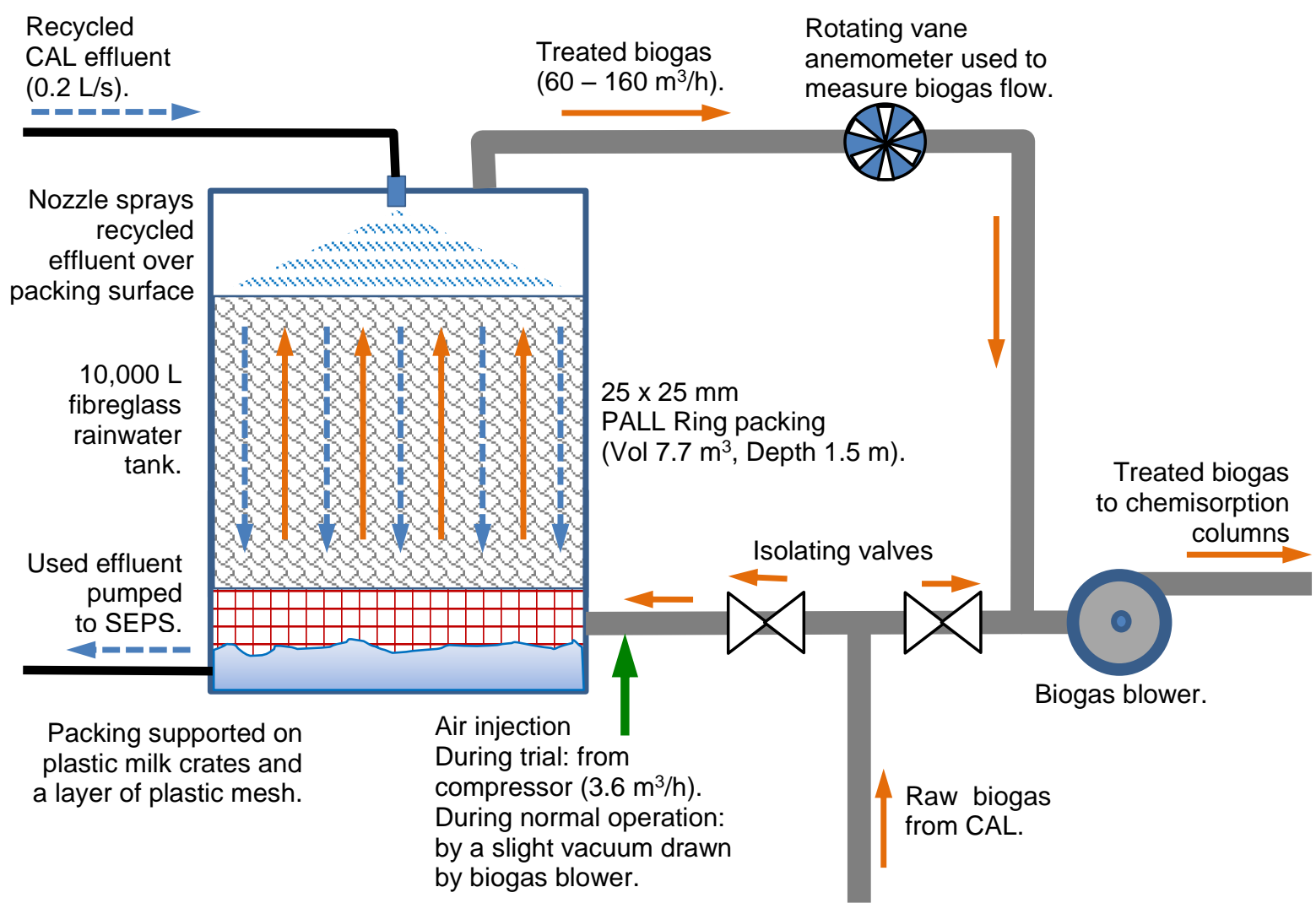

Figure 4.2 Schematic drawing of the biological $\mathrm{H}_{2} \mathrm{~S}$ removal system trialled at piggery (B).

Following some preliminary tests to confirm the system operation, biogas composition was measured over a two-day period, both upstream and downstream of the biological oxidation vessel, and less frequently after the downstream chemisorption step. During this trial period, biogas flowrates through the biological oxidation vessel were varied from the usual $140-160 \pm 2 \mathrm{~m} / \mathrm{h}$ (two generators operational, and some biogas transfer to another piggery, representing the normal scenario - Test 1) to $62 \pm 2 \mathrm{~m}^{3} / \mathrm{h}$ (one generator operational - Test 2), to $145 \pm 2 \mathrm{~m}^{3} / \mathrm{h}$ (normal - Test 3), to $100 \pm 2 \mathrm{~m}^{3} / \mathrm{h}$ (two generators operational, no transfer to other piggery - Test 4) and back to $160 \pm 2 \mathrm{~m} / \mathrm{h}$ (normal - Post test). The biogas flowrates were varied by adjusting the valves that bypassed biogas around the biological oxidation vessel (Figure 4.2) or by switching off a generator. Three to five replicate measurements were taken at each of the biogas flowrates, with at least a 30minute interval after the biogas flow-rate was changed. A post-trial measurement was also performed, once the treatment system had been returned to normal operation, with air being passively drawn in by the downstream biogas blower, rather than being injected under positive pressure using the compressor. 


\subsection{Results and discussion}

\subsubsection{Chemisorption trials at Piggery (A)}

Figures 4.3, 4.4 and 4.5 show the measured biogas composition, upstream and downstream of the test column, plotted against cumulative biogas volumes treated by the test column for the two red soil+SCM and single cg5 trials. The mean $\mathrm{O}_{2}$ concentrations measured for each of the three trial media were less than $0.05 \pm 0.02 \%$ which was less than the typical instrument accuracy $( \pm 1.0 \%)$. Table 4.2 outlines the mean concentrations of $\mathrm{CH}_{4}, \mathrm{CO}_{2}$, balance gas and $\mathrm{H}_{2} \mathrm{~S}$ measured upstream and downstream from the test column. Over most of the trial period, the test column did not significantly influence $\mathrm{CH}_{4}$, $\mathrm{CO}_{2}$ and balance gas concentrations $(\mathrm{P}>0.05) . \mathrm{CH}_{4}, \mathrm{CO}_{2}$ and balance gas concentrations measured during this trial were similar to those reported by Skerman (2013) for biogas from the same CAL, over an earlier 14-month period. However, the upstream $\mathrm{H}_{2} \mathrm{~S}$ concentrations recorded in the present trials were significantly lower than the $\mathrm{H}_{2} \mathrm{~S}$ concentrations also reported by Skerman (2013) for the earlier trial. Possible causes for this discrepancy include variability in ambient temperature affecting pond effluent temperature and $\mathrm{H}_{2} \mathrm{~S}$ solubility, variations in pig diets (depending on fluctuating cost of feed ingredients), increasing levels of sludge accumulation over time, and use of disinfectants and other animal health treatments.

The cg5 trial was interrupted by desludging of the CAL when the cumulative biogas flow volume through the test column was about $2,700 \mathrm{~m}^{3}$. During the desludging period, the test column was isolated and gas-tight, to not expose the media to air. After desludging, the pond was refilled with a mixture of bore water and recycled secondary pond effluent. Following reconnection of the biogas pipeline and associated biogas use equipment, biogas started accumulating under the cover almost immediately. When the cg5 trial resumed, following completion of desludging, there was a notable increase in $\mathrm{CH}_{4}$ concentrations (from $62 \%$ to $73 \%$ ), and a decrease in $\mathrm{CO}_{2}$ (from $36 \%$ to $26 \%$ ) and $\mathrm{H}_{2} \mathrm{~S}$ (1,883 to $1,102 \mathrm{ppm}$ ) concentrations compared to the pre-desludging concentrations (Figure 4.5). These changes could have resulted from the altered composition of the CAL, differences in gas solubilities and changes in microbial activity. While the pond desludging affected upstream $\mathrm{H}_{2} \mathrm{~S}$ concentrations, the test column was sealed during the desludging period to prevent air ingress and possible re-oxidation of the cg5 media. 
Figures 4.6 and 4.7 show the $S$ chemisorption masses, per unit mass of medium, plotted against downstream $\mathrm{H}_{2} \mathrm{~S}$ concentrations for the on-farm and laboratory trials, as reported in Chapter 3. Table 4.3 gives the masses of chemisorbed $S$ per unit mass of red soil by the red soil+SCM, cg5 and red soil media, for both the on-farm and laboratory trials at a range of downstream $\mathrm{H}_{2} \mathrm{~S}$ concentrations.
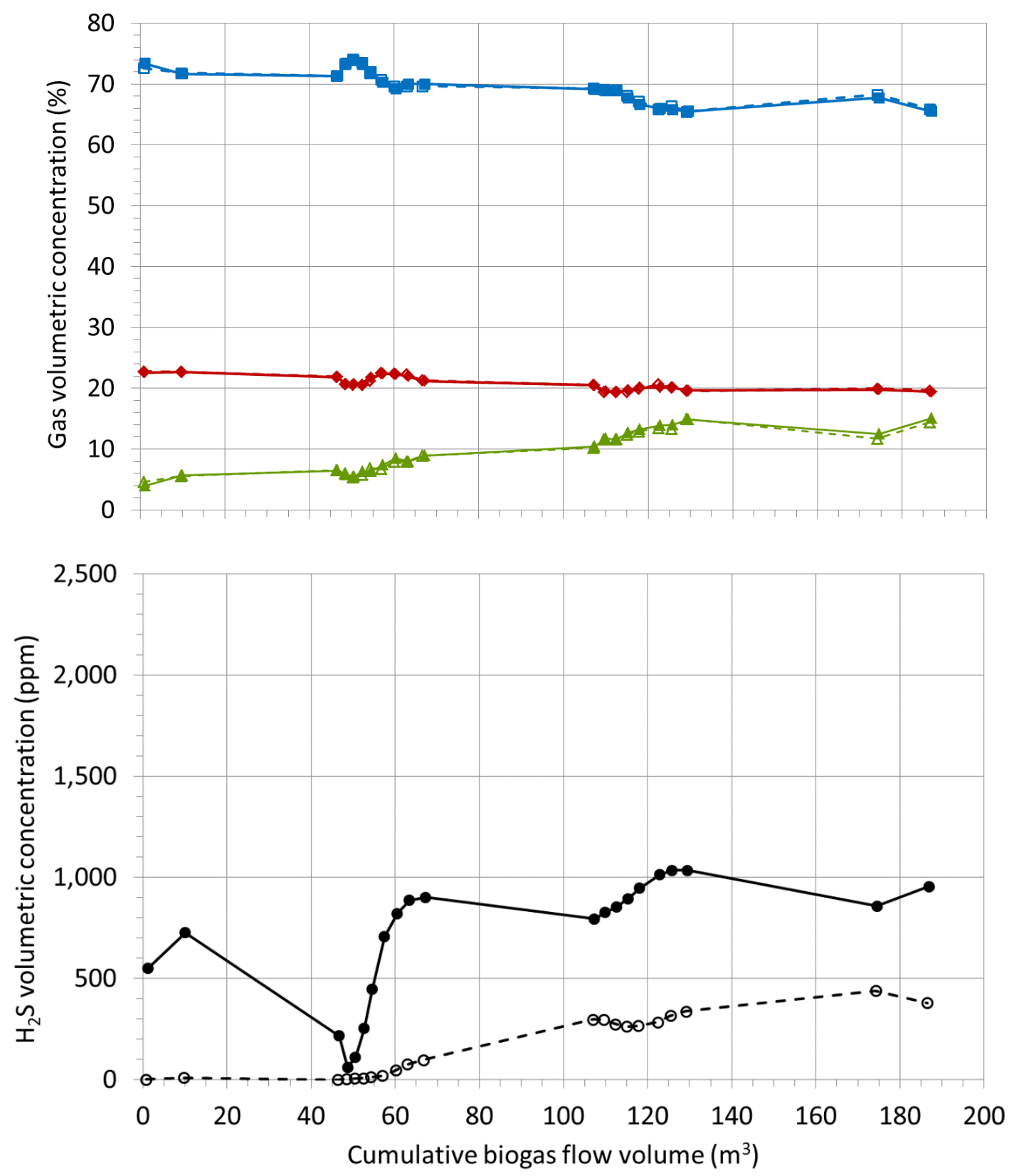

Figure 4.3 Volumetric concentrations of $\mathrm{CH}_{4}(\square), \mathrm{CO}_{2}(\diamond)$, balance gas $(\Delta)$ and $\mathrm{H}_{2} \mathrm{~S}(\bullet)$ measured upstream and downstream from the test column, plotted against the cumulative biogas volume treated in the column for the on-farm red soil+SCM 1 trial. Filled markers and full lines represent upstream concentrations while unfilled markers and dashed lines represent downstream concentrations. 

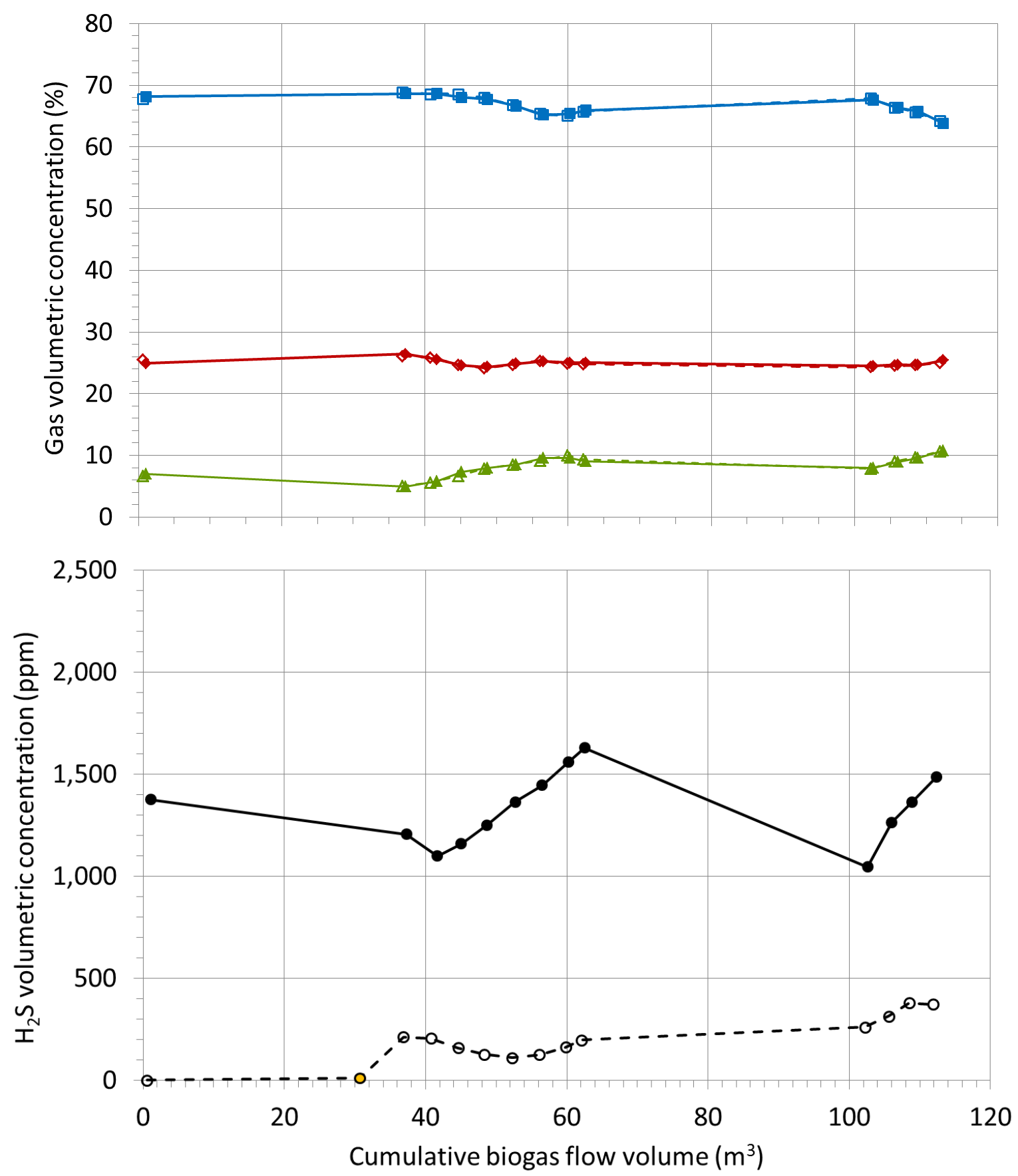

Figure 4.4 Volumetric concentrations of $\mathrm{CH}_{4}(\square), \mathrm{CO}_{2}(\diamond)$, balance gas $(\Delta)$ and $\mathrm{H}_{2} \mathrm{~S}(\bullet)$ measured upstream and downstream from the test column, plotted against the cumulative biogas volume treated in the column for the on-farm red soil+SCM 2 trial. Filled markers and full lines represent upstream concentrations while unfilled markers and dashed lines represent downstream concentrations. 

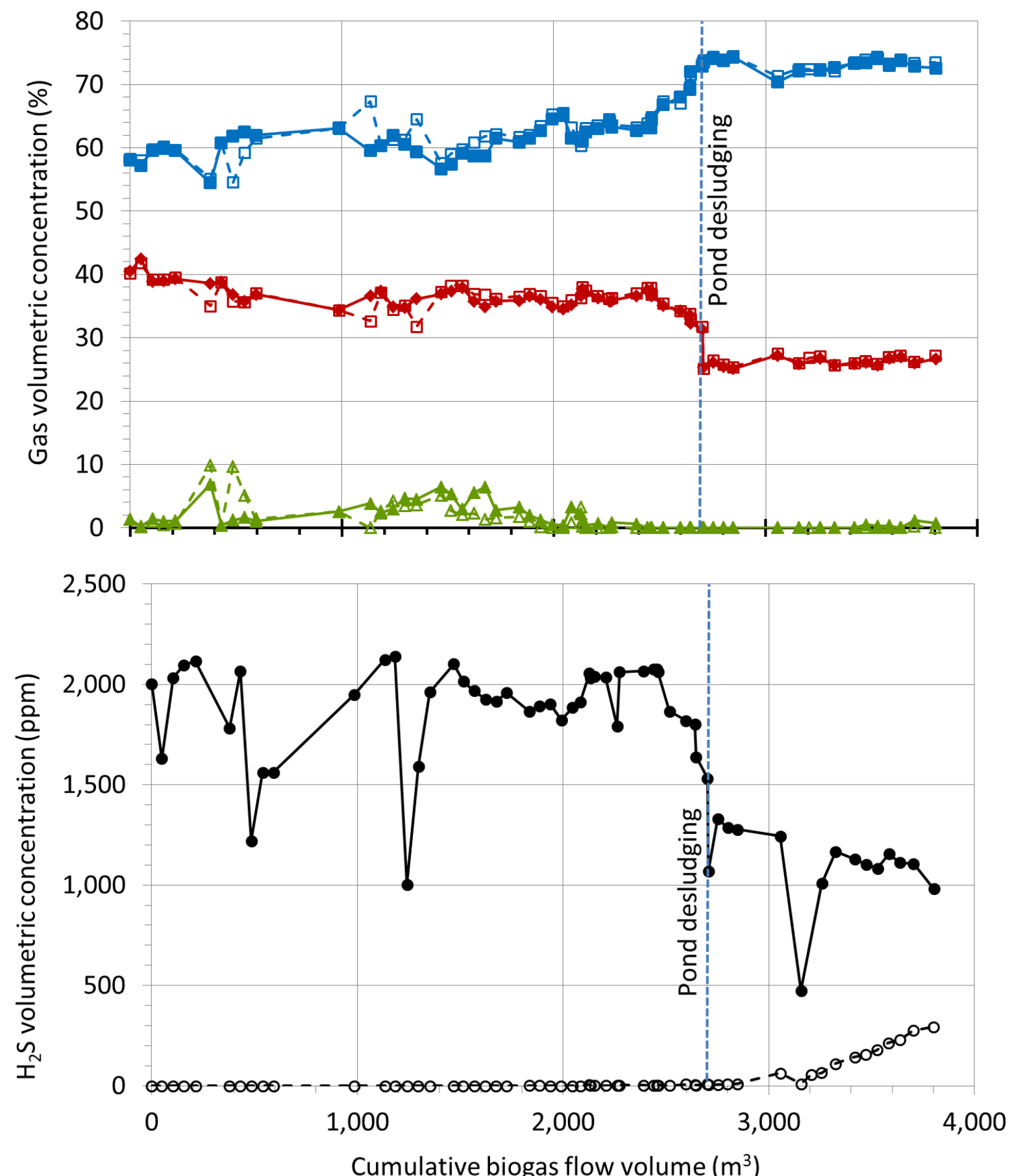

Figure 4.5 Volumetric concentrations of $\mathrm{CH}_{4}(\square), \mathrm{CO}_{2}(\diamond)$, balance gas $(\triangle)$ and $\mathrm{H}_{2} \mathrm{~S}(\bullet)$ measured upstream and downstream from the test column, plotted against the cumulative biogas volume treated in the column for the on-farm cg5 medium trial. Filled markers and full lines represent upstream concentrations while unfilled markers and dashed lines represent downstream concentrations. 
Table 4.2 Mean concentrations and 95\% confidence intervals for $\mathrm{CH}_{4}, \mathrm{CO}_{2}$, balance gases and $\mathrm{H}_{2} \mathrm{~S}$, measured upstream (US) and downstream (DS) of the chemisorption column, for the two red soil+SCM trials and the single cg5 trial.

\begin{tabular}{lllll}
\hline Medium / Trial & $\mathrm{CH}_{4}$ & $\mathrm{CO}_{2}$ & Balance & $\mathrm{H}_{2} \mathrm{~S}$ \\
\hline Red soil+SCM trial 1 US & $69.5 \pm 0.7^{\mathrm{c}}$ & $20.8 \pm 0.3^{\mathrm{a}}$ & $9.7 \pm 0.9^{\mathrm{c}}$ & $709 \pm 77^{\mathrm{c}}$ \\
Red soil+SCM trial 1 DS & $69.7 \pm 0.7^{\mathrm{c}}$ & $20.8 \pm 0.3^{\mathrm{a}}$ & $9.4 \pm 0.8^{\mathrm{c}}$ & $161 \pm 39^{\mathrm{b}}$ \\
\hline \% decrease (US $\rightarrow$ DS) & $-0.26 \%$ & $-0.21 \%$ & $2.51 \%$ & $77.29 \%$ \\
\hline Red soil+SCM trial 2 US & $66.8 \pm 0.9^{\mathrm{b}}$ & $25.0 \pm 0.3^{\mathrm{b}}$ & $8.2 \pm 1.0^{\mathrm{b}}$ & $1,326 \pm 106^{\mathrm{d}}$ \\
Red soil+SCM trial 2 DS & $66.9 \pm 0.5^{\mathrm{b}}$ & $25.0 \pm 0.2^{\mathrm{b}}$ & $8.2 \pm 0.5^{\mathrm{b}}$ & $202 \pm 34^{\mathrm{b}}$ \\
\hline$\%$ decrease (US $\rightarrow$ DS) & $-0.14 \%$ & $0.17 \%$ & $0.78 \%$ & $84.74 \%$ \\
\hline cg5 US & $64.9 \pm 0.9^{\mathrm{a}}$ & $33.8 \pm 0.7^{\mathrm{c}}$ & $1.5 \pm 0.3^{\mathrm{a}}$ & $1,681 \pm 62^{\mathrm{e}}$ \\
cg5 DS & $65.5 \pm 0.9^{\mathrm{ab}}$ & $33.7 \pm 0.7^{\mathrm{c}}$ & $1.2 \pm 0.3^{\mathrm{a}}$ & $32 \pm 11^{\mathrm{a}}$ \\
\hline$\%$ decrease (US $\rightarrow$ DS) & $-0.93 \%$ & $0.21 \%$ & $20.47 \%$ & $98.12 \%$ \\
\hline abcde
\end{tabular}

abcde Means in a column with different superscripts differ significantly $(\mathrm{P}<0.05)$.

Table 4.3 Mass of S removed by chemisorption, per unit mass of red soil, by the red soil+SCM, cg5 and red soil media, for both the on-farm and laboratory trials at a range of downstream $\mathrm{H}_{2} \mathrm{~S}$ concentrations. The laboratory and on-farm cg5 values were interpolated from curves fitted to the experimental data (Sections 3.2.3 and 4.2.1, respectively). All other values were linearly interpolated from the experimental data.

\begin{tabular}{|c|c|c|c|c|c|c|}
\hline \multirow{3}{*}{$\begin{array}{l}\text { Downstream } \mathrm{H}_{2} \mathrm{~S} \\
\text { concentrations } \\
(\mathrm{ppm})\end{array}$} & \multicolumn{6}{|c|}{ S chemisorption mass (g S/kg red soil) } \\
\hline & \multicolumn{3}{|c|}{ On-farm } & \multicolumn{3}{|c|}{ Laboratory } \\
\hline & $\begin{array}{l}\text { Red soil+ } \\
\text { SCM } 1\end{array}$ & $\begin{array}{l}\text { Red soil+ } \\
\text { SCM } 2\end{array}$ & cg5 & $\begin{array}{l}\text { Red soil+ } \\
\text { SCM }\end{array}$ & Red soil & cg5 \\
\hline 10 & 1.68 & 1.17 & 186 & 0.92 & 2.88 & 147 \\
\hline 20 (breakthrough) & 1.80 & 1.68 & 195 & 1.12 & 2.95 & 156 \\
\hline 50 & 1.97 & 1.70 & 208 & 1.45 & 3.06 & 167 \\
\hline 100 & 2.35 & 1.75 & 217 & 1.78 & 3.23 & 176 \\
\hline 150 & 2.80 & $1.79 / 2.87^{1}$ & 222 & 2.00 & 3.40 & 181 \\
\hline 200 & 3.25 & $1.83 / 3.18^{1}$ & 226 & 2.17 & 3.60 & 185 \\
\hline 250 & 3.71 & 4.69 & 229 & 2.44 & 3.78 & 187 \\
\hline 300 & 4.86 & 5.09 & 232 & 2.66 & 3.91 & 193 \\
\hline 400 & 6.19 & & 236 & 2.84 & 4.11 & 201 \\
\hline 500 & & & 239 & 3.53 & 4.26 & 208 \\
\hline 1000 & & & 248 & 4.07 & 5.71 & 229 \\
\hline 1500 & & & 254 & 0.75 & 10.97 & 242 \\
\hline 2000 & & & 258 & & & 251 \\
\hline
\end{tabular}

${ }^{1}$ There are two ordinate (S chemisorption mass) values at some $\mathrm{H}_{2} \mathrm{~S}$ concentrations (Figure 4.6). 


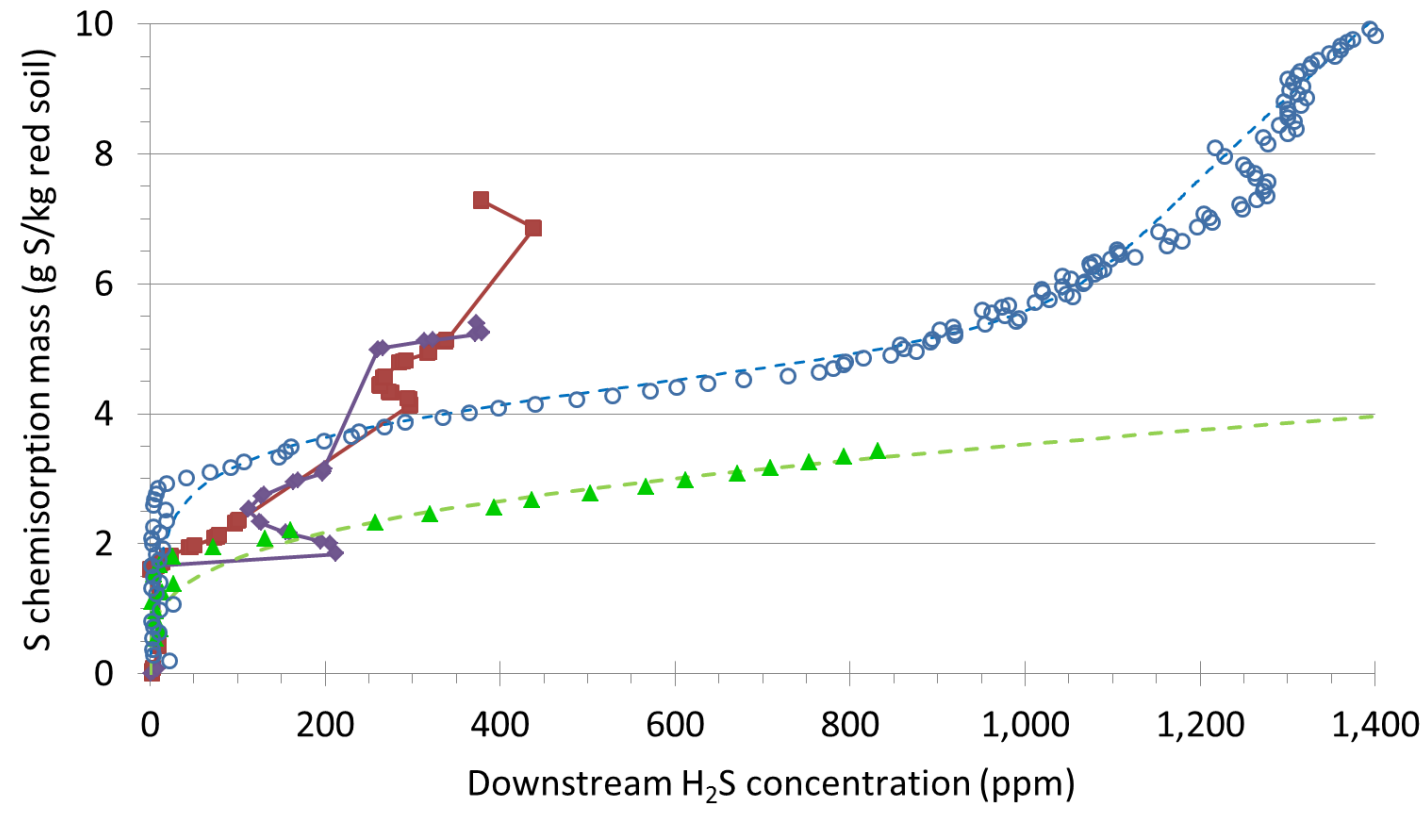

Figure 4.6 Mass of $\mathrm{S}$ removed by chemisorption, per unit mass of red soil, plotted against downstream $\mathrm{H}_{2} \mathrm{~S}$ concentrations, for the on-farm Red soil+SCM 1 ( $\square$ ), on-farm Red soil+SCM $2(\diamond)$, laboratory Red soil+SCM $(\Delta)$ and laboratory red soil only $(O)$ trials. Dashed lines are the two-phase exponential curves fitted to the laboratory data (Section 3.2.3).

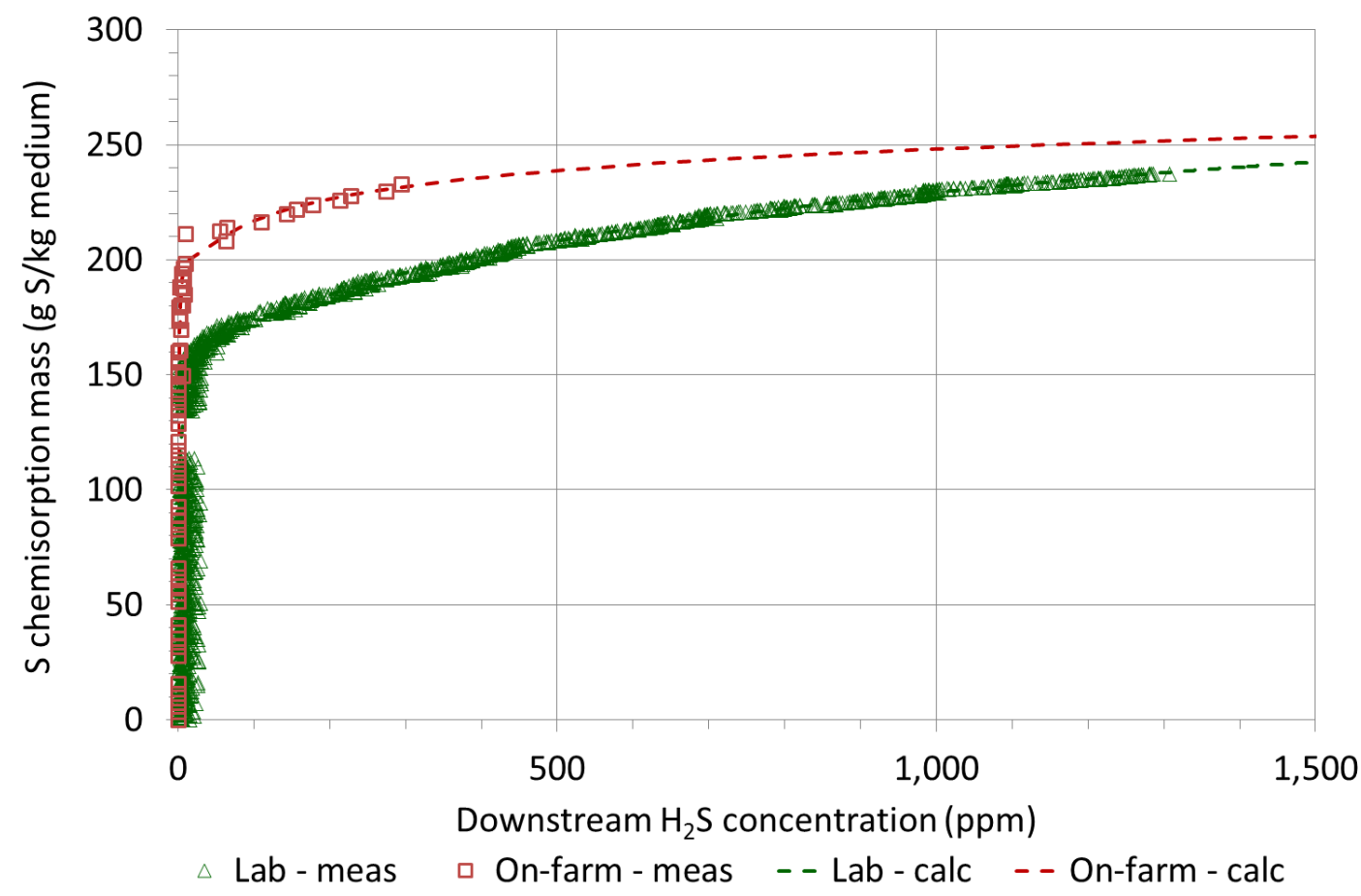

Figure 4.7 Mass of $\mathrm{S}$ removed by chemisorption, per unit mass of $\mathrm{cg} 5$ medium, plotted against downstream $\mathrm{H}_{2} \mathrm{~S}$ concentrations, for the on-farm $(\square)$ and laboratory $(\Delta)$ trials carried out using the cg5 medium. Dashed lines are the two-phase exponential curves fitted to the laboratory and on-farm data (Sections 3.2.3 and 4.2.1, respectively). 
Assuming a nominal downstream $\mathrm{H}_{2} \mathrm{~S}$ concentration of $20 \mathrm{ppm}$ at breakthrough, from Table 4.3, the breakthrough capacities of the two on-farm red soil+SCM media (1.8 and $1.7 \mathrm{~g} \mathrm{~S} / \mathrm{kg}$ red soil) were higher than the value recorded in the laboratory trial $(1.1 \mathrm{~g} \mathrm{~S} / \mathrm{kg}$ red soil) but lower than the value recorded for the straight red soil laboratory trial (3.0 g S/kg red soil). Following breakthrough, the $\mathrm{H}_{2} \mathrm{~S}$ chemisorption behaviour of the red soil+SCM was quite erratic, with what seemed to be intermittent recovery of $\mathrm{H}_{2} \mathrm{~S}$ removal capacity. Specifically, the red soil+SCM 2 curve initially followed the laboratory red soil+SCM curve quite closely, before 'reviving' and following the red soil+SCM 1 curve at a downstream $\mathrm{H}_{2} \mathrm{~S}$ concentration of approximately 100 ppm. Similar temporary 'revival' behaviour was also observed at higher downstream $\mathrm{H}_{2} \mathrm{~S}$ concentrations in the red soil+SCM 2 trial, and to a lesser extent at very high $\mathrm{H}_{2} \mathrm{~S}$ concentrations in the laboratory red soil trial. This erratic chemisorption behaviour could be due to the relatively coarse nature of the SCM and the lack of homogeneity in the red soil+SCM mixture resulting in the development of preferential flow paths, premature breakthrough of $\mathrm{H}_{2} \mathrm{~S}$ and lower overall S sorption capacities per unit mass of red soil. However, the progressive development of multiple preferential flow paths through the media, exposing the $\mathrm{H}_{2} \mathrm{~S}$ to previously inaccessible reactive surface area and chemisorption sites within the red soil+SCM structure may have triggered the observed temporary revival of $\mathrm{H}_{2} \mathrm{~S}$ removal ability. In addition, the recovery of $\mathrm{H}_{2} \mathrm{~S}$ removal could have been due to a corresponding decrease in the inlet $\mathrm{H}_{2} \mathrm{~S}$ concentration. However, in-situ regeneration of the media by minute traces of $\mathrm{O}_{2}$ in the biogas entering the chemisorption column may provide a plausible alternative explanation. The specialty cylinder gas used in the laboratory trials (Chapter 3) was highly unlikely to have been contaminated with $\mathrm{O}_{2}$. However, it is possible that the biogas entering the chemisorption column at piggery $(A)$ could have contained traces of $\mathrm{O}_{2}$, at concentrations too low to be detected by the biogas analyser. These traces of residual $\mathrm{O}_{2}$ in the biogas entering the column could have partially regenerated the ironsulphide in the medium.

Future work could also explore whether fermentation-related mechanisms affiliated with the lignocellulosic materials in SCM contribute to $\mathrm{H}_{2} \mathrm{~S}$ removal with red-soil+SCM mixtures.

Similarly to the laboratory results (Section 3.3.2), the cg5 media recorded much higher breakthrough capacities in the on-farm trials (156 and $195 \mathrm{~g} \mathrm{~S} / \mathrm{kg}$ cg5) compared to the red soil or red soil+SCM media. Furthermore, both the red soil+SCM and cg5 media recorded higher breakthrough capacities in the on-farm trials (this Chapter) compared to 
the laboratory trials (Chapter 3 ). However, the sulphur binding capacity stated in the manufacturer's product brochure (250 g S/kg cg5 medium, ACP Technologies Inc, 2012) was never achieved at breakthrough, in either the laboratory (Chapter 3) or the on-farm (this Chapter) trials. Given the optimum 3:1 to 6:1 vessel height to diameter ratio range specified in the cg5 product brochure (ACP Technologies Inc, 2012), vessel and bed dimensions could have contributed to the less than optimum performance. Assuming that the medium depth would typically be $80 \%$ of the vessel height, the laboratory trials met the manufacturer's recommendation with medium depth to diameter ratios of approximately 5; however, the on-farm trials had lower medium depth to diameter ratios of 1.3, 2.2 and 2.2, respectively, for the red soil+SCM 1, red soil+SCM 2 and cg5 trials.

The ratios of the column diameters to the media particle dimensions were substantially higher for the on-farm trials. This may have reduced the tendency for flow short-circuiting around the perimeter of the column (edge effects) and/or the establishment of preferential flow paths through the on-farm media beds. Lastly, similar to the red soils, it is possible that traces of $\mathrm{O}_{2}$ entering the biogas could have caused some partial regeneration of ironsulphide in the medium bed, thereby improving the on-farm performance of the cg5 medium.

Results from pressure drop measurements are summarised in Table 4.4 and Figure 4.8. As expected, Figure 4.8 shows a general increase in the measured pressure drop across the chemisorption column with increasing biogas flow velocity. This trend is also clearly evident in the plots of the pressure drops calculated using the Ergun equation (Ergun, 1952). The values of the surface-volume mean diameters $\left(\bar{x}_{S V}\right)$ of the packed bed particles used in the Ergun equation to give the best fit with the measured values were 64.41, 69.14 and $316.21 \mu \mathrm{m}$ for the red soil+SCM 1, red soil+SCM 2 and cg5 trials respectively. Compared to the surface-volume mean diameter values determined from the laboratory trials, the on-farm trial results for the red soil+SCM values are similar, however, the cg5 value is substantially higher (Section 3.3.3). The pressure drop values calculated using the Ergun equation for the on-farm red soil+SCM 1 trial were approximately 0.15 to $0.20 \mathrm{kPa} / \mathrm{m}$ depth higher than for the red soil+SCM 2 trial, over the measured range of flow velocities. These differences may have been due to different physical properties of the natural raw materials, and/or variations in the levels of compaction or moisture content in the media beds. Consistent with the findings of the laboratory studies (Section 3.3.3), the measured values of pressure drop per unit depth of red soil+SCM were substantially 
higher than the cg5 values, over the range of tested biogas flow rates. As stated in Section 3.3.2, this difference reflects the engineered nature of the cg5 commercial medium, providing low resistance to biogas flow together with high $\mathrm{H}_{2} \mathrm{~S}$ removal capacity.

Table 4.4 Measured and calculated (Ergun equation) pressure drop values over the range of biogas flowrates measured during the on-farm trials of the red soil+SCM and cg5 media.

\begin{tabular}{lllllll}
\hline Trial / Medium & $\begin{array}{l}\text { Biogas } \\
\text { flowrate }\end{array}$ & $\begin{array}{l}\text { Biogas flow } \\
\text { velocity }\end{array}$ & $\begin{array}{l}\text { Measured } \\
\text { pressur } \\
\text { drop } \\
(\mathrm{Pa})\end{array}$ & $\begin{array}{l}\mathrm{S} \\
\text { chemisorption } \\
\text { mass } \\
(\mathrm{g} \mathrm{S} / \mathrm{kg} \mathrm{med})\end{array}$ & $\begin{array}{l}\text { Measured } \\
\text { pressure drop } \\
\text { per unit depth } \\
(\mathrm{kPa} / \mathrm{m} \mathrm{med})\end{array}$ & $\begin{array}{l}\text { Calculated } \\
\text { pressure drop } \\
\text { per unit depth } \\
(\mathrm{kPa} / \mathrm{m} \mathrm{med})\end{array}$ \\
\hline Red soil+SCM 1 & 35.4 & 0.48 & 430 & 0.06 & 1.049 & 1.088 \\
& 45.0 & 0.62 & 577 & 2.08 & 1.407 & 1.383 \\
& 44.9 & 0.61 & 570 & 5.01 & 1.390 & 1.380 \\
\hline Red soil+SCM 2 & 46.8 & 0.64 & 808 & 0.05 & 1.224 & 1.251 \\
& 44.9 & 0.61 & 810 & 1.94 & 1.227 & 1.199 \\
& 43.8 & 0.60 & 715 & 3.15 & 1.083 & 1.168 \\
& 43.0 & 0.59 & 746 & 5.01 & 1.130 & 1.148 \\
& 45.3 & 0.62 & 864 & 5.32 & 1.309 & 1.211 \\
\hline cg5 & 38.0 & 0.52 & 13.7 & 0.00 & 0.020 & 0.022 \\
& 34.0 & 0.47 & 13.3 & 140 & 0.020 & 0.019 \\
& 40.0 & 0.55 & 15.6 & 233 & 0.023 & 0.023 \\
\hline
\end{tabular}

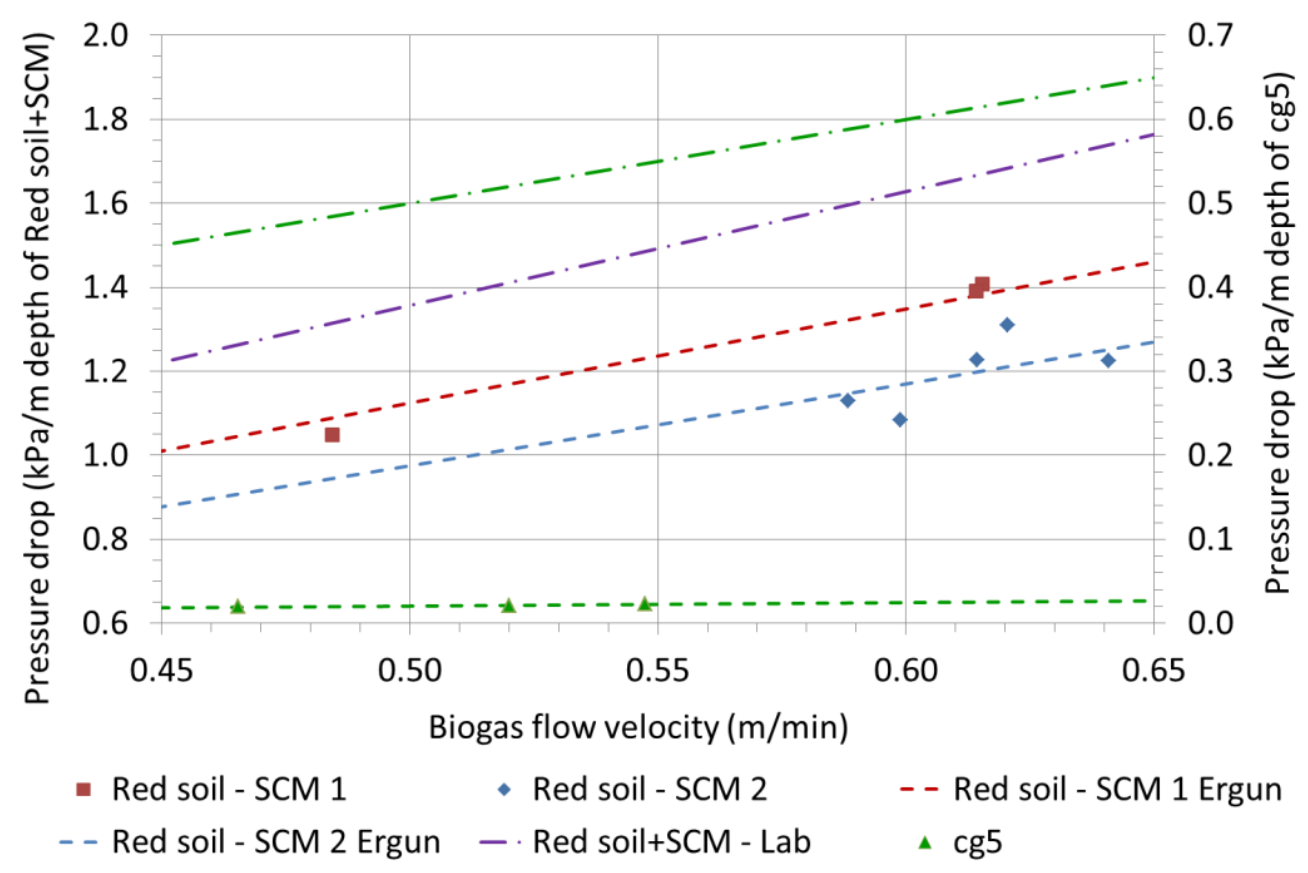

Figure 4.8 Measured (marker) and calculated (Ergun equation - dashed line) values of pressure drop across the chemisorption column, per unit depth of medium [Red soil+SCM $1(\square)$, Red soil+SCM $2(\diamond)$ and cg5 $(\bullet)$ ], for the range of biogas flow velocities measured during the on-farm trials. The Ergun equation curves fitted to the laboratory trial results (Section

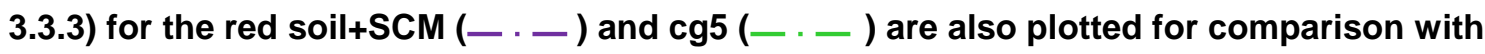
the on-farm results. 
Table 4.4 also provides corresponding $S$ chemisorption masses at the times when the pressure drop measurements were made, to examine whether the progressive build-up of sulphide mineral impacted on pressure drop. Furthermore, progressive compaction and moistening of the mulch component of the red soil+SCM could also have substantially altered the pressure drop across the media bed. However, as Figure 4.9 shows, the measured pressure drops across the column, plotted against the media $\mathrm{S}$ chemisorption mass (proportional to test time) did not show any consistent trends with time for any of the tested media.

(a)

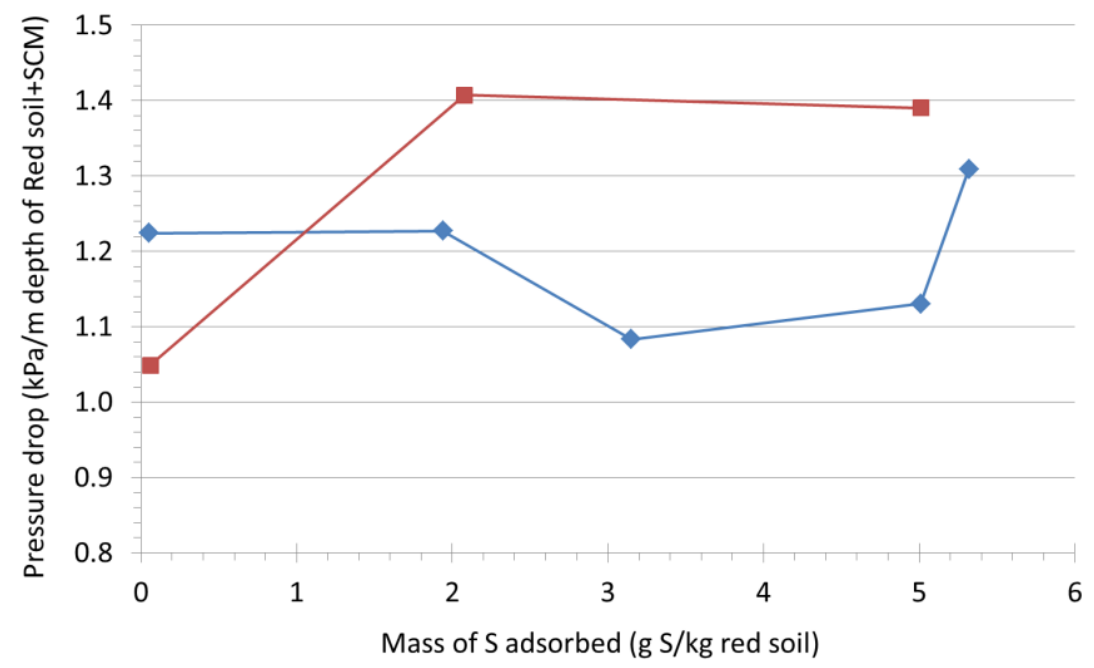

(b)

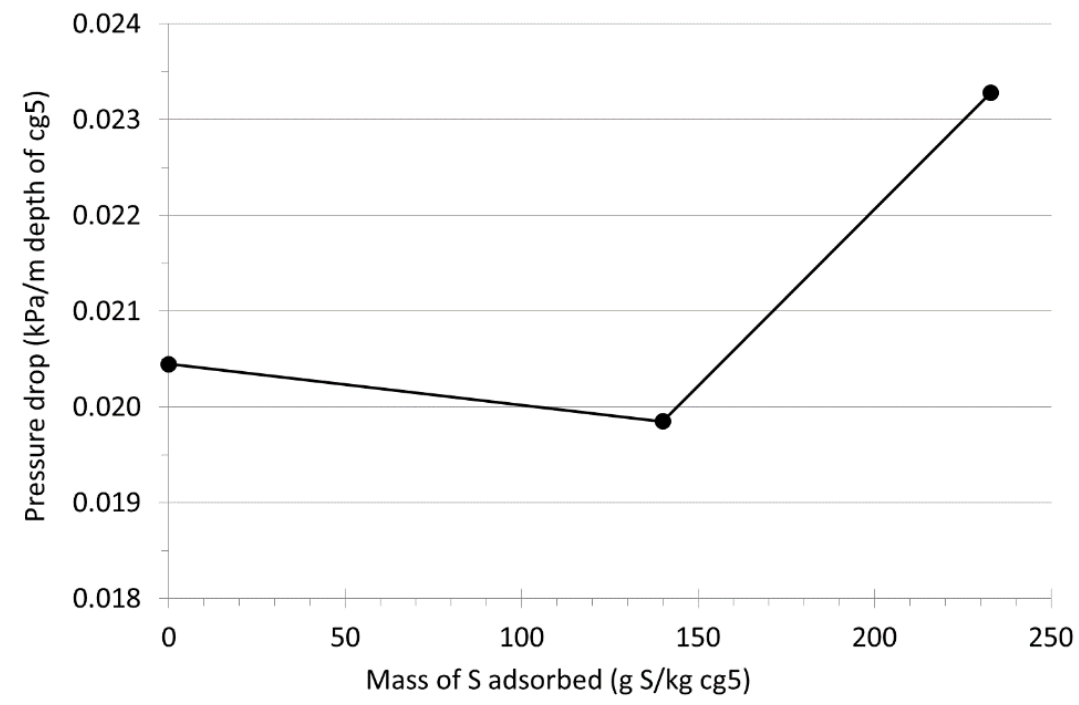

Figure 4.9 Measured values of pressure drop across the on-farm chemisorption column, per unit depth of medium for the (a) red soil+SCM $1(\square)$, red soil+SCM $2(\diamond)$ and (b) $\operatorname{cg} 5(\bullet)$ media, over the range of $S$ chemisorption values measured during the on-farm trials. 


\subsubsection{Oxidation-Based $\mathrm{H}_{2} \mathrm{~S}$ removal at Piggery (B)}

Figure 4.10 presents a time series plot of measured biogas composition upstream and downstream of the test vessel during the biological $\mathrm{H}_{2} \mathrm{~S}$ removal trial at piggery (B). Table 4.5 presents average composition data together with percentage changes across the test vessel, as well as calculated biogas-air mixture concentrations to show the expected effects of dilution with air (before $\mathrm{O}_{2}$ is consumed in the test vessel). Methane and $\mathrm{CO}_{2}$ concentrations remained largely unchanged through the test vessel, except that simple dilution with air increased the balance gas (mostly nitrogen) and $\mathrm{O}_{2}$ concentrations somewhat, as expected.

(a)

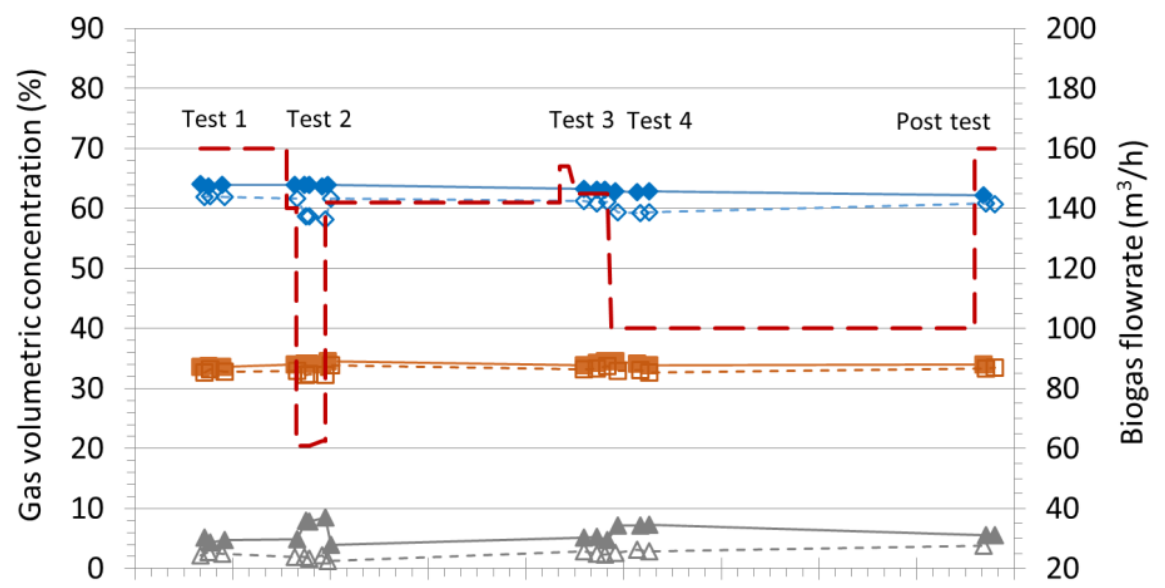

(b)
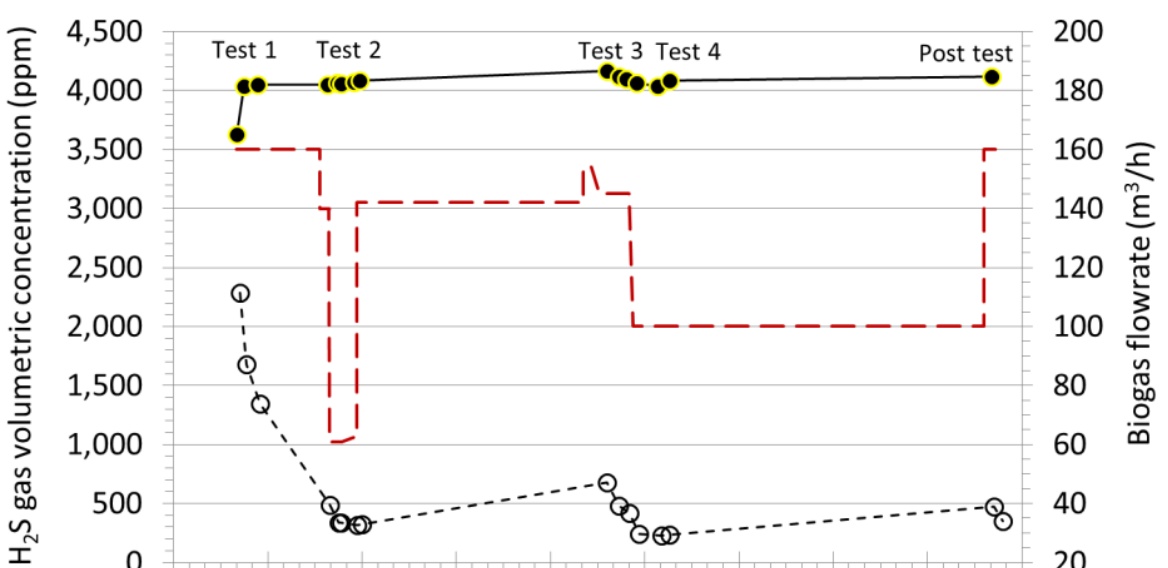

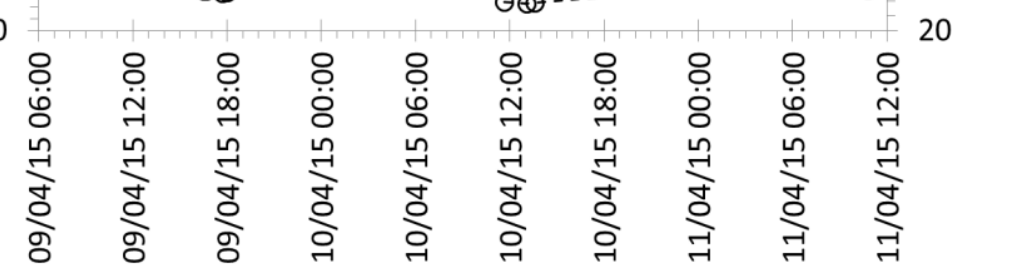

Figure 4.10 Combined time series data showing concentrations of (a) $\mathrm{CH}_{4}(\triangleleft), \mathrm{CO}_{2}(\square)$, Balance $(\triangle)$

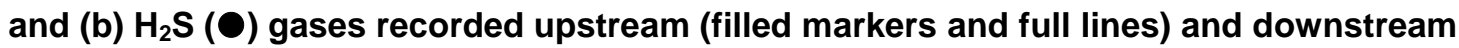
(unfilled markers and dashed lines) from the biological oxidation vessel over the five tests. Biogas flowrates are shown as dashed lines in (a) and (b). 
Table 4.5 Mean concentrations and 95\% confidence intervals for the $\mathrm{CH}_{4}, \mathrm{CO}_{2}, \mathrm{O}_{2}$, balance and $\mathrm{H}_{2} \mathrm{~S}$ gases in the raw biogas and raw biogas + air mixture measured upstream from the biological oxidation vessel, and the treated biogas measured downstream from the biological oxidation vessel, for the five individual on-farm tests and the combined data.

\begin{tabular}{|c|c|c|c|c|c|c|}
\hline $\begin{array}{l}\text { Test No } \\
\text { (Biogas } \\
\text { flowrate) }\end{array}$ & Sample location & $\begin{array}{l}\mathrm{CH}_{4} \\
(\%)\end{array}$ & $\begin{array}{l}\mathrm{CO}_{2} \\
(\%)\end{array}$ & $\begin{array}{l}\mathrm{O}_{2} \\
(\%)\end{array}$ & $\begin{array}{l}\text { Balance } \\
(\%)\end{array}$ & $\begin{array}{l}\mathrm{H}_{2} \mathrm{~S} \\
(\mathrm{ppm})\end{array}$ \\
\hline 1 & Raw biogas (i) & $63.9 \pm 0.2$ & $33.9 \pm 0.5$ & $0.0 \pm 0.1$ & $2.1 \pm 0.7$ & $3,969 \pm 238$ \\
\hline \multirow[t]{4}{*}{$\left(160 \mathrm{~m}^{3} / \mathrm{h}\right)$} & Raw biogas + air (ii) & $62.4 \pm 0.2$ & $33.1 \pm 0.5$ & $0.5 \pm 0.1$ & $3.9 \pm 0.7$ & $3,876 \pm 233$ \\
\hline & Treated biogas (iii) & $61.8 \pm 0.2$ & $33.1 \pm 0.6$ & $0.5 \pm 0.1$ & $4.6 \pm 0.6$ & $1,225 \pm 1,02$ \\
\hline & $\%$ reduction (i) to (iii) & $3.3 \pm 0.6$ & $2.4 \pm 0.8$ & & $-129.1 \pm 68.5$ & $68.4 \pm 28.0$ \\
\hline & $\%$ reduction (ii) to (iii) & $1.0 \pm 0.6$ & $0.0 \pm 0.8$ & $9.7 \pm 22.2$ & $-18.9 \pm 18.8$ & $67.7 \pm 28.7$ \\
\hline 2 & Raw biogas (i) & $63.9 \pm 0.4$ & $34.1 \pm 0.3$ & $0.0 \pm 0.0$ & $1.9 \pm 0.6$ & $4,063 \pm 19$ \\
\hline \multirow[t]{4}{*}{$\left(62 \mathrm{~m}^{3} / \mathrm{h}\right)$} & Raw biogas + air (ii) & $60.4 \pm 0.4$ & $32.3 \pm 0.3$ & $1.1 \pm 0.0$ & $6.2 \pm 0.6$ & $3,840 \pm 18$ \\
\hline & Treated biogas (iii) & $58.5 \pm 0.7$ & $32.3 \pm 0.2$ & $1.1 \pm 0.0$ & $8.1 \pm 0.9$ & $331 \pm 25$ \\
\hline & $\%$ reduction (i) to (iii) & $8.4 \pm 0.6$ & $5.4 \pm 0.4$ & & $-322.1 \pm 90.0$ & $91.9 \pm 0.7$ \\
\hline & $\%$ reduction (ii) to (iii) & $3.0 \pm 0.7$ & $-0.1 \pm 0.4$ & $4.3 \pm 0.0$ & $-31.4 \pm 2.5$ & $91.4 \pm 0.7$ \\
\hline 3 & Raw biogas (i) & $63.2 \pm 0.1$ & $34.2 \pm 0.8$ & $0.0 \pm 0.1$ & $2.5 \pm 0.7$ & $4,130 \pm 85$ \\
\hline \multirow[t]{4}{*}{$\left(145 \mathrm{~m}^{3} / \mathrm{h}\right)$} & Raw biogas + air (ii) & $61.7 \pm 0.1$ & $33.4 \pm 0.7$ & $0.5 \pm 0.1$ & $4.4 \pm 0.6$ & $4,030 \pm 83$ \\
\hline & Treated biogas (iii) & $61.1 \pm 0.5$ & $33.4 \pm 0.7$ & $0.5 \pm 0.1$ & $5.1 \pm 0.6$ & $527 \pm 337$ \\
\hline & $\%$ reduction (i) to (iii) & $3.4 \pm 0.6$ & $2.4 \pm 1.1$ & & $-103.9 \pm 49.2$ & $87.2 \pm 7.9$ \\
\hline & $\%$ reduction (ii) to (iii) & $1.0 \pm 0.6$ & $0.0 \pm 1.1$ & $13.3 \pm 26.0$ & $-16.6 \pm 18.5$ & $86.9 \pm 8.1$ \\
\hline 4 & Raw biogas (i) & $62.8 \pm 0.3$ & $34.2 \pm 0.7$ & $0.0 \pm 0.0$ & $2.9 \pm 0.6$ & $4,062 \pm 55$ \\
\hline \multirow[t]{4}{*}{$\left(100 \mathrm{~m}^{3} / \mathrm{h}\right)$} & Raw biogas + air (ii) & $60.6 \pm 0.3$ & $33.0 \pm 0.7$ & $0.7 \pm 0.0$ & $5.5 \pm 0.6$ & $3,921 \pm 53$ \\
\hline & Treated biogas (iii) & $59.3 \pm 0.3$ & $32.9 \pm 0.5$ & $0.7 \pm 0.1$ & $7.2 \pm 0.2$ & $237 \pm 16$ \\
\hline & $\%$ reduction (i) to (iii) & $5.6 \pm 0.0$ & $3.7 \pm 1.4$ & & $-152.6 \pm 59.5$ & $94.2 \pm 0.4$ \\
\hline & $\%$ reduction (ii) to (iii) & $2.2 \pm 0.0$ & $0.2 \pm 1.5$ & $8.4 \pm 19.7$ & $-30.8 \pm 16.6$ & $94.0 \pm 0.4$ \\
\hline Post test & Raw biogas (i) & 62.2 & 34.0 & 0.0 & 3.8 & 4,121 \\
\hline \multirow[t]{4}{*}{$\left(160 \mathrm{~m}^{3} / \mathrm{h}\right)$} & Raw biogas + air (ii) & 60.8 & 33.3 & 0.5 & 5.5 & 4,030 \\
\hline & Treated biogas (iii) & 60.8 & 33.4 & 0.3 & 5.5 & 414 \\
\hline & $\%$ reduction (i) to (iii) & 2.3 & 1.8 & 0.0 & -44.7 & 90.0 \\
\hline & $\%$ reduction (ii) to (iii) & 0.1 & -0.4 & 34.9 & -0.8 & 89.7 \\
\hline \multirow[t]{5}{*}{ Combined } & Raw biogas (i) & $63.4 \pm 0.3$ & $34.1 \pm 0.2$ & $0.0 \pm 0.0$ & $2.4 \pm 0.3$ & $4,049 \pm 68$ \\
\hline & Raw biogas + air (ii) & $61.4 \pm 0.5$ & $33.0 \pm 0.3$ & $0.7 \pm 0.1$ & $4.9 \pm 0.5$ & $3,918.7 \pm 70$ \\
\hline & Treated biogas (iii) & $60.5 \pm 0.7$ & $33.0 \pm 0.3$ & $0.6 \pm 0.1$ & $6.0 \pm 0.8$ & $639.7 \pm 319$ \\
\hline & \% reduction (i) to (iii) & $4.6 \pm 1.1$ & $3.1 \pm 0.7$ & & $-154.4 \pm 50.7$ & $83.9 \pm 8.6$ \\
\hline & $\%$ reduction (ii) to (iii) & $1.5 \pm 0.5$ & $0.0 \pm 0.3$ & $12.3 \pm 7.4$ & $-20.8 \pm 7.1$ & $83.4 \pm 8.7$ \\
\hline
\end{tabular}

Figure 4.11 shows the mean concentrations (calculated and measured) for (a) $\mathrm{O}_{2}$ and (b) $\mathrm{H}_{2} \mathrm{~S}$, enter and exiting the biological oxidation column, over the 5 on-farm teats and for the combined data. The extent of $\mathrm{H}_{2} \mathrm{~S}$ removal achieved was noteworthy at $68 \%-94 \%$ reduction, showing the considerable potential for biological sulphide oxidation to treat piggery biogas on-farm. This is consistent with a $95 \%$ reduction in $\mathrm{H}_{2} \mathrm{~S}$ concentrations suggested by Wellinger and Lindberg (2005), depending on factors such as temperature, 
reaction time and air placement. The $\mathrm{H}_{2} \mathrm{~S}$ concentrations achieved downstream of the test vessel were very encouraging, in terms of bulk removal of sulphur from biogas. This was especially noteworthy, because the vessel and system design was not considered to be optimal (being largely designed and built by persons who were unskilled with respect to the specific technology), and no attempt was made to optimise the air flowrate or the liquid spray rate over the plastic packing. The $\mathrm{H}_{2} \mathrm{~S}$ concentrations achieved by this biological treatment could be sufficiently low for operation of most boilers and some internal combustion engines used at piggeries (Section 2.1) without any further treatment of the biogas.

The very high extent of $\mathrm{H}_{2} \mathrm{~S}$ removal across the trial, indicated that a viable microbial consortium had been grown on the plastic packing as a result of operation since the system was first commissioned some months before the trial. This performance also suggested that sufficient nutrients and inoculum were being supplied by the recycled effluent from the CAL outflow. However, once air injection began for the trial, there was a progressive increase in $\mathrm{H}_{2} \mathrm{~S}$ removal performance over the course of the trial (most notably at the start of Test 1 , Figure $4.10 \mathrm{~b}$ ). This may have been caused by a lack of $\mathrm{O}_{2}$ supplied by the set-up during normal operation, resulting in microbes on the packing entering a semi-dormant state of lower microbial activity. However, the microbial activity appeared to recover soon after air injection was commenced (Figure 4.10b).

The amount of air added by injection during the trial matched the recommended 2 to $6 \%$ concentration of air in biogas (Wellinger and Lindberg, 2005; Ryckebosch et al., 2011). As shown in Figure 4.11, $\mathrm{O}_{2}$ was consumed in the test vessel, but not greatly, and in cases not significantly $(\mathrm{P}>0.95)$. This would indicate that $\mathrm{O}_{2}$ supply was in excess of the amount required for $\mathrm{H}_{2} \mathrm{~S}$ removal, or alternatively, there may have been some short-circuiting of untreated biogas. Stoichiometrically, $0.5 \%$ concentration of air in biogas is required for the conversion of $2000 \mathrm{ppm} \mathrm{H}_{2} \mathrm{~S}$ in biogas $\left(20^{\circ} \mathrm{C}\right.$ and $\left.1 \mathrm{~atm}\right)$ to elemental sulphur and water. A pro-longed exposure to an excess of $\mathrm{O}_{2}$ can encourage acid-forming conditions favouring the further oxidation of elemental sulphur to sulphate (Pokorna and Zabranska, 2015). However, the $\mathrm{pH}$ of liquid discharged from the base of the biological oxidation vessel was measured and remained largely unchanged at $\mathrm{pH}$ 7.3-7.4. The effluent from the CAL may have had adequate alkalinity to resist pH change (Staunton et al., 2015; Sell et al., 2011) and the nutrient liquid only flowed through the biological oxidation vessel once. Given the residual $\mathrm{O}_{2}$ observed in the present case, it may be possible to reduce the addition of air 
without compromising the $\mathrm{H}_{2} \mathrm{~S}$ removal performance. However, longer term monitoring would be beneficial to confirm this.

(a)

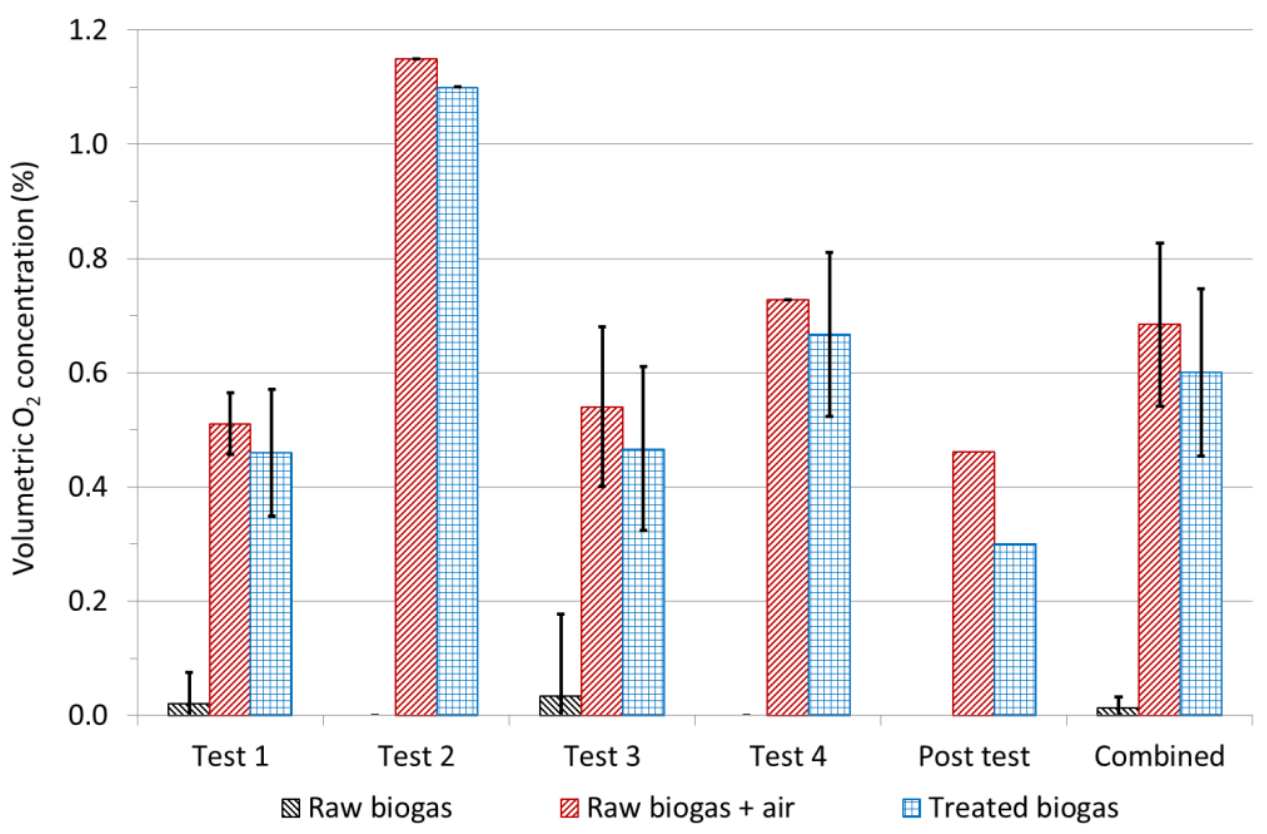

(b)

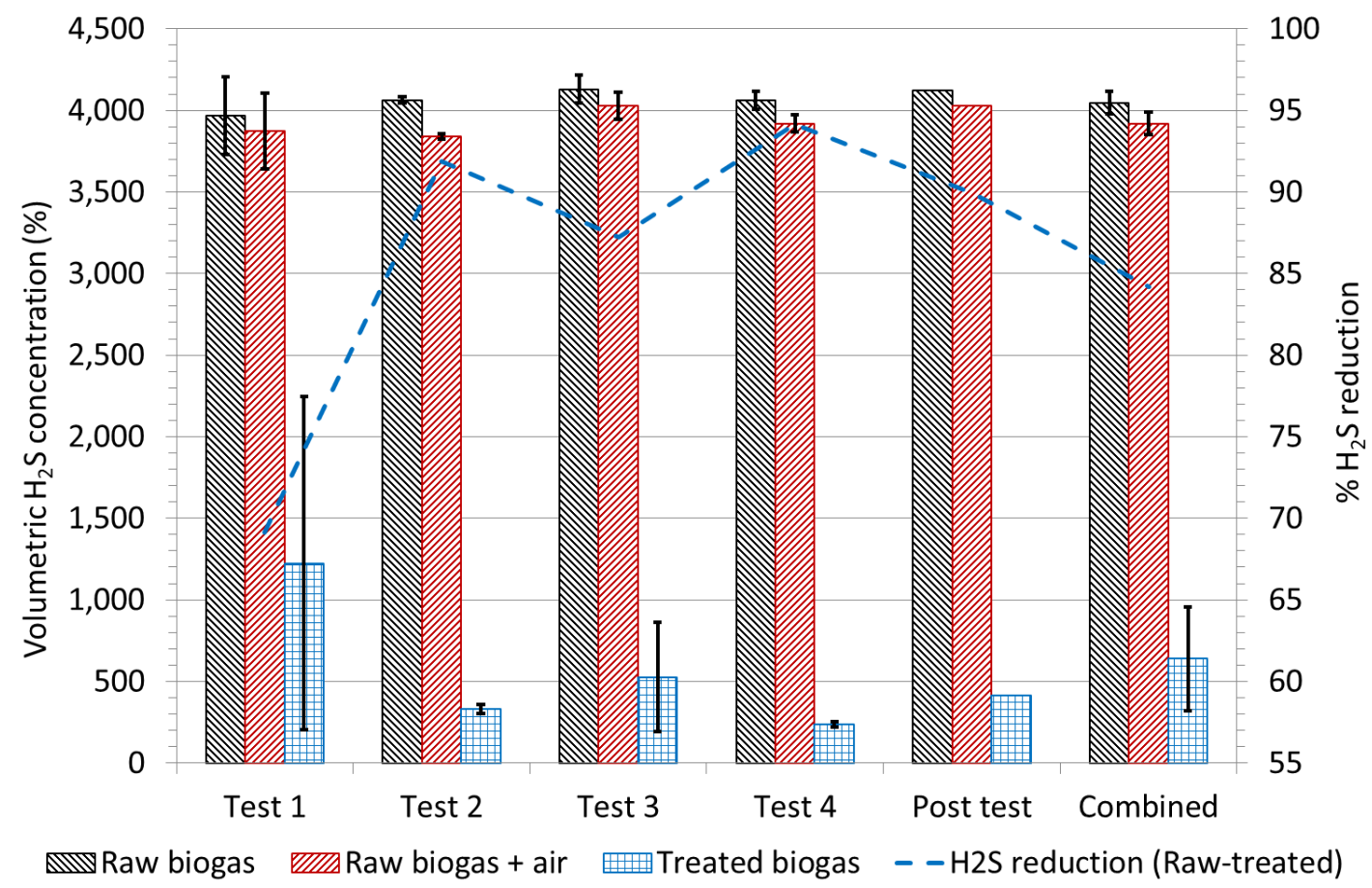

Figure 4.11 Bar graph showing the mean concentrations and $95 \%$ error bars for (a) $\mathrm{O}_{2}$ and (b) $\mathrm{H}_{2} \mathrm{~S}$, measured in the raw biogas coming from the CAL $(\mathbb{\nabla})$, in the raw biogas following air injection as estimated by calculation $(\square)$, and as measured in the treated biogas exiting the test column $(\square)$, for the five tests and combined data. The biogas flowrates for tests 1 to 4 and the post test were $160,62,145,100$ and $160 \mathrm{~m}^{3} / \mathrm{h}$, respectively. 
Whilst this was intended to be a preliminary experiment to evaluate the overall performance of the biological scrubber, rather than fully investigating the full range of mechanisms contributing to this performance, it is acknowledged that physical stripping was not categorically ruled out as a contributing mechanism. However, the effluent in the CAP (at least at the surface) was in equilibrium with biogas stored under the pond cover just prior to being pumped into the scrubber column. The CAP effluent used in the scrubber overflowed by gravity from just below the CAP effluent surface and had therefore been in contact with the stored biogas being treated in the scrubber for a considerable period of time. Consequently, the effluent stream sprayed over the packed bed in the scrubber was probably already saturated with $\mathrm{H}_{2} \mathrm{~S}$, prior to entering the scrubber column, minimising the potential for further $\mathrm{H}_{2} \mathrm{~S}$ stripping from the biogas in the scrubber column.

Preliminary biogas composition readings, taken on the previous day, while the effluent delivery pump was operating but the passive air injection system was not working effectively, indicated a raw biogas $\mathrm{H}_{2} \mathrm{~S}$ concentration of $4124 \mathrm{ppm}$ and a biological scrubber outlet $\mathrm{H}_{2} \mathrm{~S}$ concentration of $3860 \mathrm{ppm}$, less than one hour later. This relatively small (6.4\%) reduction in $\mathrm{H}_{2} \mathrm{~S}$ concentration could have been due to physical stripping, but suggested that another mechanism (other than physical stripping) was mostly responsible for the good performance observed when air was added. The rapid increase in $\mathrm{H}_{2} \mathrm{~S}$ removal performance during Test 1 (Figure 4.10(b)) following the commencement of positive air injection using a compressor, also supports the suggestion that oxidation was primarily responsible for the observed $\mathrm{H}_{2} \mathrm{~S}$ reduction.

It should also be noted that other water scrubbing processes usually require that raw biogas is cooled to $5-10^{\circ} \mathrm{C}$ and compressed to $4-8$ bar ( $400-800 \mathrm{kPa}$ ) to increase the absorption rate (Wellinger et al., 2013). Consequently, the relatively high temperature of the biogas extracted from the CAP and the slight negative pressure in the on-farm column of the present trials would not have been conducive to high levels of $\mathrm{H}_{2} \mathrm{~S}$ absorption by physical stripping. However, Wellinger et al. (2013) suggest water consumption rates of 2.1-3.3 L/d per $\mathrm{m}^{3}$ of raw biogas upgrading capacity in commercial water scrubbers. The biogas treatment capacity of the on-farm column was $160 \mathrm{~m}^{3} / \mathrm{h}(3840 \mathrm{~m} / \mathrm{d})$ which would therefore require 8,064-12,672 $\mathrm{L} / \mathrm{d}$ of water. The recycled effluent flow volume in the onfarm column was $0.2 \mathrm{~L} / \mathrm{s}(17,280 \mathrm{~L} / \mathrm{d})$ which exceeds the suggested water consumption for normal water scrubbing, so perhaps the effect of physical stripping could be enhanced if 
the $\mathrm{H}_{2} \mathrm{~S}$ could be removed from the CAL effluent before passing it to the scrubbing column. However, this concept was not tested.

While biological oxidation was anticipated due to moisture and nutrient availability, it would also have been possible for mixed chemical and biological oxidation to occur. In conclusion, any removal of $\mathrm{H}_{2} \mathrm{~S}$ from the biogas in the biological oxidation vessel by physical stripping (absorption) was likely to have been minimal.

\subsubsection{Applications}

The on-farm trials described in this Chapter confirmed the viability of the cg5 commercial medium for removing $\mathrm{H}_{2} \mathrm{~S}$ from piggery biogas. The higher chemisorption capacity observed in the on-farm trials in comparison to the laboratory trials suggested the possibility of continuous partial regeneration of the medium by traces of $\mathrm{O}_{2}$ in the biogas, at concentrations that were too low to reliably measure with the available analyser. This observation suggests the potential viability of intentional continuous regeneration of the cg5 medium during normal operation, provided any heat generated by the exothermic regeneration reaction can be safely managed at higher $\mathrm{O}_{2}$ injection rates. However, this concept requires further testing. If medium changeover is carried out in batch mode, there would still be a need to carefully manage toxic $\mathrm{SO}_{2}$ emissions for highly reactive chemisorption media.

The supply cost of a suitable red soil medium may be lower than that of the cg5 medium in some regions. However, the comparatively low chemisorption capacity of the red soil+SCM medium recorded in the on-farm trials, suggested that it would not be a viable primary treatment option for piggery biogas, due to the high labour cost associated with the required short changeover intervals and/or larger reactor vessels with higher pressure drops and energy use.

Whilst the breakthrough chemisorption capacities of the red soil+SCM media were similar for the on-farm and laboratory trials, further on-farm trials would be desirable to determine whether the erratic post-breakthrough chemisorption behaviour is evident for straight red soil (without the addition of the SCM bulking agent). This would require the installation of a higher power blower to overcome the increased pressure drop through the same depth of medium. The on-farm performance of alternative red soil bulking agents could also be 
trialled to determine pressure drop and chemisorption behaviour. The laboratory trials indicated improving breakthrough performance of the red soil medium after successive regenerations, but this could not be tested within the scope of the present on-farm trials. On-farm testing of regeneration is considered important and of considerable practical interest.

The highly effective performance observed in on-farm trials using biological oxidation, suggested that this treatment method would be a viable, low-cost option for removing bulk $\mathrm{H}_{2} \mathrm{~S}$ from raw piggery biogas. The impressive performance of this system was achieved without detailed optimisation of design characteristics such as the column geometry, biogas flowrate and liquid nutrient source flowrate, and despite its relative simplicity and use of readily available materials. Furthermore, recycled CAL effluent appeared to work effectively as the liquid nutrient source sprayed over the packing. These characteristics suggest that biological oxidation is likely to be an ideal method for the primary treatment of piggery biogas. Further trials are recommended to evaluate methods for safely and costeffectively adding air into the biogas stream, to produce the $\mathrm{O}_{2}$ concentrations required to sustain the microorganisms responsible for oxidising the $\mathrm{H}_{2} \mathrm{~S}$.

Once the bulk of the biogas $\mathrm{H}_{2} \mathrm{~S}$ has been removed by biological oxidation, commercial cg5 or red soil media could be used to remove the residual $\mathrm{H}_{2} \mathrm{~S}$ in a secondary treatment step, to ensure that the treated biogas is consistently suitable for use in downstream appliances such as ICEs and boilers. The viability of the red soil medium is likely to depend on the proximity of the piggery to supplies of suitable red soils, which in turn would dictate the supply cost of this material.

\subsection{Conclusions}

The on-farm trials discussed in this Chapter showed that, following the establishment of a suitable air injection rate, a relatively simple, single biological oxidation vessel successfully removed over $90 \%$ of the $\mathrm{H}_{2} \mathrm{~S}$ in raw biogas generated in a CAL treating the waste stream from a commercial piggery. This result suggests that biological oxidation has considerable potential as a low-cost option for removing the bulk of the $\mathrm{H}_{2} \mathrm{~S}$ from raw piggery biogas.

The high chemisorption capacity of the commercial cg5 medium tested in the on-farm trials suggested that it could be used in either a primary or secondary biogas treatment role; 
however, the relatively low chemisorption capacity of the red soil+SCM medium suggested that it would not be suitable as a primary treatment medium, due to the short replacement intervals. However, both of these solid media could be viable for polishing biogas, following primary treatment in a biological oxidation vessel, to achieve a consistent quality suitable for use in downstream appliances such as ICEs and boilers. The economic viability of the red soil medium in a secondary treatment role is likely to depend on the proximity of the piggery to supplies of suitable red soils, which in turn would dictate the supply cost of this material. 


\section{General Discussion}

\subsection{General drivers for Biogas Technology}

The Australian Pork Industry is committed to reducing greenhouse gas (GHG) emissions and has adopted an ambitious emission target of approximately $1 \mathrm{~kg} \mathrm{CO}$-e/ $/ \mathrm{kg}$ pork, to be achieved by June 2019 (Murphy et al., 2013). A recent life cycle assessment study (Wiedemann et al., 2016) suggested that piggery GHG emissions could be reduced by changing housing/manure management systems, with the greatest reductions achieved by installing biogas capture and combined heat and power systems (CAP-CHP), resulting in total emissions reductions up to $64 \%$. Clearly, the wide adoption of biogas capture, treatment and use systems by Australian pork producers would be crucial for the achievement of the proactive industry goals noted above.

While several larger producers (>1000 sows, farrow to finish, or equivalent) have readily embraced biogas technology over the past five to ten years, primarily motivated by the potential for offsetting or eliminating on-farm energy costs, biogas use has not generally been economically viable for smaller producers ( $<500$ sows, farrow to finish, or equivalent). However, achievement of the industry GHG emission goals will rely on such smaller piggeries also capturing and using biogas in the future. The availability of relatively simple, cost-effective, biogas treatment technologies, which meet the majority of the criteria outlined in Section 1.2, would be a necessity for encouraging the needed widespread adoption of biogas systems, especially by the smaller piggery operators. Of key concern is the high concentration of a toxic and corrosive ingredient, hydrogen sulphide $\left(\mathrm{H}_{2} \mathrm{~S}\right)$ in raw piggery biogas. Common uses of biogas at piggeries (e.g. internal combustion engines and boilers) will likely require some removal of $\mathrm{H}_{2} \mathrm{~S}$ from the piggery biogas prior to use (Section 2.1).

\subsection{Biological oxidation - A low-cost primary treatment step for biogas}

The results of the trials described in Chapter 4 of this Thesis indicated that $90 \%$ of piggery biogas $\mathrm{H}_{2} \mathrm{~S}$ could be removed by biological oxidation in a system simple enough to fabricate and install using on-farm labour, and with minimal detailed design and no system operational optimisation. This result suggested considerable potential for this biogas treatment method. However, as noted in Section 4.3.2, the rate of air injection could be 
optimised or at least minimised to prevent the formation of an explosive methane-oxygen mixture. Fortunately, because relatively small amounts of oxygen are required for effective $\mathrm{H}_{2} \mathrm{~S}$ removal, these safety aspects could likely be managed relatively simply on-farm. As shown in Section 4.3.2, dilution of the methane with $\mathrm{N}_{2}$ and $\mathrm{O}_{2}$ from the added air stream is unlikely to adversely affect the operation of most biogas engine-driven CHP systems commonly installed at Australian piggeries. Although biological oxidation systems would require some maintenance to remove excess elemental sulphur, sulphate compounds and biofilm which accumulate over time on the packing elements, BIOREM® (2010) suggested that these by-products of the biological oxidation process could be purged by a continuous flushing design, using the recirculated liquid.

In conclusion, biological oxidation appears to offer the simplest, most cost-effective option for removing the majority of the $\mathrm{H}_{2} \mathrm{~S}$ from piggery biogas, in a single process reactor vessel, without the addition of chemicals. These characteristics indicate that this method would be ideal for primary treatment of raw piggery biogas on-farm.

\subsection{Chemisorption - Low-cost alternative media for polishing of biogas}

Although the short-term trials described in Chapter 4 indicated relatively uniform $\mathrm{H}_{2} \mathrm{~S}$ concentrations in the treated biogas, some form of secondary biogas treatment would likely be necessary over the longer term, especially for more sensitive biogas uses where it is imperative that treated biogas quality consistently meets high standards (Section 2.1). The results of the trials described in Chapter 4 indicated that chemisorption of residual $\mathrm{H}_{2} \mathrm{~S}$ onto solid, iron-oxide rich media could provide the simplest, most practical and effective secondary treatment option. Whilst solid chemisorption media will inevitably require replacement and/or in-situ regeneration, the required quantities and ongoing labour could be reduced by a factor of approximately 10 (compared to using the solid media in a primary treatment role), if the chemisorption step followed primary biological treatment of the raw biogas.

The results of the trials described in Chapter 3 suggested that the most promising solid chemisorption media were the cg5 commercial iron-oxide pellets and the Tor Street (Toowoomba) red soil, as a low-cost alternative. A simple hypothetical case study was carried out to assess the practicality of using both of these solid media for secondary treatment of the biogas produced from a 500 sow farrow-to-finish piggery, following 
primary treatment of the raw biogas by biological oxidation. A 500 sow farrow to finish piggery was chosen for the case study because it is representative of the smaller piggeries which the industry will be encouraging to adopt biogas systems, in order to meet its GHG emission goals.

The results of the case study, along with many of the input parameter values, are summarised in Table 5.1. The PigBal 4 model (Skerman et al., 2013) was used to estimate the VS loading from the piggery entering the CAL or digester. Based on a biogas production rate of $0.43 \mathrm{~m}^{3}$ biogas $/ \mathrm{kg}$ VS added, the estimated biogas flow volume from the CAL or digester was $447 \mathrm{~m}^{3}$ biogas/d. It was assumed that the $\mathrm{H}_{2} \mathrm{~S}$ concentration in the raw biogas was 2000 ppm, which appears to be a typical value for Australian piggeries, based on the results reported by Skerman and Collman (2012). This value is lower than the mean value given in Chapter 4 for the piggery (B) trial (4049 ppm); however, piggery $B$ uses a high percentage of by-products in the pig diets fed through a sophisticated liquid feeding system. This atypical diet could have caused an elevated mean biogas $\mathrm{H}_{2} \mathrm{~S}$ concentration which may not be representative of biogas across the industry.

For the analysis, it was assumed that $90 \%$ of the $\mathrm{H}_{2} \mathrm{~S}$ in the raw biogas was removed by the primary biological oxidation treatment, resulting in a residual $\mathrm{H}_{2} \mathrm{~S}$ concentration of 200 ppm entering the secondary treatment chemisorption column. The $\mathrm{H}_{2} \mathrm{~S}$ chemisorption capacities of the red soil and cg5 media were assumed to be 10 and $143 \mathrm{~g} \mathrm{~S} / \mathrm{kg}$ medium, respectively, at breakthrough. The cg5 chemisorption capacity was adopted based on the mean value measured in the laboratory trial (Table 3.2, Section 3.3.2) while the red soil chemisorption capacity was towards the higher end of the range of values recorded in the media regeneration tests summarised in Table 3.4 (Section 3.3.4). The diameter and media capacity of the commercial chemisorption columns used at piggery (B) $(600 \mathrm{~mm}$ and $30 \mathrm{~L}$, respectively) were adopted for this case study. 
Table 5.1. 500 sow farrow-to-finish case study summary, based on primary biogas treatment by biological oxidation and secondary treatment in a solid medium chemisorption column using red soil and cg5 media.

\begin{tabular}{|c|c|c|c|}
\hline Parameter & Units & Value & \\
\hline No of pigs & pigs & 5,411 & \\
\hline No of SPU & SPU & 5,445 & \\
\hline VS from sheds & $\mathrm{kg} \mathrm{VS/d}$ & 1,387 & \\
\hline Pre-treatment VS removal & $\%$ & $25 \%$ & \\
\hline VS to CAP/Digester & $\mathrm{kg} \mathrm{VS/d}$ & 1,040 & \\
\hline Biogas production rate & $\mathrm{m}^{3}$ biogas $/ \mathrm{kg}$ VS added & 0.43 & \\
\hline Biogas flowrate & $\mathrm{m}^{3}$ biogas $/ \mathrm{d}$ & 447 & \\
\hline Biogas flowrate & $\mathrm{m}^{3}$ biogas $/ \mathrm{hr}$ & 19 & \\
\hline Raw biogas $\mathrm{H}_{2} \mathrm{~S}$ concentration & ppm & 2000 & \\
\hline Bio-trickling filter $\mathrm{H}_{2} \mathrm{~S}$ removal rate & $\%$ & $90 \%$ & \\
\hline Primary treated biogas $\mathrm{H}_{2} \mathrm{~S}$ concentration & ppm & 200 & \\
\hline $\mathrm{H}_{2} \mathrm{~S}$ flowrate & $\mathrm{m}^{3} \mathrm{H}_{2} \mathrm{~S} / \mathrm{d}$ & 0.09 & \\
\hline $\mathrm{H}_{2} \mathrm{~S}$ flowrate & $\mathrm{g} \mathrm{H}_{2} \mathrm{~S} / \mathrm{d}$ & 144 & \\
\hline \multirow[t]{2}{*}{ S flowrate } & $\mathrm{g} \mathrm{S} / \mathrm{d}$ & 136 & \\
\hline & & Red soil & $\operatorname{cg} 5$ \\
\hline Medium S removal capacity at breakthrough & g S/kg medium & 10 & 143 \\
\hline Medium bulk density & $\mathrm{kg} / \mathrm{m}^{3}$ & 1,110 & 699 \\
\hline Chemisorption column medium capacity & $\mathrm{L}$ & 300 & 300 \\
\hline Chemisorption column diameter & $\mathrm{mm}$ & 600 & 600 \\
\hline Superficial biogas flow velocity & $\mathrm{m} / \mathrm{min}$ & 1.10 & 1.10 \\
\hline Medium depth & $\mathrm{mm}$ & 1,061 & 1,061 \\
\hline Medium pressure loss & $\mathrm{kPa}$ & 8.0 & 0.8 \\
\hline Medium mass & $\mathrm{kg}$ medium & 333 & 210 \\
\hline Total medium S removal capacity at breakthrough & g S & 3,330 & 29,987 \\
\hline Breakthrough time & $\mathrm{d}$ & 25 & 221 \\
\hline Breakthrough time & months & 0.81 & 7.26 \\
\hline
\end{tabular}

The resulting breakthrough times for the red soil and cg5 media were 25 and 221 days, respectively. While the cg5 breakthrough time, and therefore the effective life of the medium before replacement or regeneration, was approximately 9 times longer than the red soil value, it should be noted that the red soil was successfully regenerated four times during the laboratory trials and that the $S$ removal capacity increased following each successive regeneration. This suggests that if two parallel chemisorption columns could be used so that one column is actively treating the biogas while the other is being regenerated in-situ by the passage of air, significantly longer medium replacement intervals could be achievable, with minimal additional labour. Furthermore, it may be impractical to regenerate the cg5 medium in-situ, due to the excessive amount of heat generated by the exothermic regeneration reaction and the high $\mathrm{S}$ binding capacity of the cg5 medium. Consequently, the cg5 regeneration process would require careful management to avoid combustion and/or melting of any plastic components. 
The estimated pressure drops across the $\mathrm{cg} 5$ and red soil media were estimated at $0.8 \mathrm{kPa}$ and $8.0 \mathrm{kPa}$, respectively, using Ergun equation calculations for a superficial flow velocity of $1.1 \mathrm{~m} / \mathrm{min}$ through the chemisorption column (Figure 3.5). This tenfold difference in pressure drops would require the use of a more costly, higher pressure blower/pressure booster to circulate biogas through the red soil chemisorption column, resulting in higher sacrificial energy consumption.

Whilst the use of the cg5 pellets may be more convenient in some cases, the red soil option may be attractive at sites which have access to supplies of a suitable red soil, at minimal cost. It should also be noted that only two red soils were tested in the laboratory trials described in Chapter 3 . There may be other red soils with higher $\mathrm{S}$ chemisorption capacities, occurring naturally at other localities. Furthermore, the regeneration trials described in Section 3.3.4 did not establish the ultimate $S$ chemisorption capacity of the Tor Street red soil, with increasing breakthrough capacities following each regeneration. Consequently, the $\mathrm{S}$ chemisorption capacity assumed in the case study may be conservative, and longer breakthrough/regeneration/replacement time intervals might be possible.

\subsection{Recommendations for future work}

Based on the outcomes of the research described in this thesis, it is recommended that future work should focus on the following:

\subsubsection{Solid chemisorption media}

Further laboratory and/or on-farm trials are recommended:

- To establish the ultimate $S$ chemisorption capacity of the Tor Street red soil, given the increasing breakthrough capacities observed following each regeneration in these trials (Section 3.3.4).

- To determine the $\mathrm{H}_{2} \mathrm{~S}$ chemisorption capacities of other iron-rich soils (Section 3.4).

- To confirm the soil properties/characteristics which result in superior $S$ chemisorption performance (Section 3.3.1).

- To investigate the practicality and economic viability of pre-treating red soil to maximise its chemisorption capacity prior to use. 
- To establish the most practical and economically viable methods to regenerate the red soil medium (e.g. continuous or batch) while managing the emission of (i) heat, which could damage columns or other infrastructure, and (ii) dangerous $\mathrm{SO}_{2}$ offgases, which could affect human and livestock health (Section 4.3.3).

- To investigate alternative bulking materials for mixing with red soils to effectively reduce biogas pressure drop through chemisorption columns, while minimising dilution of the active chemisorption ingredients, and maintaining structural stability following prolonged exposure to (i) heat (during in-situ regeneration) and (ii) biogas saturated with moisture (Section 4.3.3).

- To explore whether fermentation-related mechanisms, affiliated with the lignocellulosic materials in SCM, contribute to the observed $\mathrm{H}_{2} \mathrm{~S}$ removal observed with red-soil+SCM mixtures.

\subsubsection{Biological oxidation}

Further on-farm trials are recommended:

- To measure the long term performance of single biological oxidation vessels for removing $\mathrm{H}_{2} \mathrm{~S}$ from piggery biogas under a wider range of operating conditions.

- To establish optimal column geometries, packing depths and diameters, and liquid nutrient source flowrates, to suit the range of biogas flowrates and $\mathrm{H}_{2} \mathrm{~S}$ concentrations encountered at commercial piggeries.

- To develop relatively simple design and operational guidelines to achieve consistently high $\mathrm{H}_{2} \mathrm{~S}$ removal performance.

- To investigate the performance of passive versus mechanically-assisted air injection into the incoming biogas stream and to provide guidance on practical, costeffective and safe control systems.

- To investigate column packing cleaning methods and intervals for effective operation.

- To investigate the microbiological processes occurring in the biological oxidation system, potentially to optimise the conversion of $\mathrm{H}_{2} \mathrm{~S}$ to elemental sulphur or sulphate. 


\section{Bibliography}

Abatzoglou, N. and Boivin, S. (2009) A review of biogas purification processes. Biofuels, Bioprod. Bioref. 3: 42-71. doi: 10.1002/bbb.117

ACP Technologies Inc (2012) Brochure: Clean-gas cg4 cg5 dry H2S removal system, distributed exclusively in North America by Univar Inc., Commerce, CA 90040. http://www.acp-cg.com/documents/cg4\%205\%20Univar\%20brochure\%202012.pdf (accessed 11 November 2015).

ADI International (2009) SULFA-BIND® - hydrogen sulfide removal from biogas, landfill gas, and air streams, ADI International, Fredericton, NB E3B3Z2 Canada.

Air Liquide (2012) Material Safety Data Sheet - Hydrogen sulphide, Revised edition No 5, EIGA073. http://docs.airliquide.com.au/msdsau/AL077.pdf

Air Liquide (2016) Gas Encyclopaedia http://encyclopedia.airliquide.com/Encyclopedia.asp?GasID=59\#GeneralData

Allan, A. (2012) Review of Biogas Cleaning - Final Report to Meat \& Livestock Australia Limited, Project code: A.ENV.0098, Prepared by GHD Pty Ltd, published by Meat \& Livestock Australia Limited, North Sydney, NSW.

Allegue, L.B. and Hinge, J. (2014) Biogas upgrading - Evaluation of methods for $\mathrm{H}_{2} \mathrm{~S}$ removal, Danish Technological Institute.

Alphasense (ND) Application Note AAN 104 - How Electrochemical Gas Sensors Work, Issue 12.

AMPC and MLA (2013) Fact Sheet - Biogas quality \& cleaning technology.

Anerousis, J.P. and Whitman, S.K. (1985) Iron Sponge: Still a Top Option for Sour Gas Sweetening. Oil and Gas Journal February 18: 71-76. 
Aquafix (2015) Hydrogen Sulfide Toxicity, Aquafix, Madison, WI 53708.

https://teamaquafix.com/hydrogen-sulfide-toxicity/

Accessed 29 July 2016.

ASAE (2003) Manure Production and Characteristics, ASAE D384.1 FEB03, American

Society of Agricultural Engineers.

ASTM D7481-09: Standard Test Methods for Determining Loose and Tapped Bulk Densities of Powders using a Graduated Cylinder.

Australian Pork Limited (2015). Code of practice for on-farm biogas production and use at piggeries. APL Project 2011/1013.423.

BIOREM® (2010) Biogas sweetening solutions, Information sheet, http://www.biorem.biz/images/stories/Sell\%20Sheets/biogas-sweetening.pdf

Capstone Turbine Corporation (2003) C30 landfill or digester biogas product datasheet, Chatsworth CA 91311

http://www.build-a-biogas-plant.com/PDF/Capstone Turbine C30biogas.pdf

Capstone (2009) Capstone MicroTurbine Fuel Requirements, Technical Reference, 410002 Rev F (January 2009).

Caterpillar (2013) Maximizing Productivity of Biogas Engines, Seventh AgSTAR National Conference, 'Expanding the Horizons of AD Systems' Session' June 12, 2013

Cherosky, P. and Li, Y. (2013) Hydrogen sulfide removal from biogas by bio-based iron sponge. Biosystems Engineering 114: 55-59.

Chou, C.-H. Selene J. (2003) Hydrogen sulphide: Human health aspects, Concise International Chemical Assessment Document 53, World Health Organisation, Geneva. http://www.who.int/ipcs/publications/cicad/en/cicad53.pdf

Dane, J.H. and Topp, G.C. (Eds) (2002) Methods of Soil Analysis, Part 4 - Physical Methods, Soil Science Society of America, Inc. Madison, Wisconsin USA. 
Department of Sustainability, Environment, Water, Population and Communities (2013) Hydrogen sulphide, National Pollutant Inventory (NPI),

http://www.npi.gov.au/resource/hydrogen-sulfide

Ergun, S. (1952) Fluid Flow through Packed Columns. Chemical Engineering Progress, 48(2): 89-94.

FNR (2005) Ergebnesse des Biogas-Messprogramms - Results of the Biogas monitoring program. Technical monitoring report. FNR, Guezlow, Germany.

Gas Processors Suppliers Association Data Book, 12th Ed., (2004), Tulsa, Oklahoma, USA.

Gevantman, L.H. (ND) Solubility of selected gases in water, in Haynes, W.M. (editor-inchief) (2016).

Greenberg, A.E., Clesceri, L.S. and Eaton, A.D. (Eds) (1992) Standard Methods for the Examination of Water and Wastewater. American Public Health Association, Washington.

Hagen, M., Polman, E., Jensen, J., Myken, A., Jönsson, O. and Dahl, A. (2001) Adding gas from biomass to the gas grid, Final Report, Contract No: XVII/4.1030/Z/99-412.

Haynes, W.M. (editor-in-chief) (2016) CRC Handbook of Chemistry \& Physics Online, 96th edition. http://www.hbcponline.com.ezproxy.library.uq.edu.au/ (accessed 14 March 2016).

Heubeck, S. and Craggs, R.J. (2010) Biogas recovery from a temperate climate covered anaerobic pond. Water Science \& Technology 61(4): 1019-1026.

Higgs, J. (2006) Gas absorption by wet scrubbing, Air pollution control manual, $3^{\text {rd }}$ Edition, Ed: Jack Chiodo and lan Holden, Clean Air Society of Australia and New Zealand.

Hirsch, A.R. and Zavala, G. (1999) Long term effects on the olfactory system of exposure to hydrogen sulphide. Occupational and Environmental Medicine, 56:284-287. http://oem.bmj.com/content/56/4/284.full.pdf+html 
Innovative Waste Consulting Services, LLC (ND), Best Management Practices to Prevent and Control Hydrogen Sulfide and Reduced Sulfur Compound Emissions at Landfills that Dispose of Gypsum Drywall, Prepared for U.S. Environmental Protection Agency, Cincinnati, OH, U.S. EPA Contract Number EP-W-09-004. http://epa.ohio.gov/portals/34/document/guidance/bmp\%20guide\%202014.pdf

lowa State University Extension (2004) The Science of Smell Part 1: Odor perception and physiological response.

Isbell, R.F. (1996) The Australian soil classification. CSIRO Publishing, Collingwood, Vic 3066 .

Kido, W., Krishnaiah, R., Yurovsky, T. and Schafer, P. (1995) Iron sponge reduces toxic emissions, 471 Water Environment \& Technology, 7 (5), 13-14.

Ko, T.H. (2008) Removal of hydrogen sulphur from coal derived gas by iron oxides in various oxisols. Environ. Eng. Sci. 25: 969-973.

Ko, T.H. (2011) Application of Zn-contaminated soil: feasibility study on the removal of $\mathrm{H}_{2} \mathrm{~S}$ from hot coal derived gas. Environ. Chem. Lett. 9: 77-82.

Ko, T.H. and Hsueh, H.T. (2012) Removal of hydrogen sulphide by iron-rich soil: application of the deactivation kinetic model for fitting breakthrough curve. Aerosol and Air Quality Research, 12: 1355-1361, doi: 10.4209/aaqr.2012.03.0060

Kochaba, T. (2013) Selection and Design of a Full-Scale Biological Hydrogen Sulfide System for Digester Gas Treatment, VWEA Education Committee Seminar, May 2, 2013, HDR Inc.

Kohl, A. and Neilsen, R. (1997). Gas Purification. Golf Publishing Company, Houston,Texas: $1395 \mathrm{p}$.

Krich K., Augenstein, D., Batmale, J.P., Benemann, J., Rutledge, B. and Salour, D. (2005) Biomethane from Dairy Waste - A Sourcebook for the Production and Use of Renewable 
Natural Gas in California, Prepared for Western United Dairymen, Funded in part through USDA Rural Development.

http://www.calstart.org/Libraries/Publications/Biomethane from Dairy Waste Full Report. $\underline{\text { sflb.ashx }}$

Kronos ecochem (2014) Hydrogen sulfide elimination from biogas, Technical Information 5.01, KRONOS International, Inc., Leverkusen Germany.

http://www.kronosecochem.com/ehome en.nsf/Multi\%20Media\%20Files/ADB0C38C533E 747385257BB900581CA0/\$File/KRONOS\%20ecochem\%20TI\%205 01 EN.pdf?OpenEle $\underline{\text { ment }}$

Kuria, J. and Maringa, M. (2008) Developing simple procedures for selecting, sizing, scheduling of materials and costing of small bio - gas units, International Journal for Service Learning in Engineering, Vol. 3, No. 1, pp. 9 - 40, Spring 2008, ISSN 1555-9033.

Lin, WC, Chen, YP and Tseng, CP (2013) Pilot-scale chemical-biological system for efficient $\mathrm{H}_{2} \mathrm{~S}$ removal from biogas, Bioresource Technology 135: 283-291.

Loeppert, R.H. and Inskeep, W.P. (1996) Iron, Chapter 23 in: Methods of Soil Analysis Part 3, Chemical Methods. Published by Soil Science Society of America Inc and American Society of Agronomy Inc, Madison, Wisconsin, USA.

Maddox, R.N. and M.D. Burns (1968) Iron-Oxide Process Design Calculations, Oil and Gas Journal 54 (August).

McGahan, E., Valentine, J., Heubeck, S. and Murphy, C. (2013) Five Piggery Biogas Capture and Energy Generation Feasibility Studies, Final Report prepared for Pork CRC project 4C-102.

Mears, D. (2001) Biogas Applications for Large Dairy Operations: Alternatives to Conventional Engine-Generators, Prepared under contract to Cornell Cooperative Extension Association of Wyoming County, Warsaw, NY. Final Edition. http://citeseerx.ist.psu.edu/viewdoc/download;jsessionid=9FC171CCE4072BE79A72A628 23CF6FB0?doi=10.1.1.195.6183\&rep=rep1\&type $=$ pdf 
McVay, R.D. (ND) Processes for Removal of Hydrogen Sulfide Found in Florida Ground Water Sources, Florida Rural Water Association.

www.frwa.net/uploads/4/2/3/5/42359811/removalofhydrogensulfide010511.doc

M-I SWACO (2010) SULFATREAT® - Setting the standard in $\mathrm{H}_{2} \mathrm{~S}$ removal, Brochure http://www.slb.com/ /media/Files/miswaco/brochures/sulfatreat 10881.pdf

Murphy, C.M., Wiedemann, S.G. and McGahan, E.J. (2013) Pathways to carbon neutral pork production, Mitigation strategies and their application to a Victorian piggery case study. Report prepared for the Co-operative Research Centre for an Internationally Competitive Pork Industry by FSA Consulting, Toowoomba, Queensland. http://porkcrc.com.au/wp-content/uploads/2013/11/4C-107-Final-Report.pdf

Muyzer, G. and Stams, A.J.M. (2008) The ecology and biotechnology of sulphate-reducing bacteria, Nature reviews - microbiology, Volume 6, 441-454.

Noyola, A., Morgan-Sagastume, J.M. and Lopez-Hernandez, J.E. (2006) Treatment of biogas produced in anaerobic reactors for domestic wastewater: odor control and energy/resource recovery. Reviews in Environmental Science and Bio/Technology (2006) 5:93-114_ Springer 2006, DOI 10.1007/s11157-005-2754-6

NSCA (2006) Biogas as a road transport fuel - An assessment of the potential role of biogas as a renewable transport fuel, Research undertaken for the National Society for Clean Air and Environmental Protection (UK).

http://www.cleanvehicle.eu/fileadmin/downloads/UK/nsca biogas as a road transport 0849263001011 24042007.pdf

Paques THIOPAQ® Brochure, Paques website, accessed 8 December 2015, http://en.paques.nl/mediadepot/18227457a52e/WEB5800000175brochureThiopaq.pdf201 3).

Payne RW, Harding SA, Murray DA, Soutar DM, Baird DB, Glaser AI, Welham SJ, Gilmour AR, Thompson R, Webster R (2011) 'The guide to GENSTAT release 14, part 2: statistics.' (VSN International: Hemel Hempstead, UK) 
Petersson, A. and Wellinger, A. (2009) Biogas upgrading technologies - developments and innovations, IEA Bioenergy Task 37 - Energy from biogas and landfill gas

Pokorna, D., Zabranska, J. (2015). Sulfur-oxidizing bacteria in environmental technology. Biotechnology Advances, 33(6), 1246-1259.).

Pomeroy, R.D. and Parkhurst, J.D. (1977), The forecasting of sulfide build-up rates in sewers, Prog. Water Tech., 9 (3), 621-628.

Pork CRC (2015) Annual Report 2014-2015, Cooperative Research Centre for High Integrity Australian Pork, Australian Government - Department of Industry, Innovation and Science.

Revell, C. (1997). Dear Mr. Iron Sponge Plant Operator. Connelly-GPM, Inc., Chicago, IL: $9 \mathrm{p.}$

Reinhold, G. (2005) Vortrag: Entschweflung - eine Herausforderung an die Betreiber von Biogasanlagen - Working group presentation, Sulphur removal - a challenge for biogas plant operators, Thuringia State Ministry for Agriculture, Conservation and the Environment, 12. Oktober 2005, Bösleben, Germany. http://www.tll.de/ainfo/pdf/ents1005.pdf।

Ross, C.C. and Walsh, J.L. (1996) Handbook of Biogas Utilization, p. 3-4. US Department of Energy.

Ryckebosch, E., Drouillon, M. and Vervaeren H. (2011) Techniques for transformation of biogas to biomethane. Biomass and Bioenergy 35: 1633 - 1645.

Safe Work Australia Workplace (2013) Exposure Standards for Airborne Contaminants. ISBN 978-1-74361-055-8, http://www.safeworkaustralia.gov.au/sites/SWA/about/Publications/Documents/772/Workpl ace-exposure-standards-airborne-contaminants.pdf (accessed 11 November 2015).

Safley, L.M. and Westerman, P.W. (1988) Biogas production from anaerobic lagoons. Biol. Wastes 23: 181-193. 
Sander, R. (2015) Compilation of Henry's law constants (version 4.0) for water as a solvent, Atmos. Chem. Phys 15, 4399-4981, doi: 10.5194/acp-15-4399-2015.

Schomaker, A.H.H.M., Boerboom, A.A.M., Visser, A. and Pfeifer, A.E. (2000) Anaerobic digestion of agro-industrial wastes: Information networks, Technical summary on gas treatment. AD-NETT; Project: FAIR-CT96-2083 (DG12-SSMI).

Schwertmann, U. and Cornell, R.M. (2000) Iron oxides in the laboratory, preparation and characterisation, $2^{\text {nd }}$ edition. Wiley-VCH, Weinheim, Federal Republic of Germany, DOI: $10.1002 / 9783527613229$.

Seadi, T.A., Rutz, D., Prassl, H., Köttner, M., Finsterwalder, T., Volk, S. and Janssen, R. (2008) Biogas Handbook, Big East Project, Published by University of Southern Denmark Esbjerg, Niels Bohrs Vej 9-10, DK-6700 Esbjerg, Denmark. http://www.bigeast.eu/downloads/IR-reports/ANNEX\%202-39 WP4 D4.1 Master-Handbook.pdf

Sell, S.T., Burns, R.T., Moody, L.B., Raman, D.R. (2011) Comparison of methane production from bench- and sub pilot-scale anaerobic digesters. Applied Engineering in Agriculture, 27(5), 821-825.).

Shang, G., Shen, G., Liu, L., Chen, Q. and Xu, Z. (2013) Kinetics and mechanisms of hydrogen sulphide adsorption by biochars. Bioresource Technology 133: 495-499.

Shang, G., Shen, G., Wang, T. and Chen, Q. (2012) Effectiveness and mechanisms of hydrogen sulfide adsorption by camphor-derived biochar. Journal of the Air \& Waste Management Association, 62:8, 873-879, DOI:10.1080/10962247.2012.686441.

Siefers, A.M. (2010) A novel and cost-effective hydrogen sulfide removal technology using tire derived rubber particles, lowa State University, Graduate Theses and Dissertations. Paper 11281.

Simons Green Energy (2014) Shuangliang absorption chiller, accessed December 2014 http://simonsgreenenergy.com.au/wpcontent/themes/energy/pdf/shuangliang brochure.pdf 
Skerman, A. (2013) Methane recovery and use at a piggery - Grantham, Addendum to Final Report - RIRDC Project No PRJ-005672, RIRDC, Barton, ACT.

Skerman, A. and Collman, G. (2012) Methane recovery and use at a piggery Grantham, Final Report - RIRDC Project No PRJ-005672, RIRDC, Barton, ACT.

Skerman, A., Collman, G., Sohn, J.H. and Pott, L. (2012) Options for biogas cleaning and use on-farm, Final Report - RIRDC Project No PRJ-004547, RIRDC, Barton, ACT.

Skerman, A.G., Willis, S., McGahan E.J. and Marquardt, B. (2013) PigBal 4 - A model for estimating piggery waste production, Department of Agriculture, Fisheries and Forestry, Queensland, and Australian Pork Limited. Available for download from APL website: http://australianpork.com.au/library-resources/research-reports/snapshot-final-reports/

Spoelstra, S. F. (1980) Origin of objectionable odorous components in piggery wastes and the possibility of applying indicator components for studying odour development. Agric. \& Environ. 5: 241-260.

Stace, H.C.T., Hubble, G.D., Brewer, R., Northcote, K.H., Sleeman, J.R., Mulcahy, M,J, and Hallsworth, E.G. (1968) A handbook of Australian soils. Rellim Technical Publications, Glenside, South Australia.

Staunton, E.T., Bunk, S.R., Walters, G.W., Whalen, S.C., Rudek, J., Aitken, M.D. (2015). Coupling Nitrogen Removal and Anaerobic Digestion for Energy Recovery from Swine Waste through Nitrification/Denitrification. Environmental Engineering Science, 32(9), 741749 .

Stevens, R. J., R. J. Laughlin, and Frost, J.P. (1993). Effects of diet and storage time on the concentration of sulphides in dairy-cow slurry. Bioresource Technol. 45: 13-16.

STM Power (2002). Pure Energy on Demand, Brochure for STM Stirling Engines, STM Power, Ann Arbor, Ml: $6 \mathrm{p}$.

www.stmpower.com/Markets/STMPureEnergyBrochure.pdf 
Syed, M., Soreanu, G., Falletta, P. and Béland, M. (2006) Removal of hydrogen sulfide from gas streams using biological processes - a review, Canadian Biosystems Engineering, Volume 48 2006, 2.1.

TAPC (Total Air Pollution Control) (2013) Website: Gas Scrubbing - Activated Carbon Adsorbers. http://www.tapc.com.au/gas/ac.html

Taylor, D.K. (1956) Natural Gas Desulfurization (Parts 1-4), Oil and Gas Journal (November 5, 19, and December 3, 10): 4 p.

Tippayawong, N. and Thanompongchart, P. (2010) Biogas quality upgrade by simultaneous removal of CO2 and H2S in a packed column reactor, Energy 35 (2010) 4531-4535.

Trogisch, S., Baaske, W.E., Accettola, F., Bailón, L., Benito, M., Berger, P. et al. (2004) Biogas Powered Fuel Cells. Trauner Verlag, Linz.

Truong, L.V.-A. and Abatzoglou, N. (2005) A $\mathrm{H}_{2} \mathrm{~S}$ reactive adsorption process for the purification of biogas prior to its use as a bioenergy vector, Biomass and Bioenergy 29(2): 142-151. DOI: 10.1016/j.biombioe.2005.03.001

Tucker, R.W., McGahan, E.J., Galloway, J.L. and O'Keefe, M.F. (2010) National Environmental Guidelines for Piggeries - Second Edition, APL Project 2231, Australian Pork Limited, Deakin ACT Australia.

UOP - A Honeywell Company (2009) UOP Selexol ${ }^{\mathrm{TM}}$ Technology for Acid Gas Removal, PowerPoint presentation.

http://www.uop.com/?document=uop-selexol-technology-for-acid-gasremoval\&download $=1$

Wang, D.M. (2008) Breakthrough Behaviour of $\mathrm{H}_{2} \mathrm{~S}$ Removal with an Iron Oxide Based CG-4 Adsorbent in a Fixed-Bed Reactor. Master of Science Thesis, University of Saskatchewan, Saskatoon, SK, Canada. 
Wang, H., Fang, D. and Chuang, K,T. (2008) A sulfur removal and disposal process through $\mathrm{H}_{2} \mathrm{~S}$ adsorption and regeneration: Ammonia leaching regeneration. Process safety and environment protection 86: 296-302.

Wang, H., Wang, D.M. and Chuang, K.T. (2011) A sulphur removal and disposal process through $\mathrm{H}_{2} \mathrm{~S}$ adsorption and regeneration: Breakthrough behaviour investigation, Process Safety and Environmental Protection 89, Issue 1, p53-60.

DOI: $\underline{\text { http://dx.doi.org/10.1016/i.psep.2010.08.001 }}$

Weiland, P. (2010) Biogas production: current state and perspectives - mini-review. Appl Microbiol Biotechnol (2010) 85: 849-860, DOI 10.1007/s00253-009-2246-7

Wellinger, A. and Linberg A. (2005) Biogas Upgrading and Utilization - IEA Bioenergy Task 24: Energy from biological conversion of organic wastes. International Energy Association, Paris, France http://www.iea-biogas.net/ download/publi-task37/Biogas\%20upgrading.pdf

Wellinger, A., Murphy, J. and Baxter, D. (Eds.) (2013) The Biogas Handbook - Science, production and applications, Woodhead Publishing.

Werner, U., Stohr, U. and Hees, N. (1989) Biogas plants in animal husbandry : a practical guide, A publication of Deutsches Zentrum für Entwicklungstechnologien - GATE in Deutsche Gesellschaft für Technische Zusammenarbeit (GTZ) GmbH, Braunschweig; Wiesbaden : Vieweg, 1989.

White, J.W. (2010) Development of an activated carbon from anaerobic digestion byproduct to remove hydrogen sulphide from biogas, M Sc Thesis, Department of Chemical Engineering and Applied Chemistry, University of Toronto.

Wiedemann, S.G., McGahan, E.J. and Murphy, C.M. (2012) Energy, water and greenhouse gas emissions in Australian pork supply chains: a life cycle assessment. Report prepared for the Pork CRC, FSA Consulting, Toowoomba, Queensland.

Wiedemann, S.G., McGahan, E.J. and Murphy, C.M. (2016) Environmental impacts and resource use from Australian pork production assessed using life-cycle assessment. 
1. Greenhouse gas emissions. Animal Production Science, CSIRO.

http://dx.doi.org/10.1071/AN15881,

http://porkcrc.com.au/wp-content/uploads/2016/06/4C-117-Fianl-report.pdf

Willis, S. (2015) Toowoomba Pig Focus Group data, 12 months ending Sep 2015.

Department of Agriculture and Fisheries, Toowoomba, Queensland.

Willis, S. and Collman, G. (2007) Providing chilled drinking water to lactating sows using a modified milk vat, Final Report to Australia Pork Limited, Group Demonstration Project Number: 2154, Department of Primary Industries and Fisheries, Toowoomba, Qld.

Wiltsee, G. and Emerson, H. (2004) Clean Power from Microturbines Using Biogas. Biocycle, Feb. 2004, Vol. 45, Iss. 2: 53-55.

XENERGY, Inc. (2002). Toward a Renewable Power Supply: The Use of Bio-based Fuels in Stationary Fuel Cells. Prepared for the Northeast Regional Biomass Program, Washington, DC: $63 p$

Zicari, S. M. (2003) Removal of hydrogen sulphide from biogas using cow-manure compost. A thesis presented to the Faculty of the Graduate School of Cornell University in Partial Fulfilment of the Requirements for the Degree of Master of Science.

http://www.green-trust.org/Al\%20Rutan/MS-Thesis-Steve-Zicari.pdf (accessed 21 January 2016). 